University of Denver

Digital Commons @ DU

8-1-2018

\title{
Thriving with Down Syndrome: A Qualitative Multiple Case Study
}

Talia G. Thompson

University of Denver

Follow this and additional works at: https://digitalcommons.du.edu/etd

Part of the Disability and Equity in Education Commons, and the Educational Psychology Commons

\section{Recommended Citation}

Thompson, Talia G., "Thriving with Down Syndrome: A Qualitative Multiple Case Study" (2018). Electronic Theses and Dissertations. 1497.

https://digitalcommons.du.edu/etd/1497

This Dissertation is brought to you for free and open access by the Graduate Studies at Digital Commons @ DU. It has been accepted for inclusion in Electronic Theses and Dissertations by an authorized administrator of Digital Commons@DU. For more information, please contact jennifer.cox@du.edu,dig-commons@du.edu. 
Thriving with Down Syndrome: A Qualitative Multiple Case Study

\author{
A Dissertation \\ Presented to \\ the Faculty of the Morgridge College of Education \\ University of Denver \\ In Partial Fulfillment \\ of the Requirements for the Degree \\ Doctor of Philosophy \\ by
}

Talia G. Thompson

August 2018

Advisor: Devadrita Talapatra, Ph.D. 
Author: Talia G. Thompson

Title: Thriving with Down Syndrome: A Qualitative Multiple Case Study Advisor: Devadrita Talapatra, Ph.D.

Degree Date: August 2018

\begin{abstract}
Down syndrome (DS) is a chromosomal abnormality associated with intellectual disability (ID) and multiple medical complications. However, despite significant deficits related to the disability, there are people with DS who are thriving in our community. This dissertation examines those who thrive with DS and the individual and environmental factors that influence their thriving within two manuscripts. Manuscript One presents a synthesis of seminal and current positive psychology and disability studies literature. Review indicates that thriving with ID occurs when individuals report (a) a healthy transactional relationship between the individual and the ecological system; (b) high subjective well-being; and, (c) an upward developmental trajectory. A new framework for contextualizing thriving in the ID population, the Transactional Ecological Thriving Model (TET-M), is introduced. Manuscript Two describes a qualitative multiple-case study examining the lives of four young adults who are thriving with DS. Descriptive case contexts and a cross-case thematic analysis elucidate individual and environmental factors that facilitate thriving in the DS population: (a) supportive social ecologies, (b) creating family, (c) high expectations for independence, (d) vulnerability in adulthood, (e) advocacy, (f) a focus on physical health, and (g) a limited utility for standardized assessments. Based on these findings and the TET-M, it is suggested that school psychologists work to promote thriving for all students, including those with DS. Recommended practices include focusing on student subjective emotional experiences
\end{abstract}


and life satisfaction, measuring self-reported strengths, examining student growth trajectories rather than normative deficits, and using an ecological lens for both assessment and intervention planning. 


\section{TABLE OF CONTENTS}

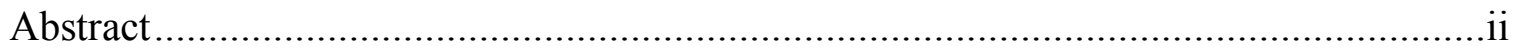

Table of Contents ............................................................................................ iv

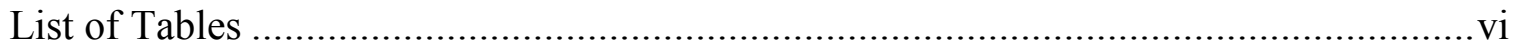

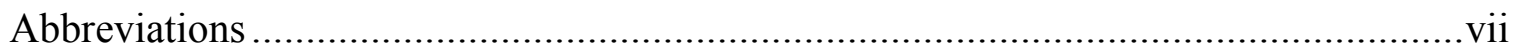

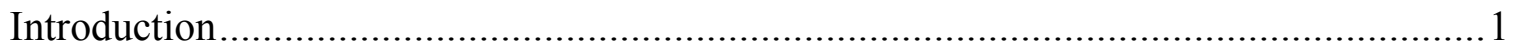

Manuscript One: Thriving with intellectual disability: A framework for school

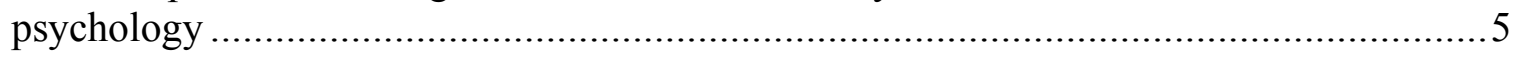

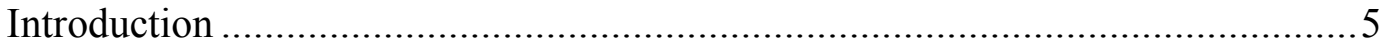

Understanding current perspectives on intellectual disability......................... 7

Positive psychology ............................................................................. 11

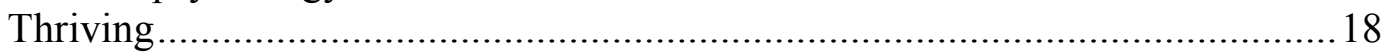

Transactional Ecological Thriving Model..................................................26

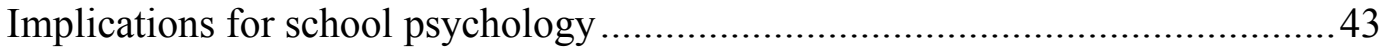

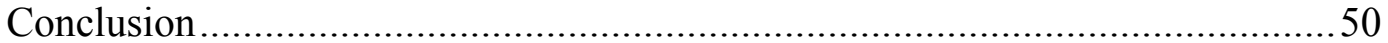

Manuscript Two: Thriving with Down syndrome: A qualitative multiple case study......52

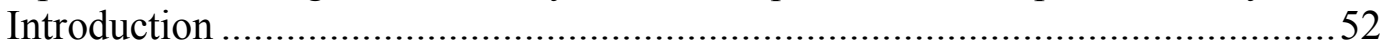

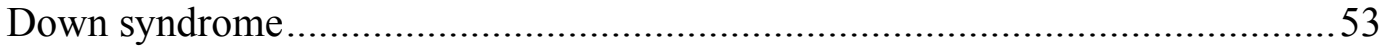

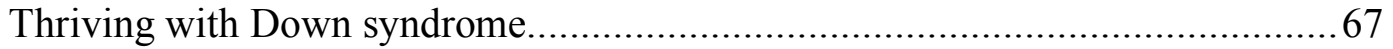

Purpose of the Study .......................................................................... 70

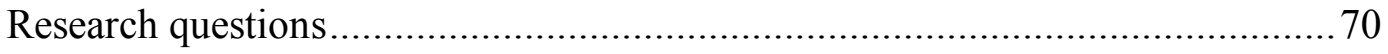

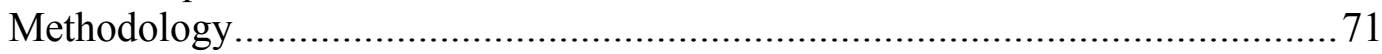

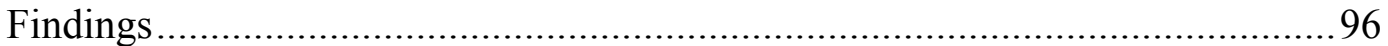

Discussion ................................................................................ 142

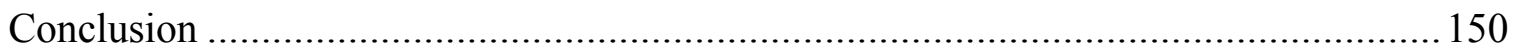

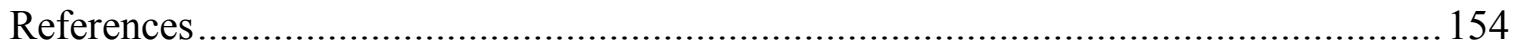

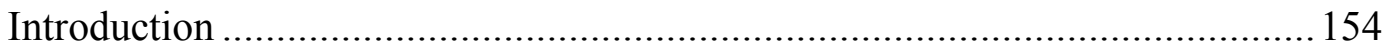

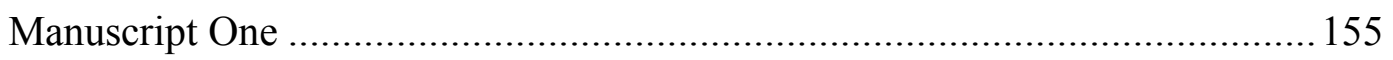

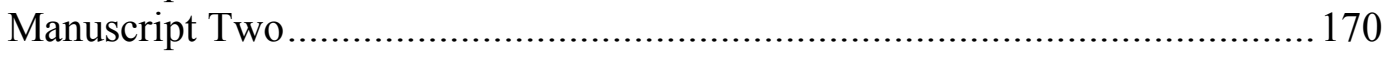

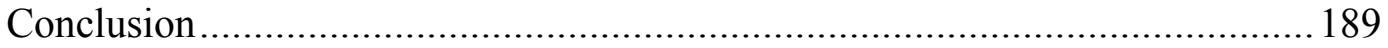

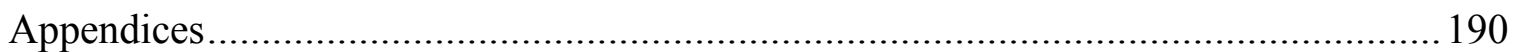

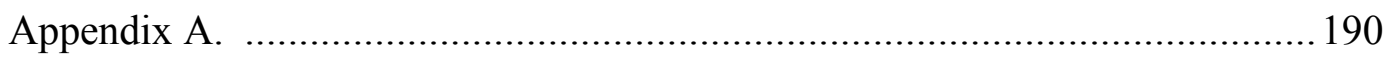

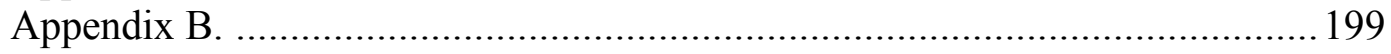

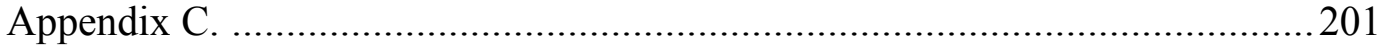

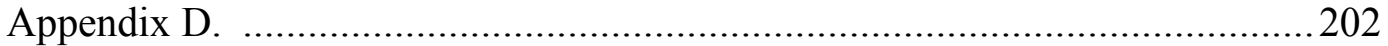




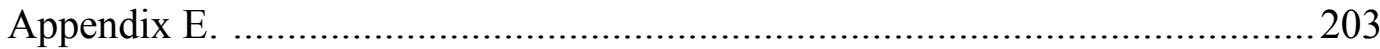

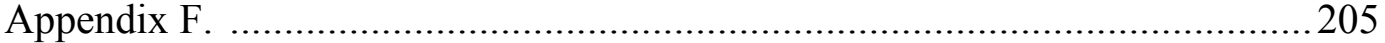

Appendix G. .............................................................................. 210

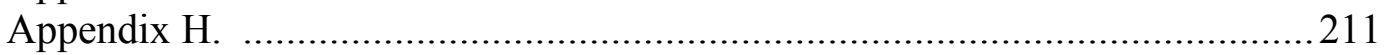

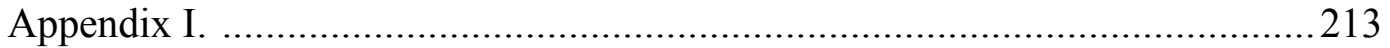

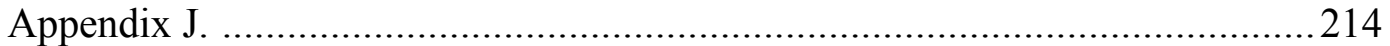

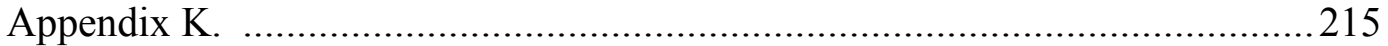

Appendix L. ....................................................................................... 216

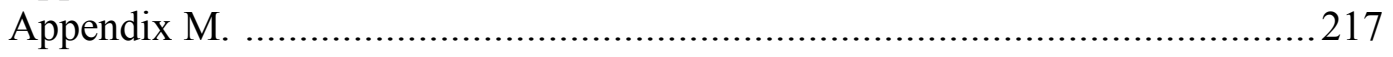




\section{LIST OF TABLES}

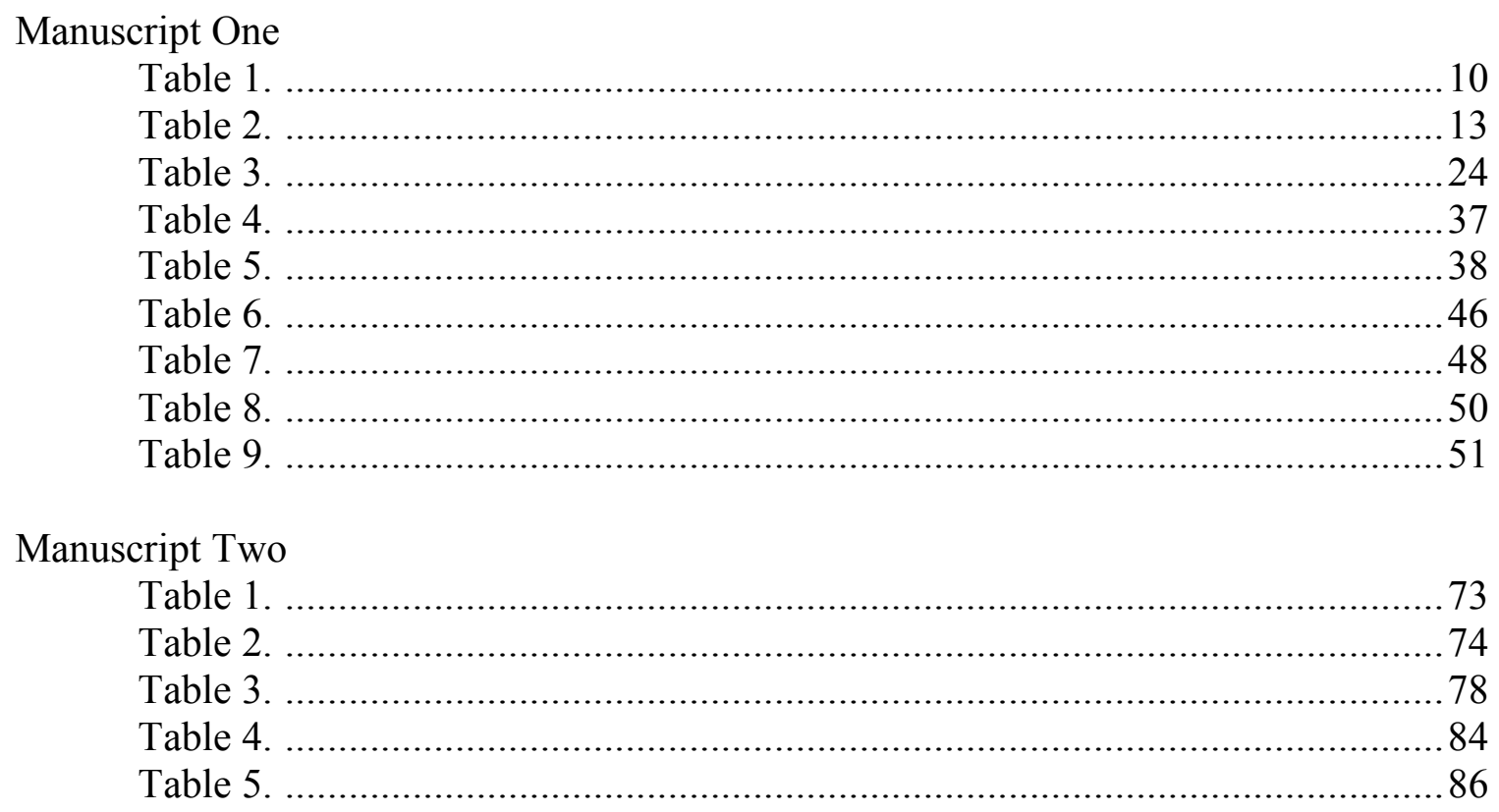




\section{ABBREVIATIONS}

$\begin{array}{ll}\text { ASD } & \text { Autism spectrum disorder } \\ \text { DD } & \text { Developmental disability } \\ \text { DS } & \text { Down syndrome } \\ \text { EE } & \text { Expressed emotion } \\ \text { FMSS } & \text { Five-minute speech sample } \\ \text { FXS } & \text { Fragile X syndrome } \\ \text { ID } & \text { Intellectual disability } \\ \text { NASP } & \text { National Association of School Psychologists } \\ \text { PYD } & \text { Positive youth development } \\ \text { QOL } & \text { Quality of life } \\ \text { SBA } & \text { Strengths based assessment } \\ \text { SWB } & \text { Subjective well-being } \\ \text { SWPBIS } & \text { School-wide positive behavior intervention supports } \\ \text { TET-M } & \text { Transactional Ecological Thriving Model } \\ \text { VIA } & \text { Values in Action }\end{array}$




\section{INTRODUCTION}

The vision of the National Association of School Psychologists (NASP) is to help students thrive. School psychologists promote student learning and well-being to ensure positive student outcomes in healthy and supportive school settings. School psychologists use assessments, direct intervention, consultation, and advocacy efforts to build student capacity and encourage growth. However, research indicates that students with intellectual disability (ID) have significant challenges upon exiting the public-school systems, with a lack of critical schooling experiences required for thriving in life (Lipscomb, 2017). The field of school psychology can and should do more to support this student population through effective service-delivery programs and school policies.

In order to help facilitate thriving for students with ID, the field of school psychology must dig further into the construct of thriving, including what it looks and feels like to thrive with ID and what facilitators and barriers influence thriving for this student population. This requires a solid theoretical framework to inform research in this area of scholarship. Furthermore, field research with individuals who are currently thriving and an analysis of what individual and environmental factors may facilitate their quality of life will enhance our understanding of what it means to thrive with ID.

This dissertation includes two distinct, yet related, manuscripts regarding this topic of study. The first manuscript contextualizes thriving with ID and provides a newly proposed model for the field of school psychology. It includes an historic perspective on 
the marginalization of students with ID in our society and the currently accepted theoretical models used to conceptualize and understand a "good life" in the field of disability studies, including the quality of life (QOL) concept and the social ecological model for human functioning. Further, the first manuscript outlines the ways in which positive psychology informs disability studies and school psychology. When all three areas of scholarship are combined, the definition of what it means to thrive with ID becomes clearer.

Integrating established models in positive psychology, school psychology, and disability studies, the first manuscript delivers a framework for identifying thriving in students with ID. Per this new framework, the Transactional Ecological Thriving Model (TET-M), thriving with ID is defined a combination of high levels of subjective wellbeing (SWB) and state of continued developmental growth. Thriving occurs within a series of supportive systems and requires meaningful and self-determined social inclusion. School psychologists can assess students using a bioecological lens with a data-based decision-making process to inform service-delivery within a multi-tiered system of supports (MTSS). An emphasis on thriving provides a holistic understanding of students with ID, aiming to improve developmental outcomes while also encouraging happiness and joy that contribute to QOL for this student body.

Building upon this framework, the second manuscript applies the TET-M definition of thriving with ID to a subpopulation: individuals with Down syndrome (DS). DS is the most common known genetic cause of ID, with a prevalence rate of 1 in 700800 U.S. births (Roizen, 2013). Although there are multiple medical and developmental complications associated with DS, a vast majority of those living with DS report high 
levels of life satisfaction (Skotko, Levine \& Goldstein, 2011). This population may provide unique insights to what it means to thrive with ID.

The empirical study in manuscript two is a multiple case study of young adults who are currently thriving (i.e., high levels of SWB coupled with an upward developmental trajectory) with DS. The case study addresses three main research questions: How do individuals with DS and their families define thriving? What individual characteristics influence thriving for people with DS? And, what environmental factors influence thriving with DS? A qualitative case study methodology allowed for in-depth investigations into the lives of those with DS, including subjective inquiry and more objective analysis. Interviews with participants, parents, and other adults in their systems of support provided insight and opinion from those experiencing the phenomenon firsthand. Observations in a variety of key support systems provided rich, detailed, descriptive information about the settings, routines, and behaviors of those thriving with DS. A review of educational and medical documents provided an historic account of each individual's life experiences and systemic influences. Finally, psychoeducational assessments provided data on present levels of development and psychosocial profiles for each participant. Thick contextual descriptions are provided for all four cases, including detailed vignettes from field observations. Findings from a crosscase thematic analysis elucidate seven key themes related to thriving with DS: a supportive social ecology, creating family, high expectations for independence, vulnerability in adulthood, advocacy, a focus on physical health, and limited utility for traditional assessments. 
When combined, these two manuscripts fill a gap in the literature about how the field of school psychology can best support students with ID. A thorough and welldeveloped model on thriving with ID provides practitioners with an overarching philosophical approach to our work with this population. Further, it provides guidance to researchers in this area of scholarship, so that inquiry is relevant to both the population and the profession of school psychology. Application of the model to real-life individuals who are thriving contributes to the positive psychology field with a scientific study of what enables individuals with ID to thrive. It provides detailed descriptions of those living good lives with DS and insight as to how school psychologists can promote thriving within the school setting. Finally, this exploratory work helps to generate hypotheses for future research and prompt a new focus for the field of school psychology on the well-being and learning of this unique student body. 


\section{MANUSCRIPT ONE}

\section{THRIVING WITH INTELLECTUAL DISABILITY: A FRAMEWORK FOR SCHOOL PSYCHOLOGY}

"My mission in life is not merely to survive, but to thrive; and to do so with some passion, some compassion, some humor and some style." -Maya Angelou (2011)

School psychologists are responsible for promoting mental health and learning for all students, ages birth to 21 (National Association of School Psychologists [NASP], 2010). This indicates that school psychologists are concerned with both well-being and developmental growth over a wide portion of the lifespan. Furthermore, this responsibility is to all students, including those with the most significant disabilities in our schools. Students with intellectual disability (ID) require the highest levels of support and have historically been misunderstood, neglected, and even abused in our schools (Dykens, 2006; Wehmeyer, 2013). As school psychologists, we must ensure that our most marginalized students receive the most ethical and respectful education possible. We must strive to build healthy and supportive learning environments for these students, advocating for each individual to meet his or her own highest potential.

Thriving is a complex construct that emerges as a worthy goal for students with ID in our schools (Benson \& Scales, 2009; Lerner, von Eye, Lerner, Lewen-Bizan, \& Bowers, 2010; Weiss \& Riosa, 2015). NASP's vision is that school psychologists will help students to thrive in school, at home, and throughout life (NASP, n.d.). Thriving is 
more than "getting by" or meeting an expectation for development. Thriving is exceeding the expectations: flourishing in one's life. Weiss and Riosa (2015) state that "thriving reflects both well-being and an upward developmental trajectory, the demonstration of continued growth of knowledge and skills, and success in relationships with others" (p. 2474). The promotion of thriving for students is a proactive process aimed at building student capacity and capitalizing on strengths. However, current thriving theories have limited utility for school psychologists, and the field has yet to define and operationalize the meaning of thriving for students with ID.

Current theoretical models for thriving tend to be limited to specific age ranges (Benson \& Scales, 2009; Lerner et al., 2010), focused solely on professional work settings (Boyd, 2015; Spreitzer, Sutcliffe, Dutton, Sonenshein, \& Grant, 2005), or are exclusive of the developmental trajectory and growth that characterizes the birth to 21 age range (Buettner, 2010; Seligman, 2011; Vallerand \& Carbonneau, 2013). Furthermore, to this date, there is no comprehensive framework for understanding what it means to thrive with ID in the schools, and the factors that can facilitate thriving for this population. In order to better understand and promote thriving for students with ID, the field of school psychology needs a robust theoretical model that merges research and theories from the fields of school psychology, positive psychology, and disability studies. A comprehensive model for thriving with ID in the schools must address the unique considerations of this specific student population and the contextual factors associated with schools. 


\section{Understanding Current Perspectives on Intellectual Disability}

ID is currently defined as a disability characterized by significant limitations in both intellectual and adaptive functioning with an onset before the age of 18 (Schalock et al., 2010). In order to qualify for special education services with ID, students must present with intelligence quotient (IQ) and adaptive scores falling well below average, and in some states students must also present with significantly diminished academic skills (Individuals with Disabilities Education Act [IDEA], 2004; McNicholas et al., 2017). Although only one percent of all U.S. students have ID, approximately seven percent of students receiving special education services have ID (U.S. Department of Education, 2015). Thus, although the ID student population is in the minority, it is not insignificant and merits the attention of the field of school psychology. School psychologists are an integral piece of assessment, education planning, and service delivery for students with ID. It is imperative that practitioners understand the unique history of this student population, the currently accepted theoretical models in the disabilities research field, and how to best support students with ID (Roach, 2003).

\section{A History of Marginalization}

As early as Roman times, there has been documentation of the elimination of individuals born with ID (Wehmeyer, 2013). The weak and feeble were deemed a burden to a society, and eradicated or banished. Then, starting in the late $18^{\text {th }}$ Century in Europe, the focus shifted to training "educable" individuals with disabilities to remove the effects of their handicaps (Dykens, 2006). Children with ID were removed from their homes for treatment in residential school settings. Early special educators developed methods of specialized instruction to "cure" disabilities by addressing sensorimotor needs and 
teaching language (Gargiulo \& Bouck, 2018). This era embraced the medical model for disability, where disability was viewed as pathology and interventions were aimed at eliminating the effects of the disabling condition (Dykens, 2006; Wehmeyer, 2013).

However, the focus of these institutions shifted when rehabilitation efforts were not immediately successful, and the disabilities appeared to persist despite educational interventions (Dykens, 2006). Rather than evolving as spaces dedicated to promoting the welfare of vulnerable citizens, institutions shifted into warehouses responsible for the complete removal of those with disabilities from society. This period was marked by abuse, restraints, overcrowded facilities, complete segregation, and neglect (Blatt \& Kaplan, 1966). Forced sterilization was part of the "negative eugenics" movement, where selective breeding and immigration policies were used to improve the human race by eliminating "lower stock” (Merydith, Bamanto, Stalker \& Larkin, 2017, p. 31). Those born with disabilities had a poor quality of life and had little opportunity to contribute society. Additionally, the geographic isolation of facilities for those with disabilities led to an unawareness of the injustice in the broader society; out of sight, out of mind (Blatt \& Kaplan, 1966; Dykens, 2006).

Starting in the 1950s, several factors contributed toward a shift in thinking about individuals with disabilities (Wehmeyer, 2013). Soldiers returning from the war with newly acquired physical and mental disabilities highlighted the issues of access and citizen rights. Parents began to resist the cultural norm of the institutionalization of their children (Wyllie, 2012). Medical advances improved the life expectancies and quality of life for many with disabilities. Qualitative researchers and photojournalists documented the conditions in institutions, sparking awareness and acting as a catalyst for change 
(Blatt \& Kaplan, 1966). By the 1970s, the country had a new focus on inclusion and antidiscrimination with federal education and civil rights laws (e.g., Education for All Handicapped Children Act of 1975 [PL 94-142]; Section 504 of the Rehabilitation Act of 1973). Government sponsored programs increased community-based care services for those with disabilities. Over the next few decades, there would be a complete dismantling of the institutionalization system and a shift toward broad inclusion in the general society (Wehmeyer, 2013).

\section{Social Ecological Model}

Currently, a social ecological model prevails in the field of ID (Buntinx, 2014; Schalock et al., 2010). Rather than merely looking for pathology to cure through the lens of the medical model for disability, the social ecological model emphasizes the concept of human functioning and states that disability is a function of individual impairments that are inadequately accommodated by the environment (Buntinx, 2014; Schalock et al., 2010). Shifting away from a focus on individual limitations, the social ecological model highlights the match between individual needs and support systems in the environment. Supports that are individualized and bolster a person's strengths can enhance overall functioning (Schalock et al., 2010). The bioecological systems theory (Bronfenbrenner, 1979) informs the model, noting that disability exists within a series of embedded systems. Individuals with ID are surrounded by systems of support including family and friends, colleagues and classmates, general public services, and publically funded programs related to disability (Buntinx, 2014). These systems of support can enhance or detract from the individual's overall development and well-being. 
Quality of Life. Underlying the social ecological model for disability is the concept of quality of life (QOL; Schalock \& Alonso, 2014). QOL is a complex phenomenon influenced by interactions between an individual and the environment; it is mediated by systems of support and the opportunity to pursue life goals (Verdugo, Navas, Gomez, \& Schalock, 2012). In measuring QOL for individuals with ID, there are three main categories, each containing eight core domains (see 1; Schalock \& Alonso, 2014). Some of the key domains of QOL are measured with subjective indicators (e.g., emotional well-being), while some can be measured objectively (e.g., rights). This highlights the value of input and perceptions of those with disabilities, but also contends that QOL depends on a supportive society and social justice. Altogether, the framework promotes "dignity, equality, empowerment, self-determination, nondiscrimination, and inclusion" for those living with ID (Schalock \& Alonso, 2014, p. 46).

Table 1

Quality of Life (QOL) Categories, Domains, and Indicators

\begin{tabular}{lll}
\hline Category $^{\mathrm{a}}$ & Domain $^{\mathrm{a}}$ & Indicators $^{\mathrm{b}}$ \\
\hline Independence & $\begin{array}{l}\text { Personal development } \\
\text { Self-determination }\end{array}$ & $\begin{array}{l}\text { Education status, personal skills } \\
\text { Choices, autonomy, personal control }\end{array}$ \\
Inclusion & $\begin{array}{l}\text { Personal relations } \\
\text { Social inclusion } \\
\text { Rights }\end{array}$ & $\begin{array}{l}\text { Friendships, social networks } \\
\text { Community participation and roles } \\
\text { Legal access, dignity, respect, equality }\end{array}$ \\
Emotional well-being & $\begin{array}{l}\text { Positive experiences, safety, } \\
\text { contentment } \\
\text { Health, recreation, leisure } \\
\text { Financial and employment status }\end{array}$ \\
\hline
\end{tabular}

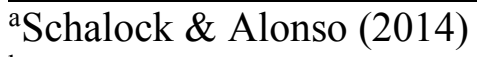

bVerdugo et al. (2012) 


\section{Positive Psychology}

While the social ecological model for disability and the QOL concept aim to improve the lives of those who have historically led marginalized lives, they do not necessarily address the concept of thriving, flourishing in life, or exceeding expectations for happiness and growth. To better understand what allows people with ID to thrive, we can look toward the field of positive psychology. In positive psychology, the focus is on building mental health and well-being: making life worth living (Seligman \& Csikszentmihalyi, 2000). The field aims to compliment, rather than dispute the pervasive deficit model of psychology, whereby psychologists work to remediate pathology of those with mental illness. Positive psychologists, rather, work to build mental health, prevent pathology, and enhance well-being (Seligman \& Csikszentmihalyi, 2000). The ultimate goal of positive psychology is to build individuals and communities that flourish (International Positive Psychology Association [IPPA], n.d.; Seligman, 2011).

Positive psychology is a broad field with multiple areas of focus. Hart and Sasso (2011) assessed the contemporary concepts within the field of positive psychology since its inception at the turn of the century. They conducted a content analysis of over 50 published articles that claimed to define positive psychology, analyzed the syllabi of college level positive psychology coursework in the US and Canada, examined the tableof-contents in positive psychology books, and interviewed experts in positive psychology. An analysis of their collected data revealed several themes under the umbrella of positive psychology, including flourishing/thriving (which the authors coupled as a unitary construct), the good life, a life worth living, life satisfaction, resilience, and happiness. 
While positive psychology is oriented toward enhancing the lives of individuals and communities; making life worth living, it is much more than "happiology" (Jayawickreme, Forgeard, \& Seligman, 2012, p. 338) or a simple focus on encouraging positive emotions. Rather, positive psychology aims to encourage the development and use of strengths and assets in order to meet life's challenges (Peterson \& Seligman, 2004). Positive psychology recognizes that mental illness and disasters are a natural aspect of life. By understanding those who flourish despite, or even because of, these trials, positive psychology can promote the development of healthy, functioning individuals and societies (Seligman \& Csikszentmihalyi, 2000; Seligman, 2011).

\section{Character Strengths and Virtues}

One of the most influential products of the field of positive psychology is the understanding that everyone possesses a handful of signature character strengths and virtues that contribute to their well-being (Peterson \& Seligman, 2004). In their groundbreaking manual, Peterson and Seligman (2004) identified six universal core virtues and 24 character strengths, differentiated from talents (e.g., athleticism) and abilities (e.g., intelligence), as the "psychological ingredients" that make up the virtues (see Table 2; Peterson \& Seligman, 2004, p. 13).

The authors argue that those who frequently use their strengths have higher levels of well-being. In further support of this proposition, the Values in Action (VIA) Institute on Character produced a survey to measure character strengths in individuals around the world. Multiple studies on character strengths using the classification system outlined above and the VIA survey have indicated that targeting either the development of one's top five strengths or the development of one's bottom five strengths, leads to higher 
levels of well-being and decreased levels of depression (Lavy, Littman-Ovadia, \& Bareli, 2014; Proyer et al., 2014; Proyer et al., 2015). Therefore, in opposition to the widely utilized Diagnostic and Statistical Manual of Mental Disorders (DSM-5; American Psychiatric Association, 2013) used to diagnose pathology, Peterson and Seligman's (2004) Handbook and Classification System helps individuals and practitioners to identify, research, and promote strengths and subsequent well-being.

Table 2

Character Strengths and Virtues (Peterson \& Seligman, 2004)

\begin{tabular}{|c|c|}
\hline Virtue & Strength \\
\hline \multirow[t]{5}{*}{ Wisdom and Knowledge } & Creativity \\
\hline & Curiosity \\
\hline & Open-mindedness \\
\hline & Love of learning \\
\hline & Perspective \\
\hline \multirow[t]{4}{*}{ Courage } & Bravery \\
\hline & Persistence \\
\hline & Integrity \\
\hline & Vitality \\
\hline \multirow[t]{3}{*}{ Humanity } & Love \\
\hline & Kindness \\
\hline & Social intelligence \\
\hline \multirow[t]{3}{*}{ Justice } & Citizenship \\
\hline & Fairness \\
\hline & Leadership \\
\hline \multirow[t]{4}{*}{ Temperance } & Forgiveness and mercy \\
\hline & Humility/modesty \\
\hline & Prudence \\
\hline & Self-regulation \\
\hline \multirow[t]{5}{*}{ Transcendence } & $\begin{array}{l}\text { Appreciation of beauty and } \\
\text { excellence }\end{array}$ \\
\hline & Gratitude \\
\hline & Hope \\
\hline & Humor \\
\hline & Spirituality \\
\hline
\end{tabular}




\section{Positive Psychology and Disability Studies}

Positive psychology research does not typically investigate those who live with limited capacity or who have been historically marginalized; rather, it has primarily focused on those with majority status and few risk factors (Dykens, 2006; Prilleltensky, 2012; Wehmeyer, 2014). In a seminal article for positive psychology, Seligman and Csikszentmihalyi (2000) asserted that positive psychology is about "making normal people stronger and more productive and making high human potential actual"' (p. 8). This very definition is problematic for the population of those with ID. The term "normal" is pejorative and infers that those who fall outside the typical range may not be worthy of the benefits of positive psychology. However, as Michael Bérubé (1996), disabilities scholar and father of a young adult with ID states, "outside the 'norm' there's all kind of variety... some of it quite normal" (p. 208). Thus, individuals who fall outside the average range on a bell curve can still strive to build capacity and thrive. Furthermore, the question of "high human potential" can be challenging in the disabilities community. After all, who decides an individual's potential when a disability diagnosis is defined by functional limitations? And when does one consider an individual with significant disabilities' potential to be "actualized"? Rather than examining those with ID through a strength-based perspective, most research has documented deficits and examined ways to reduce the impact of the disability (Shogren, 2014).

However, positive psychology has begun to gain traction in disability studies (Wehmeyer, 2014) with the development of the social ecological model (Schalock et al., 2010) and the advent of the QOL concept for ID (Schalock \& Alonso, 2014). Research and interventions aimed at understanding and promoting the strengths and well-being of 
those with ID are now being created to target individuals as well as their systems of support. One the most researched positive psychology constructs for individuals with ID is that of self-determination (Shogren, 2014). Self-determination refers to individuals with ID acting as the causal agents in their own lives (Wehmeyer et al., 2012). Even those with significant personal limitations associated with ID (e.g., lack of verbal communication skills; need for assistance with daily living) can actively direct their systems of support in order to enhance their own QOL (Shogren, 2014). Rather than addressing deficits, self-determination interventions involve the development of critical skills such as problem-solving, goal setting, self-management, and self-advocacy (Shogren, 2014). Higher levels of self-determination for those with ID are associated with higher QOL and more optimal outcomes for education and employment (Shogren, Palmer, Wehmeyer, Williams-Diehm, \& Little, 2012; Palmer \& Wehmeyer, 2003). However, despite the emphasis on self-determination and other aspects of student choice, research articles focused on positive psychology constructs not only have a narrow definition of the construct, but also represent a minority of all published articles in the most prominent ID journals (Shogren, Wehmeyer, Pressgrove, \& Lopez, 2006).

\section{Positive Psychology and School Psychology}

NASP's mission to enhance mental health and learning for all students (NASP, 2010) aligns well with the field of positive psychology. School psychologists have the skills to optimize student outcomes using data-based decision making and to build healthy functioning communities through systems level interventions. Furthermore, schools are uniquely positioned for positive psychology. All children attend school; thus, schools can reach a wide variety of individuals regardless of economic resources. 
Moreover, students start attending school at an early age before most pathology has developed, thus allowing school psychologists to focus on preventative efforts such as building mental health and well-being rather than treating mental illness (Vella-Brodrick, 2016). Additionally, special education law requires that teams consider a student's strengths when developing educational programs (IDEA, 2004). Altogether, the school setting, professional skill sets, and legal mandates make the field of school psychology a natural fit for practicing from a positive psychology framework.

However, school psychology research has been slow to embrace positive psychology (Gilman, Huebner, \& Furlong, 2014). As evidence, Froh, Huebner, Youssef, and Conte (2011) analyzed four major school psychology journals for the number of articles with a positive psychology research orientation over the past 50 years. They found that, as of 2008, in contrast to other fields of psychology, school psychology scholarship had no growth in the number of studies with a positive focus, with only $25 \%$ $30 \%$ of all research focusing on positive constructs. The authors concluded that the historic school psychology emphasis on assessment and diagnosis of problems was still pervasive in the literature.

Still, there remains a strong contingent of school psychology researchers committed to furthering the work of positive psychology through school-based approaches. The Handbook of Positive Psychology in Schools (Furlong et al., 2014) highlights research to date using the theories of positive psychology in the school setting. Within the handbook, a conceptual model for the application of positive psychology to school psychology illuminates how the two fields can merge for assessment, research, and application in the schools (Gilman et al., 2014). By considering a student's individual 
differences (e.g., strengths) within a series of ecological systems (Bronfenbrenner, 1979), positive school psychologists can better understand, measure, and enhance student physical, social-emotional, and cognitive well-being.

One such application is strengths-based assessment (SBA). SBA is a burgeoning practice for school psychologists and can be used to supplement the more traditional deficit-based assessment process used in schools for qualification purposes (Jimerson, Sharkey, Nyborg, \& Furlong, 2004). Initial research shows promising results that by understanding a child's strengths, an educational team may have a more thorough, balanced, and hopeful picture of a child with more predictions for a student's future success (Donovan \& Nickerson, 2007). The use of a child's uniquely identified strengths in school-based mental health interventions may be associated with positive change and enhanced student self-confidence (Bozic, 2013).

Understanding the strengths of students with ID is a critical step in the development of healthy community inclusion and QOL:

When all that is known about someone with ID is what he or she cannot do, it is not surprising when others struggle to envision a place for people with such labels in their workplaces, congregations, community groups, or personal networks. (Carter et al., 2015, p. 102)

A study conducted by Carter et al. (2015) determined that character strength profiles are unique for each student with ID and include a wide variety of domains (e.g., interpersonal relations, personality traits, cognitive abilities, unique skills, and personal hobbies).

Rather than solely focusing on deficits and needs for treatment and remediation, school psychologists should also examine assets in this population, so that students with ID may be known for their unique ability to contribute as they venture into the community. 
In addition to assessment, positive psychological interventions can be used in the schools (Miller, Nickerson, \& Jimerson, 2014; Suldo, 2017). Positive psychology interventions aimed at improving the happiness and SWB of individual students include interventions to enhance student gratitude (Roth, Suldo, \& Ferron, 2016), build optimism (Brunwasser, Gillham, \& Kim, 2009), understand personal strength profile (Proctor et al., 2011), and develop mindfulness skills (Schonert-Reichel et al., 2015). Additionally, multiple universal supports use a positive psychology approach, including school-wide positive behavioral interventions and supports (SWPBIS; Horner \& Sugai, 2015), class wide consultation methods (Doll et al., 2014), positive youth development-multitiered system of supports (PYD-MTSS; Hazel, 2016), and social emotional learning (SEL; Durlak, Weissberg, Dymnicki, Taylor, \& Schellinger, 2011). In all, the school setting is well suited to positive psychology's goal of enabling individuals and communities to thrive.

\section{Thriving}

Although positive psychology aims to understand what enables some individuals and communities to thrive (IPPA, n.d), a clear definition for what it means to thrive is more elusive. Furthermore, the concept of thriving with ID is only beginning to be explored (Weiss \& Riosa, 2015), and still lacks a solid theoretical framework of its own. Thriving appears to indicate an intersection of growth and happiness. According to the Oxford Dictionary of English (n.d.), to thrive is to grow or develop well or vigorously. Thriving is more than surviving; thriving is living well and enjoying the process (Angelou, 2011). A number of developmental, industrial/organizational, and positive psychologists have proposed theories on what it means to thrive, flourish, or function 
optimally (Benson \& Scales, 2009; Lerner et al., 2010; Prilleltensky, 2012; Seligman, 2011; Vallerand \& Carbonneau, 2013), yet a consensus on terms and meaning has yet to be determined.

Overall, research indicates that thriving is rooted in context, highly influenced by power and privilege, and may differ for different populations and cultures (Buettner, 2010; Prilleltensky, 2012). Thriving involves present levels of well-being, as well as a sense of growth and hope for a positive future (Gallup, 2009). There are subjective components to thriving, wherein individuals perceive their own conditions positively, as well as objective and measureable components such as relationships, learning, and income (Prilleltesnky, 2012; Seligman, 2011; Spreitzer et al., 2005; Vallerand \& Carbonneau). Furthermore, the literature indicates that a combination of individual factors (e.g., personal strengths and passions) coupled with contextual factors (e.g., environments that support positive relationships and opportunities for growth) must be present for thriving to occur (Benson \& Scales, 2009; Boyd, 2015; Lerner et al., 2010; Vallerand \& Carbonneau, 2013; Weiss \& Riosa, 2015). The following four theories outline current thriving concepts in the literature and begin to provide insight and understanding for what it means to thrive with ID.

\section{Thriving in Adolescence}

Benson and Scales (2009) emphasize that thriving for adolescents is more than getting by or meeting standards. Rather, thriving is a "journey to idealized personhood" (Benson \& Scales, 2009, p. 90). The authors define thriving as a process in which an adolescent identifies and exercises his or her special interests, or "sparks," within a supportive context. Thriving involves both well-being and an "upward developmental 
trajectory" (Benson \& Scales, 2009, p. 90). Growth is encouraged through interdependent and bidirectional relationships within the community. Youth who are thriving can identify their own passions, demonstrate positive affective states, have a strong sense of spirituality and purpose, and are motivated to develop their "sparks." Thriving for adolescents is deeply rooted in the developmental stages of this specific age range. Teens are developing their identity and growing in their independence (Cobb, 2001; Erikson, 1950).

Lerner and colleagues (2013) operationalized adolescent thriving with the six Cs of positive youth development: competence (youth has a positive view of his or her actions in the world), confidence (youth has a high sense of self-worth and self-efficacy), compassion (youth demonstrates caring attitudes, interpersonal warmth, empathy, and understanding), character (youth is reliable and has integrity), contribution (youth is helpful in a broader context with family, community, and society), and connection (youth has positive relationships). Adolescents who demonstrate these six strengths can be considered thriving. Supportive developmental assets (e.g., families, schools, and communities) can enhance these attributes and foster thriving for youth (Lerner et al., 2010; Lerner et al., 2013).

\section{Flourishing}

In 2011, Seligman reframed his original "authentic happiness" theory (Seligman, 2002) to a theory of well-being titled flourishing. The term flourishing is similar to the concept of thriving. In fact, Seligman (2011) states that flourishing is the ultimate goal of positive psychology (p. 26). Flourishing differs from Benson and Scales (2009) definition of thriving in adolescence in that it does not include a developmental perspective. 
However, the concept is similar in that it implies an ideal condition of living, rather than a mere absence of pathology. Indeed, flourishing and thriving have been identified as a single construct in systematic reviews of positive psychology literature (Hart \& Sasso, 2011).

Flourishing involves five key elements known as PERMA, which stands for: positive emotions, engagement, relationships, meaning, and achievement. Positive emotions refer to the pleasant life: happiness, joy, and life satisfaction (Diener et al., 2016). These positive feelings and thoughts are crucial; yet, Seligman argues they are not enough to flourish. One must also have engagement, also referred to as "flow," which occurs when individuals are completely immersed in an activity, lose track of time, and abandon self-consciousness (Csikszentmihalyi, 1990). Furthermore, relationships and positive interactions with other people are crucial for flourishing. Flourishing theory posits that another key element is meaning, or working for something greater than one's self. Finally, success and mastery leave one with a feeling of accomplishment and achievement necessary for true well-being. An individual's character strengths (Peterson \& Seligman, 2004) underlie each element of PERMA, contributing to one's positive emotions, engagement, quality of relationships, ability to find meaning, and levels of accomplishment.

\section{Optimal Functioning in Society}

Optimal Functioning in Society (OFIS) is a multidimensional construct related to thriving, made up of five key elements: psychological well-being, physical health, positive interpersonal relationships, high performance in one's field, and contributing to society (Vallerand \& Carbonneau, 2013). OFIS theory emphasizes that moving people 
into the upper levels of well-being is more important than merely eradicating mental illness. Vallerand and Carbonneau (2013) encourage positive psychologists to aim for promotion of the highest levels of psychological functioning with their OFIS theory. Using the analogy of a metric for mental health with a -10 to a +10 scale, the authors state that rather than aspiring to move people from a -10 to the status quo of 0 or +1 , the goal should be to move individuals into the $+7-+10$ range of mental health (Vallerand \& Carbonneau, 2013, p. 53). Thus, they argue the ultimate goal of positive psychology is to encourage growth in all five elements so that individuals will experience optimal levels of functioning.

Similar to Benson and Scales' (2009) notion of a "spark" as a part of thriving in adolescence, Vallerand and Carbonneau (2013) assert that passion is a major contributing factor for OFIS. Passion is defined as "a strong inclination toward a self-defining activity that one loves, finds important and meaningful, and in which one invests time and energy" (Vallerand \& Carbonneau, 2013, p. 55). Two types of passion, obsessive and harmonious, are possible. Obsessive passion is marked by an individual's uncontrollable preoccupation with something and may detract from quality of life. In contrast, harmonious passion - that which is freely embedded into a person's identity without rigid obsession - is associated with and can encourage all five elements of OFIS. Thus, harmonious passion is a variable to be fortified and fostered to promote the OFIS, or thriving, for all individuals.

\section{Thriving at Work}

Spreitzer et al. (2005) define thriving at work as a combination of two key factors: vitality and learning. Vitality is similar to Seligman's (2011) concept of flourishing; it is 
an energetic sense of well-being. In the work place, employees with vitality have a positive affective state and a feeling of "aliveness" in their jobs (Spreitzer et al., 2005, p. 538). Learning at work refers to a cognitive process, in which the employee is gaining knowledge in his or her field, growing in the profession. Overall, these two elements indicate a state of thriving at work that is highly influenced by internal resources (e.g., knowledge, a sense of meaning) and contextual features (e.g., healthy and positive work

climates). Furthermore, a sense of community (SOC, feelings of belonging and connection) in the workplace can contribute to an employee's well-being (vitality), while a sense of community responsibility at work (SOC-R, the feeling of responsibility for the collective well-being of an organization) contributes toward an employee's work engagement and pursuit of leadership opportunities (learning) (Boyd, 2015). Work is a major part of any individual's life, and therefore thriving at work can ultimately lead to positive life outcomes such as personal development and positive physical and mental health (Spreitzer et al., 2005).

\section{Thriving and Intellectual Disability}

In order to promote thriving for students with ID, school psychologists must combine theories and research from disability studies with these existing thriving models (see Table 3). The concept of QOL (Schalock \& Alonso, 2014) serves as a guide to maintaining relevance and validity for this specific population while encompassing many of the most prominent models of thriving outlined above.

As indicated in Table 3, several thriving models involve aspects of well-being and happiness (Seligman, 2011; Spreitzer et al., 2005; Vallerand \& Carbonneau, 2013) as well as personal growth, achievement, and skill development (Lerner et al., 2013; 
Seligman, 2011; Vallerand \& Carbonneau, 2013; Spreitzer et al., 2005). Furthermore, relationships have been identified as vital to both thriving and QOL (Lerner et al., 2013; Seligman, 2011; Vallerand \& Carbonneau, 2013). However, the major thriving models lack several critical elements deemed necessary in the population of people with ID.

Table 3

Alignment of Quality of Life (QOL) concept with four major thriving theories

\begin{tabular}{|c|c|c|c|c|}
\hline $\begin{array}{l}\text { Quality of Life } \\
\text { for Individuals } \\
\text { with ID } \\
\text { (Schalock \& } \\
\text { Alonso, 2014) }\end{array}$ & $\begin{array}{l}\text { Adolescent } \\
\text { Thriving: } 6 \text { Cs of } \\
\text { Positive Youth } \\
\text { Development } \\
\text { (Lerner et al., } \\
\text { 2013) }\end{array}$ & $\begin{array}{l}\text { Flourishing: } \\
\text { PERMA } \\
\text { (Seligman, 2011) }\end{array}$ & $\begin{array}{l}\text { Optimal } \\
\text { Functioning } \\
\text { In Society } \\
\text { (Vallerand \& } \\
\text { Carbonneau, } \\
\text { 2013) }\end{array}$ & $\begin{array}{l}\text { Thriving at } \\
\text { Work } \\
\text { (Spreitzer } \\
\text { et al., } \\
\text { 2005) }\end{array}$ \\
\hline $\begin{array}{l}\text { Personal } \\
\text { development }\end{array}$ & $\begin{array}{l}\text { Competence } \\
\text { Character }\end{array}$ & Achievement & High performance & Learning \\
\hline $\begin{array}{l}\text { Self } \\
\text { determination }\end{array}$ & Confidence & & & \\
\hline $\begin{array}{l}\text { Interpersonal } \\
\text { relations }\end{array}$ & $\begin{array}{l}\text { Connection } \\
\text { Compassion }\end{array}$ & Relationships & $\begin{array}{l}\text { Positive } \\
\text { relationships }\end{array}$ & \\
\hline Social inclusion & Contribution & Meaning & $\begin{array}{l}\text { Contributing to } \\
\text { society }\end{array}$ & \\
\hline $\begin{array}{l}\text { Emotional well- } \\
\text { being }\end{array}$ & & $\begin{array}{l}\text { Positive } \\
\text { emotions } \\
\text { Engagement }\end{array}$ & $\begin{array}{l}\text { Psychological } \\
\text { well-being }\end{array}$ & Vitality \\
\hline $\begin{array}{l}\text { Physical well- } \\
\text { being }\end{array}$ & & & Physical health & \\
\hline \multicolumn{5}{|l|}{$\begin{array}{l}\text { Material well- } \\
\text { being }\end{array}$} \\
\hline Rights & & & & \\
\hline
\end{tabular}

Specifically, a discussion of thriving for individuals with ID requires the acknowledgement that those who thrive do so within structures of power and oppression (Buettner, 2010; Prilleltensky, 2012). Prilleltensky (2012) places thriving on a well-being 
continuum that is directly correlated with levels of justice. Suffering is the lowest state of well-being and is associated with continuous discrimination and inequality. Thriving is the highest level of well-being and only occurs under optimal conditions of justice. He asserts that the notion of growing and succeeding because of internal drive, hard work, and skill is only possible in an equitable situation. When contextual variables lead to inequity, an individual will struggle to achieve or experience feelings of well-being and is unlikely to thrive.

For those with ID, the notion of social justice is, indeed, a prerequisite for thriving. The QOL for individuals with ID is dependent on successful and meaningful social inclusion and participation in the community as well as broader socio-cultural beliefs, policies, and practices that enhance statutory rights and material/physical wellbeing (Schalock \& Alonso, 2014). The social ecological model for disabilities (Schalock et al., 2010) must inform the construct development of what it means to thrive with ID.

To date, only one study has directly examined the construct of thriving for those with ID (Weiss \& Riossa, 2015). This pioneering study was based on the six C's of positive youth development (PYD) framework for thriving in adolescence (Lerner et al., 2013). In their study, the authors used a survey methodology to sample the parents of 330 children ages 11 to 21 who had ID and participated in the Special Olympics. Results indicated that, in the population of individuals with ID, those with a comorbid diagnosis of autism spectrum disorder (ASD) demonstrated significantly fewer thriving indicators (i.e., fewer of the six Cs) than those with ID alone. However, a mediator analysis using both individual and contextual factors revealed that levels of social communication and community participation were better predictors of thriving than simply the presence of an 
ASD diagnosis. Thus, research supports the idea that thriving is associated with a combination of individual and contextual factors in the population of those with ID.

Weiss and Riosa (2015) noted several limitations to their study, including the use of very brief survey instruments for each variable and the lack of input from the youth with ID themselves - all data were collected from parent perspectives. One notable, and unaccounted for, assumption in the study was the adoption of the PYD model for thriving in a sample of youth with ID. The PYD model for thriving and the six Cs brief survey was developed for the general population of youth (Lerner et al., 2010); construct validity for adolescents with ID has yet to be determined. Therefore, while some aspects of the six Cs appear relevant as a measure of thriving for students with ID (see Table 3), the PYD model does not entirely address some of the most pressing issues for this population such as the importance of well-being or issues of social justice and civil rights. Therefore, although the Weiss and Riosa (2015) study is an excellent start to examining the positive psychology of those with ID, it lacks a framework that is specific to the population.

\section{Transactional Ecological Thriving Model}

The Transactional Ecological Thriving Model (TET-M) is a newly proposed framework for understanding thriving for students with ID (see Figure 1). In this model, thriving involves the continuums of subjective well-being (SWB) and developmental growth within a series of support systems. Four quadrants emerge from the vertical and horizontal axes, including thriving, static, suffering, and taxed. The following sections outline in detail each element of TET-M, including the systems of support, the axes of SWB and developmental growth, and the four quadrants. 


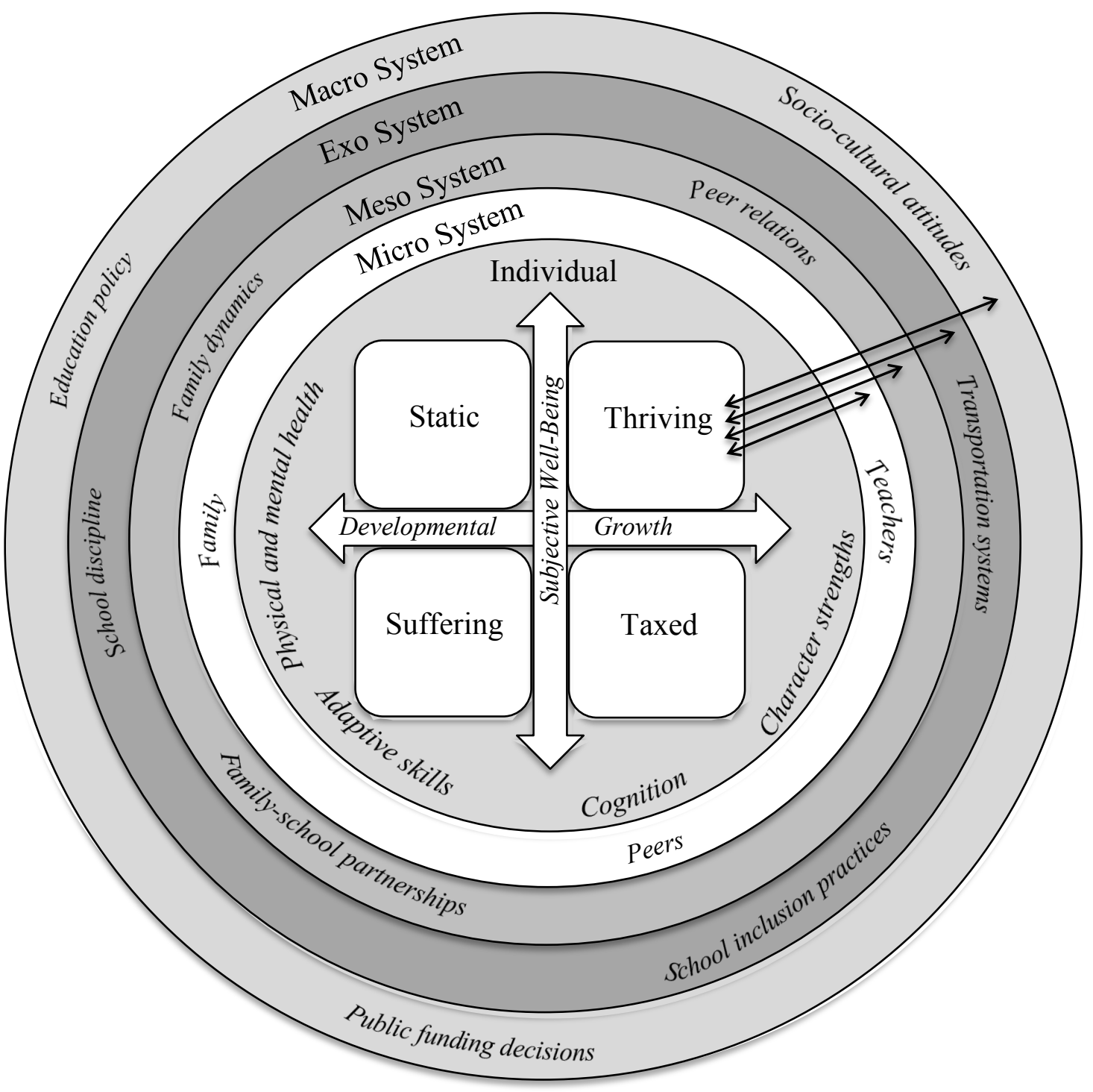

Figure 1. Transactional Ecological Thriving Model (TET-M): A theoretical framework for school psychology.

\section{Systems of Support}

Thriving requires a reciprocally supportive context to enhance and maintain both SWB and developmental growth (Bronfenbrenner, 1979; Prilleltesnky, 2012). The TET-M embeds the individual within a series of systems of support based on the 
concentric circles of the bioecological systems theory (Bronfenbrenner, 1979).

Bidirectional arrows in the thriving quadrant indicate a healthy and functional exchange between the student's individual characteristics and his or her environment. These arrows reflect key domains from the QOL concept (Schalock \& Alonso, 2014), including some that are missing from other critical thriving models (see Table 3). Namely, arrows between the individual and the micro and meso systems reflect the importance of reciprocal interpersonal relations. Furthermore, inward facing arrows between the individual and the exo and macro systems indicate the role of distal systems on both rights and material well-being. Outward facing arrows communicate the role of participation on social inclusion and self-determination. Altogether, these arrows indicate the transactional relationship between thriving individuals and their ecological systems.

The examples listed in each ring of the systems of support (e.g., teachers, school policies) are limited and specific to the school setting in order to enhance clinical utility for practicing school psychologists. However, this model may also be applicable to other environments and life stages (e.g., vocational, community) where other variables may be more relevant (e.g., supervisors, spouses, work-place policies, housing). After all, the NASP vision is that all students thrive in school, at home, and in life (NASP, n.d.). While our work as school-based mental health providers is typically focused on the birth-to-21 age range, we aspire to impact students throughout the lifespan, well into adulthood. Thus, the model can and should be expanded to include a variety of factors that impact long-term functioning and outcomes for any individual with ID, even those who are no longer enrolled in the schools. 
Individual variables. School psychologists practicing from a positive psychology framework should begin by considering students' individual characteristics that they bring to the situation, including their character strengths (Gilman et al., 2014). Further, the social ecological model (Buntinx, 2014; Schalock et al., 2010) states that human functioning for individuals with ID is heavily influenced by the capacity of systems to support the individual's unique needs (e.g., intellectual ability, adaptive skills, and health). In order to design effective and responsive support systems from a positive psychology and social-ecological model orientation, school psychologists must have a clear understanding of these individual traits. Individual characteristics lie at the core of the TET-M. These include character strengths, cognitive abilities, adaptive skills, and physical and mental health. All of these variables are influenced by, and subsequently influence, the systems of support in which the student develops.

Bioecological systems. Bronfenbrenner's (1979) influential theory of contextual development was originally conceptualized as a succession of instrumental systems surrounding a developing person. The theory was refined over the course of Bronfenbrenner's career to include a biological component (i.e. bioecological systems model) acknowledging the impact of child attributes on the systems (Rosa \& Tudge, 2013). In the bioecological systems theory, there is an emphasis on bi-directionality and interdependency of the developing individual and others within the systems. All of this influences the nature and course of development, and is the context for the TET-M.

The innermost ring of the ecological model, closest to the developing person, is described as the microsystem. This includes the most immediate face-to-face relationships and systems surrounding an individual, such as a family unit or classroom. 
As with all the systems in this model, the child affects the system in which he or she interacts as much as the adult caregivers affect the child. It is not a unidirectional relationship where a parent or teacher delivers interventions and the child grows in response; instead, both individuals' personal characteristics influence the frequency, the manner, and the quality of the interactions (Bronfenbrenner, 1979). Factors such as parental expressed emotion (EE; Magana-Amato, 2015), teacher instructional styles, and peer attitudes are all encompassed within this microsystem.

At the second level, the mesosystem is a unique "system of systems," where Bronfenbrenner (1979) noted the ways in which the relationships between microsystems can significantly impact development (p. 25). The strength and quality of interactions between key players in an individual's life can enhance or detract from a child's development. For instance, the relationships between home and school can greatly impact a child's cognitive development and academic growth (Miller, Lines, \& Fleming, 2014).

Moving outward to the third ring, the exosystem refers to those systems that indirectly influence an individual's development. A family's extended support systems, a parent's employment situation, the policies of a school district, or neighborhood crime rates are all examples of the exosystem. While the relationship between the individual and the exosystem is less direct, it is still significant. For instance, students who attend schools with well-developed school-wide positive behavior intervention systems (SWPBIS) tend to demonstrate fewer behavior problems and more prosocial behaviors (Bradshaw, Waasdorp, Leaf, 2012).

Finally, Bronfenbrenner (1979) noted the impact of the macrosystem on an individual's development. As the outermost system, the macrosystem refers to the 
overarching institutional structures that surround an individual. This includes broad cultural and ideological belief systems, political influences, public program funding decisions, legal issues, education systems, and access to opportunities. This system permeates all other systems and impacts development in an indirect, but highly influential, manner.

Systems of support and intellectual disabilities. In regard to disability studies, the bioecological systems model is highly useful. In fact, the social ecological model of human functioning (Buntinx, 2014; Schalock et al., 2010) is based on Bronfenbrenner's (1979) concept of ecological systems. People with ID rely heavily on the systems of support to facilitate development and well-being. For instance, in young adulthood, a primary developmental task may be vocational training. However, to access job skills training and, eventually, a location of employment, an individual with ID is highly dependent on his or her community's public transportation system (exosystem). If the public bus system is inaccessible, unsafe, or unpredictable, an individual with ID will be unlikely to access the training required for professional development. Human functioning is greatly affected by the systems within which an individual with ID interacts and contributes.

\section{Axes}

Two axes provide structure for the matrix embedded within TET-M. The vertical axis indicates a continuum of SWB; or a spectrum of life satisfaction and positive affective state (Diener et al., 2016). The upper half of the matrix represents relatively high levels of SWB, while the lower half represents those with lower levels of SWB. The horizontal axis signifies a trajectory of developmental growth (Benson \& Scales, 2009). 
The right side of the matrix indicates continued personal development; an upward moving path. To reemphasize, this right side does not refer to normatively high developmental skills, but rather the act of continuous improvement. In contrast, the left side represents those at a stagnant developmental state, or those who are regressing in personal growth and development.

Subjective well-being. SWB is defined as "people's overall evaluations of their lives and their emotional experiences" (Diener et al., 2016, p.87). The concept of subjectivity in SWB is critical; it is determined by the individual him or herself through self-reflection and reporting, rather than determined externally by objective outcome measurements (Huebner \& Furlong, 2016). SWB includes a cognitive component in which one assesses levels of satisfaction with life, as well as an affective component in which one experiences feelings and moods (Diener et al., 2016). Those who have positive thoughts about their lives, as well as frequent positive emotions and infrequent negative emotions, have high SWB (Nes \& Roysamb, 2015). This conceptualization might cause SWB to be mistaken for a simple measure of happiness (Jayawickreme et al., 2012); however, SWB is a more complex construct. Each of the three elements of SWB (life satisfaction, positive affect, infrequent negative affect) is influenced by and influences different variables and aspects of a person's life. For example, the quality of one's work can influence life satisfaction, the dynamics of interpersonal relationships can influence positive affect, and internal conflicts can increase negative affect (Diener et al., 2016). Further, positive emotions may enhance sociability and negative affect may impact how an individual perceives personal problems (Diener et al., 2016). Moreover, SWB is not an inborn trait explained primarily by heritability. In fact, only $40 \%$ of SWB variance can be 
explained by genetics (Nes \& Roysamb, 2015). Diener and colleagues (2016) caution against over-interpreting the effects of heritability based on ample evidence that demonstrates the impact of life events and support systems on an individual's SWB.

SWB can be further categorized as hedonic or eudaimonic (Jayawickreme et al., 2012; Ryff, 2014). Hedonic well-being is primarily concerned with liking and enjoying one's life. Fredrickson's (2001) “broaden and build” theory can be considered a hedonic form of SWB. It emphasizes that those with positive emotions may have many more opportunities to engage in the world, therefore possessing higher levels of SWB. Simply experiencing a positive emotion can cause an individual to expand his or her horizons and develop new skills. For example, experiencing the positive emotion of curiosity may cause a student to explore the environment. Then, the "broadened" opportunities triggered by the positive emotion may lead to "building" new vocabulary skills, learning new concepts, and increasing social skills. Thus, development is directly related to one's SWB.

A eudaimonic approach asserts that well-being involves deeper rooted constructs than mere happiness and life satisfaction. Ryff (2014) argues for more than the traditional simplistic and reductionist views of SWB. Her model of psychological well-being includes six major elements: environmental mastery, personal growth, self-acceptance, life purpose, relations with others, and autonomy (Ryff, 2014). When these six constructs are present, an individual has an overall high level of well-being. This conceptualization of well-being better reflects the causal conditions for the positive emotions and life satisfaction outlined in the traditional SWB theories. With eudaimonic SWB, the emphasis is on the individual's reciprocal relationships with the community; where one 
"find[s] fulfillment as a contributing member of society" (Hazel, 2016, p. 23).

Furthermore, eudaimonic SWB refers to the deeper needs of an individual as opposed to simply examining what an individual wants and desires (Ryff, 2014; Seligman, 2011).

Subjective well-being and intellectual disability. SWB for individuals with ID has historically been an underexplored construct (Dykens, 2006; Shogren, 2014). While researchers have examined the SWB of parents and overall family well-being of children with ID (e.g., Werner \& Shulman, 2013), tools for measuring and understanding how individuals with ID experience SWB are limited due to language and cognitive constraints (Vos, De Cock, Petry, Van Den Noortgate, \& Maes, 2013). Researchers have begun using adapted assessments with visual prompts and tablet computer technology to elicit information on the SWB of individuals with ID (Bostrom \& Broberg, 2017). Additionally, systematic caregiver behavioral observations of mood and emotions have been used to measure SWB in those with severe and profound ID and significantly limited communication skills (Vos et al., 2013). A few qualitative researchers have also explored the topic of SWB in the ID community, bringing the voices of participants into the conversation about what the phenomenon of SWB means to those living with ID (Foley et al., 2012; Haigh et al., 2013; Scott; Foley, Bourke, Leonard, \& Girdler, 2014). Initial research indicates that SWB for this population is characterized by a joyful attitude, positive relationships, meaningful participation, and autonomy (Bostrom \& Broberg, 2017; Scott et al., 2014; Foley et al., 2012). Individual characteristics such as emotional competency (Rey, Extremera, Duran, \& Ortiz-Tallo, 2014), a positive sense of self (Foley et al., 2012) or a hope for the future (Scott et al., 2014) are associated with SWB, while advanced age, medical problems, and compromised adaptive behaviors may 
detract from SWB (Vos, De Cock, Petry, Van Den Noortgate, \& Maes, 2010). Contextual factors such as access to safe and inclusive settings are also associated with higher levels of SWB (Haigh et al., 2013).

Developmental Growth. Developmental growth can be defined as the process of changing with age, building new skills, gaining new knowledge, and transforming into something new (Trawick-Smith; 2014). Developmental growth does not stop at a certain age; aside from temporary plateaus, humans develop continually over the lifespan, sometimes steadily, sometimes with sudden transformations (Shonkoff, Phillips, \& National Research Council, 2000). In TET-M, continued developmental growth must accompany SWB in order to achieve a state of thriving.

For school psychologists, student developmental growth is traditionally characterized and measured by academic progress as well as social, emotional, and behavioral development (NASP, 2010). The wide range of ages covered by school psychological services (birth to 21) requires any consideration of developmental growth to be grounded in a strong understanding of cognitive and psychosocial developmental theories (see Erikson, 1950; Piaget, 1954) with knowledge of developmental milestones and expectations across the life span as well as evidence-based strategies for supporting development (NASP, 2010). Again, it is important to note that the developmental growth axis of TET-M is not a measure of normative development. Students with ID, who may be functioning well below same-aged peers, may still fall in the high range of the developmental growth continuum. The emphasis is on the trajectory of development. Therefore, students who are making progress and moving toward individualized goals 
that are lower than expected based on grade-level standards or developmental stages can still be considered thriving.

Stage theories of development break down an individual's growth into measurable chunks, following a biological process, over time (Trawick-Smith, 2014). Developmental stage theorists were concerned with capturing the typical or "normative" process of human development over the lifespan, and typically failed to capture the developmental experience of those with disabilities (Smart, 2012). However, school psychologists can still utilize stage theories of development when assessing a student's growth trajectory and setting goals, while making sure to consider the unique aspects of a student's developmental profile related to ID.

Erikson's (1950) psychosocial development theory and Piaget's (1954) theory of cognitive development are particularly salient in a discussion about developmental growth and thriving. Erikson (1950) laid out eight stages of psychosocial development, in which an individual resolves a series of personal crises as he or she ages (see Table 4). Satisfactory resolutions to the developmental crises result in the development of major new social and emotional skills and moving on to the next life stage.

Piaget's (1954) theory on cognitive development outlined the stages in which a child constructs knowledge (see Table 5). Piaget (1954) asserted that the process of assimilation allows children to fit new information into their pre-existing understanding of the world, whereby accommodation is the process in which the child's cognition develops to adapt to the new information. School psychologists can reflect on these critical stage theories as they consider a student's placement on the developmental growth axis of TET-M. Furthermore, a deep understanding of developmental stage 
theories allows the school psychologist to set appropriate and meaningful goals for growth based on developmentally appropriate stages.

Table 4

Erikson's Stages of Psychosocial Development (Erikson, 1950)

\begin{tabular}{lll}
\hline Age & Stage & Developmental task \\
\hline $0-18$ months & Trust vs. Mistrust & $\begin{array}{l}\text { Building trusting relationships } \\
\text { with caregivers }\end{array}$ \\
$\begin{array}{ll}18 \text { months- } \\
3.5 \text { years }\end{array}$ & Autonomy vs. shame & $\begin{array}{l}\text { Building independence to separate } \\
\text { from caregivers and explore } \\
\text { surroundings }\end{array}$ \\
$\begin{array}{l}\text { 3.5 years- } \\
6 \text { years }\end{array}$ & Initiative vs. guilt & $\begin{array}{l}\text { Taking risks, expressing thoughts } \\
\text { and feelings }\end{array}$ \\
6 years- 12 years & Industry vs. inferiority & $\begin{array}{l}\text { Developing skills, acquiring } \\
\text { competence, learning to work }\end{array}$ \\
Adolescence & Identity vs. identity confusion & $\begin{array}{l}\text { Working out one's place in the } \\
\text { world, identifying personal values } \\
\text { and beliefs }\end{array}$ \\
& & $\begin{array}{l}\text { Learning to relate closely with } \\
\text { other people }\end{array}$ \\
Young adulthood & Intimacy vs. isolation & $\begin{array}{l}\text { Contributing to society and } \\
\text { nurturing the next generation }\end{array}$ \\
Adulthood & Generativity vs. stagnation & Contemplating one's life \\
\hline
\end{tabular}

Table 5

Piaget's Stages of Cognitive Development (Piaget, 1954)

\begin{tabular}{lll}
\hline Age & Stage & Developmental task \\
\hline $0-18$ months & Sensorimotor & $\begin{array}{l}\text { Using movement and senses to } \\
\text { understand the world }\end{array}$ \\
18 months-7 years & Preoperational & $\begin{array}{l}\text { Beginning of internal thought and use of } \\
\text { symbols, concrete reasoning } \\
\text { Early logical reasoning, continue to } \\
\text { benefit from the use of concrete } \\
\text { materials } \\
\text { Abstract reasoning and hypothetical } \\
\text { thinking }\end{array}$ \\
\hline
\end{tabular}


Developmental growth and intellectual disability. Research indicates that students with ID can and do experience the stages outlined above (Smart, 2012). However, a strict or rigid adherence to the normative linear progression through the stages is unlikely to prove valid in a population of people with limitations imposed from both biological and societal factors. Thus, while stage theories are useful for understanding typical human development, they fail to acknowledge the influence of the individual/context interaction that is so critical for the ID population.

The concept of plasticity may be more useful when considering developmental growth for those with ID. Development need not be stagnant or predetermined by society or genetics; rather development can be encouraged and advanced. In developmental psychology, the concept of plasticity refers to the notion that adequately supportive environments can move individuals toward healthy developmental outcomes (Lerner et al., 2006). Further, in neuroscience, plasticity refers to the brain's capacity to change, grow, and adapt, especially with exposure to enriched learning environments (Bryck \& Fisher, 2012). For example, the life expectancy, IQ scores, and developmental outcomes of those with some genetic conditions that cause ID have drastically improved over the past half-century due to historical changes in the ecological systems of support (e.g., advances in the medical community and an inclusive public education system; Roizen, 2013). A supportive environment can drastically impact development for many with ID; it is impossible to predict potential when outcomes change over time with historical advances. Rather, it is more useful to consider the plasticity of each individual's development, and work to promote growth in all developmental areas over the lifespan. 
In the QOL concept, personal growth for people with disabilities is a key domain in the category of independence (Schalock \& Alonso, 2014). The personal growth domain is operationalized as having valid assessment data about present levels of performance, learning new skills that are of interest to the individual, accomplishing individualized academic goals, and obtaining educational degrees (Gomez, et. al., 2015; Schalock \& Alonso, 2014). This domain aligns well with school psychologists' professional responsibility to promote learning for all students regardless of disability status (NASP, 2010). School psychologists can advocate for students with ID by continuing to encourage academic, social, and behavioral growth regardless of stereotypes or documented phenotypes for a disability. A strong understanding of developmental stage theories, individual characteristics of the student, as well as the student and family's particular desires for social inclusion can guide the formation of appropriate goals and interventions to support student advancement in multiple domains and at all levels of functioning.

\section{Quadrants}

In TET-M, the intersecting axes of SWB and developmental growth create four quadrants for consideration: thriving, static, suffering, and taxed. Each quadrant represents general "modes of being." Students will identify with each of these four conditions at different times, depending on the systems of support and unique life circumstances. Furthermore, school psychologists can provide consultation, intervention, and advocacy services within the systems of support to move students upward on the axis of SWB and forward on the axis of developmental growth in order to promote student thriving. 
Thriving. A state of thriving falls in the upper right quadrant, when both SWB and developmental growth are in the elevated range. Thriving is the ultimate goal for students with ID. A thriving student is satisfied with his or her life conditions, enjoys a positive mood, while also exhibiting continued personal growth and development. Developmental levels need not be high when compared with developmental expectations for the student's chronological age. Rather, the focus is on learning and progress - an upward trajectory toward individualized goals (Benson \& Scales, 2009; Schalock \& Alonso, 2014; Spreitzer et al., 2005). The systems of support address student needs, and students contribute meaningfully to their communities with the use of personal strengths and self-determination (Schalock et al., 2010; Peterson \& Seligman, 2004). Bidirectional arrows between the thriving quadrant and the systems of support indicate high levels of social justice, self-determined social inclusion, meaningful contribution to the broader society, as well as enjoyable and reciprocal personal relationships.

For example, a student who is thriving may be a twenty-year-old student with ID and ASD in the transition program of his public-school district. Three days a week, he participates in a job-training program at a local electronics-recycling center. The work involves systematically breaking down computer motherboards and properly disposing of the materials. The student enjoys the predictable and stable work expectations, the quiet individual workstation, and the interaction with technology. The student's supervisor and job coach have developed a visual schedule for his daily activities so that he knows exactly what is expected of him at each point of the day and when he will be able to take a break. In addition to learning specific job skills that will benefit him when he is seeking future employment, as well as new vocabulary related to the work, the student has also 
developed some valuable new adaptive skills. With the help of his transition teacher, the student has learned to navigate the regional transportation system application on his phone so that he can independently and successfully ride a bus to work for each shift.

Static. The upper left quadrant is titled static and refers to students with high levels of SWB but halted development. This state of being neglects the innate capacities of a student to grow, learn, and contribute to society in meaningful and self-directed ways. Students in the static quadrant may be students who are happy and well behaved but are failing to make adequate growth or are even regressing in their skills. Here, stereotypes of low developmental potential, a desire to maintain SWB at the expense of growth, inadequate curricula, or a lack of appropriate academic interventions may keep students from thriving.

For example, a high school student with Down syndrome (DS) may be in the static state. She may present with a cheerful mood and a pleasant disposition, enjoying her days at school and forming friendships with peers and educators. However, a close examination of her development indicates that she plateaued academically with a firstgrade reading level at the end of elementary school. The student and her family may assert that this reading level is inadequate to help her navigate the community for postsecondary employment and educational opportunities. In order to promote thriving for this student, the school psychologist may advocate for the student's developmental growth in her individualized education program (IEP) with some specific academic goals in addition to functional life skills.

Suffering. In the lower left quadrant, students with low levels of SWB and stagnant development or regression can be classified in a state of suffering. Students with 
ID who are suffering are of particular concern for school psychologists and will require a high level of support. In retrospect, individuals with disabilities living in institutionalized settings in the late $19^{\text {th }}$ and early $20^{\text {th }}$ centuries may have spent vast amounts of their lives in the suffering quadrant. The goal set for these individuals was complete removal from society through systematic warehousing, as opposed to a focus on personal satisfaction or growth (Wehmeyer, 2013). For students in the suffering quadrant, school psychologists can provide evidence-based strategies at all levels of the students' bioecological systems to first increase SWB and then developmental growth. Basic neurological development suggests starting with strategies to improve SWB before improving developmental growth. Students who are more regulated emotionally will be better equipped to access interventions aimed at developing higher-level thinking and learning tasks (Perry, 2009). An example of a student in the suffering quadrant may be a middle school student with ID who spends a significant portion of her day in the school's time-out room due to persistent aggressive behaviors. When she is not in seclusion, the student is in a selfcontained classroom where she receives small group and one-on-one instruction from a special educator or paraprofessional. With a lack of valid and current assessment results, in part due to the student's lack of verbal communication skills, the teacher knows little about her present levels of academic ability. Therefore, the student has some general IEP goals related to self-management and communication, but she has failed to make progress over the course of the year. The school psychologist can use data-based decision making to address both the students SWB as well as the student's developmental growth in order to move her closer toward a state of thriving. 
Taxed. Taxed is the name of the lower right quadrant, and is characterized by continued developmental growth with low levels of SWB. The taxed quadrant indicates a condition where the focus is on student growth but mental health and well-being are neglected; progress is prioritized at any cost. Students with ID who are taxed may be referred to the school psychologist for concerns with internalizing conditions (e.g., selfinjurious behaviors or withdrawal) or externalizing behaviors (e.g., disruptive behaviors in the classroom). The student is making adequate growth toward IEP goals. However, he or she presents with general life dissatisfaction and a pervasive negative mood; personal strengths, needs, preferences, and SWB are largely sacrificed for the sake of development.

For example, a taxed state may occur when a first-grade student with fragile $\mathrm{X}$ syndrome (FXS) is engaged in an educational program aimed at teaching reading in a loud, unpredictable, and busy inclusive classroom environment. The student may make some progress on his phonemic awareness per his IEP goals, but individual needs related to sensory processing sensitivities and a preference for a predictable routine likely detract from his SWB (Hagerman, 2006). The student may engage in hand-biting or explosive behaviors in the classroom, indicating a taxed state. The school psychologist will need to address SWB through supportive systems that address individual strengths and needs in order to encourage this student to thrive.

\section{Implications for School Psychology}

Students with ID face unprecedented challenges upon graduation, and are less likely than any other students receiving IEP services in the schools to have had many of the key experiences linked to positive post-school outcomes (Lipscomb et al., 2017). A 
focus on thriving provides the field of school psychology with a holistic approach to improving school supports for this unique student population. The shift in the disabilities field from a medical model to a social ecological model is largely theoretical. The TET-M provides school psychologists with an avenue to operationalize and actualize this theoretical shift within the school setting by applying principles of positive psychology and best practices in school-based mental health supports to encourage thriving for all students with ID.

\section{Application of Thriving in School Systems}

Working within the framework of a multi-tiered system of supports (MTSS), school psychologists can apply TET-M to a data-based decision-making process to determine intervention needs and promote thriving (hereafter called the Thriving Tree; see Figure 2). Practitioners can utilize the TET-M and the Thriving Tree to determine which quadrant best describes a student's functioning (by considering biological systems of support, SWB, and developmental trajectory) and how support services can help to move the student toward a state of thriving. Implementation of evidence-based consultation, intervention, and advocacy strategies in any or all levels of the student's ecology can directly and indirectly enhance student QOL. School psychologists are well positioned for this work with expertise in meaningful assessment, school-based intervention, and systems restructuring to enhance learning and well-being for all students (NASP, 2010).

Measuring systems. School psychologists can assess and document a student's relevant bioecological systems using a wide variety of assessment instruments (see Table 6). Psychoeducational assessments provide data on individual variables that a student 
brings to the school setting such as cognitive ability, communication skills, and sensory needs (NASP, 2010; Salvia, Ysseldyke, \& Witmer, 2013). Furthermore, school psychologists can directly assess a student's character strengths with the Values in Action (VIA) Inventory of Strengths for Youth (VIA-Youth; Park \& Peterson, 2006), using cognitive accommodations for students with ID such as providing definitions and context for complex survey questions (Shogren, Wehmeyer, Forber-Pratt, \& Palmer, 2015).

Using a bioecological systems lens in a clinical assessment interview (Sattler \& Hoge, 2006) can provide insight to a student's micro and meso systems and the quality of reciprocity in those relationships. Furthermore, the clinical assessment interview will provide data regarding a student's quality and frequency of self-determined social inclusion in the community or society at large. Reviewing the student's records for social history data may reveal critical changes in a student's systems of support over time. Using direct classroom observations (Volpe, DiPerna, Hintze, Shapiro, 2005) and student surveys (Doll et al., 2010), a school psychologist can assess the class climate. A thorough documentation and analysis of the student's school disciplinary system, overall school climate (Klotz, 2016), the student's school and neighborhood resources (Adelman \& Taylor, 2013), and current cultural, legal, and political issues that may impact an individual student and his or her family (e.g. immigration policies, court case decisions regarding transgender students, high-profile acts of violence) can be useful for understanding a student's exo and macro systems. 


\section{Table 6}

Measuring Systems of Support

\begin{tabular}{ll}
\hline Instrument/Strategy & $\begin{array}{l}\text { Bioecological } \\
\text { Systems Level }\end{array}$ \\
\hline Psychoeducational assessment (NASP, 2010; Salvia et al., 2013) & Individual \\
$\begin{array}{l}\text { Values in Action (VIA) Inventory of Strengths for Youth (Park \& } \\
\text { Peterson, 2006) }\end{array}$ & Individual \\
$\begin{array}{l}\text { Clinical assessment interviews with students, parents, and teachers } \\
\text { (Sattler \& Hoge, 2006) }\end{array}$ & $\begin{array}{l}\text { Micro, Meso, } \\
\text { Exo, Macro }\end{array}$ \\
$\begin{array}{l}\text { Review of school records (Sattler \& Hoge, 2006) } \\
\text { Classroom observation (NASP, 2010; Volpe et al., 2005) }\end{array}$ & Micro, Meso, Exo \\
$\begin{array}{l}\text { Classmaps surveys (Doll et al., 2010) } \\
\text { School climate surveys (Klotz, 2016) }\end{array}$ & Micro, Meso, Exo \\
$\begin{array}{l}\text { Resource mapping (Adelman \& Taylor, 2013) } \\
\begin{array}{l}\text { Review of relevant political and legal issues for students } \\
\text { (http://www.nasponline.org/research-and-policy/current-law-and- } \\
\text { policy-priorities) }\end{array}\end{array}$ & Exo \\
\hline
\end{tabular}




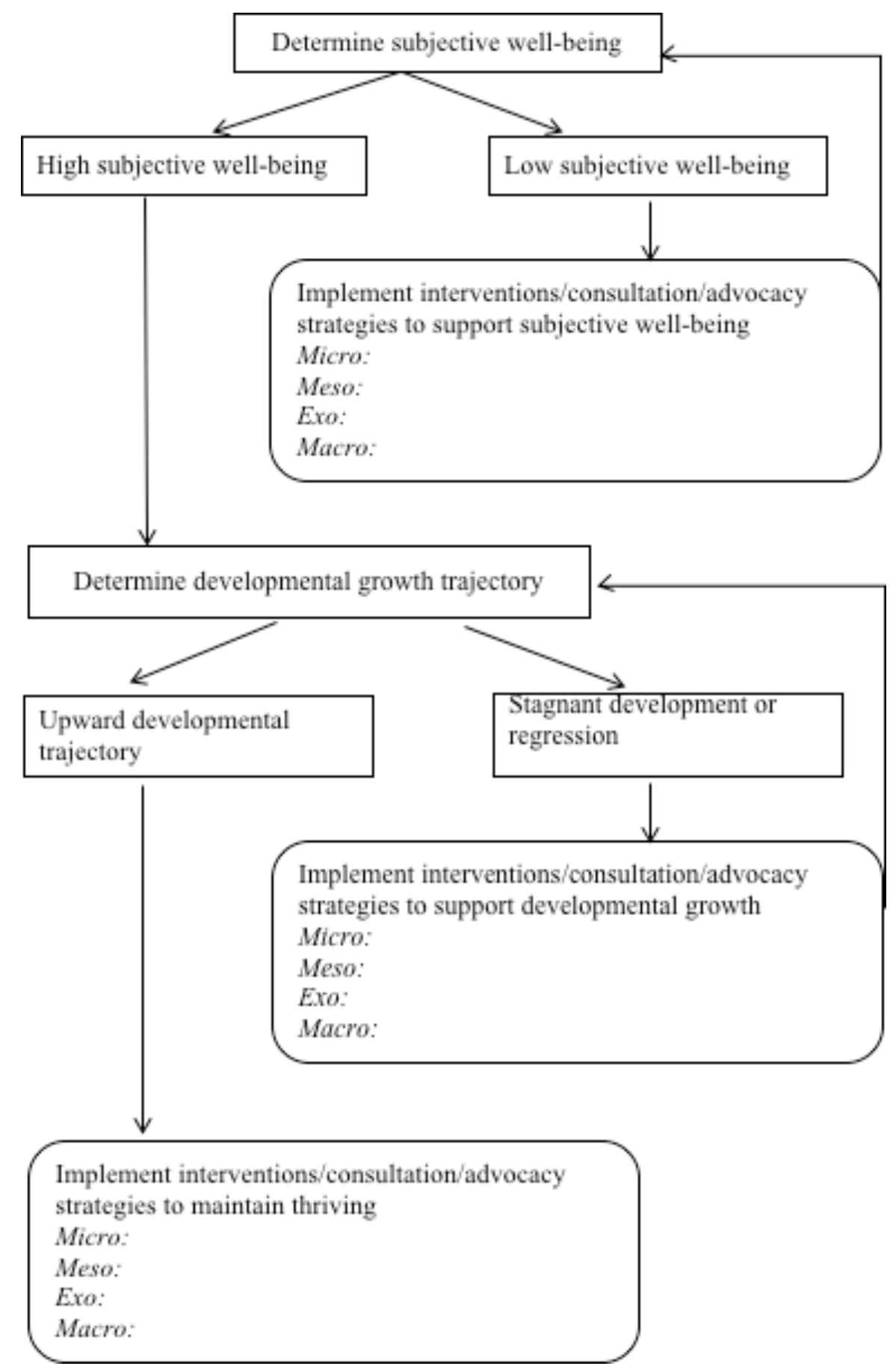

Figure 2. Thriving Tree: Data-based decision-making process to promote thriving. 
Measuring subjective well-being. In order to maintain its subjective quality, SWB must be measured through self-reporting (Huebner \& Furlong, 2016). Survey scales have been developed to directly assess a student's current perceptions of life satisfaction and mood (see Table 7). Further, student clinical assessment interviews can inform the school psychologist about more eudaimonic aspects of SWB, including questions about the student's quality of relationships, when the student feels most engaged in life or loses track of time, what the student is most proud of in terms of accomplishment, and how the student perceives his or her role in the school or broader community.

Table 7

Measuring Subjective Well-Being

\begin{tabular}{ll}
\hline Thriving Element & Assessment Instrument \\
\hline Subjective well-being & Students' Life Satisfaction Scale (Huebner, 1991) \\
& Multidimensional Students' Life Satisfaction Scale (Huebner, \\
& Zullig, \& Saha, 2012) \\
& Student clinical assessment interview (Sattler \& Hoge, 2006) \\
\hline
\end{tabular}

Measuring developmental growth. School psychologists are particularly well trained and suited for measuring the developmental growth trajectories of students. Table 8 provides suggested assessment instruments. In terms of academics, school psychologists can review academic records and progress monitoring data to analyze the growth trajectory for a variety of academic subjects (Parker, Vannest, Davis, \& Clemmens, 2012). Comprehensive psychoeducational assessments can provide data on present levels of performance (NASP, 2010; Salvia et al., 2013) and, when coupled with a review of records, will reveal the trajectory of the student's development and whether or not the student is making adequate progress toward individualized goals. A 
developmental history interview (Sattler \& Hoge, 2006) provides the family's perspectives on present developmental levels and whether or not the student is growing or at a period of stagnancy or developmental regression.

\section{Future Directions}

In order to maintain their dedication to all marginalized students, the school psychology research community must further the exploration of the thriving construct. Indepth qualitative studies aimed at better understanding the phenomenon of SWB and the developmental growth trajectories for the ID, and other, student populations would add the voices of those who currently thrive to the scholarly literature. This would support the QOL domains of social inclusion and self-determination and fulfill the NASP (2016) commitment to social justice for all students. Furthermore, researchers can investigate factors, both individual and contextual, that facilitate thriving in different populations, perhaps leading to the development of more evidence-based strategies for school-based MTSS interventions. While there are several evidence-based strategies to promote thriving by increasing SWB and developmental growth in the school psychology literature (see Table 9), few have been validated with specific populations of students (e.g., Down syndrome, social-emotional disability, cerebral palsy). There is a need for high quality research to inform practitioners on promising service-delivery models that produce optimal outcomes for students with disabilities, including those with ID. 


\section{Table 8}

Measuring Developmental Growth

\begin{tabular}{ll}
\hline Thriving Element & Assessment Instrument \\
\hline Developmental Growth & Progress monitoring (Parker et al., 2012) \\
& Psychoeducational assessment (Salvia et al., 2013) \\
& Developmental history interview (Sattler \& Hoge, 2006) \\
& Review of school records (Sattler \& Hoge, 2006) \\
\hline
\end{tabular}

\section{Conclusion}

Until now, the field of school psychology has yet to define what it means for students with ID to thrive in our schools. This new framework acknowledges that thriving with ID is a multi-faceted construct that includes elevated levels of SWB and a state of continued developmental growth within a series of inclusive and supportive systems. A history of marginalization, coupled with substantial dependence on a fair and just sociocultural and political system, compels school psychologists to advocate for this community. Our profession has long viewed the work of social justice through the lens of cultural diversity (Shriberg et al., 2008). It is time to add a focus on neurodiversity to our field's work for and with disenfranchised populations, placing a priority on building supportive school communities for students with ID and their families. This model provides focus for school psychologists to build both student learning and mental health and to promote students with ID who thrive in school, at home, and in life. 


\section{Table 9}

Evidence-Based Strategies for Promoting Thriving in Schools

\begin{tabular}{|c|c|c|c|}
\hline $\begin{array}{l}\text { Thriving } \\
\text { Element }\end{array}$ & Grade(s) & Strategy & $\begin{array}{l}\text { Bioecological } \\
\text { Systems } \\
\text { Level }\end{array}$ \\
\hline \multirow[t]{2}{*}{$\begin{array}{l}\text { Subjective } \\
\text { well-being }\end{array}$} & $\begin{array}{l}\text { Elementary, } \\
\text { Secondary }\end{array}$ & $\begin{array}{l}\text { The well-being promotion program } \\
\text { (Suldo, Savage, \& Mercer, 2014) }\end{array}$ & Micro \\
\hline & Elementary & $\begin{array}{l}\text { Awesome Us (Quinlan, Swain, } \\
\text { Cameron, \& Vella-Broderick, 2015) }\end{array}$ & Micro, meso \\
\hline \multirow[t]{8}{*}{$\begin{array}{l}\text { Developmental } \\
\text { growth }\end{array}$} & All & $\begin{array}{l}\text { Multi-tiered systems of support (MTSS; } \\
\text { Utley \& Obiakor, 2015) }\end{array}$ & $\begin{array}{l}\text { Micro, exo, } \\
\text { macro }\end{array}$ \\
\hline & All & $\begin{array}{l}\text { Problem-solving consultation (Hurwitz, } \\
\text { Kratochwill, \& Serlin, 2015) }\end{array}$ & Micro \\
\hline & All & $\begin{array}{l}\text { Social-emotional learning (Schonfeld et } \\
\text { al., 2015) }\end{array}$ & $\begin{array}{l}\text { Micro, meso, } \\
\text { exo }\end{array}$ \\
\hline & All & $\begin{array}{l}\text { Family-school partnership (Miller, } \\
\text { Lines, \& Flemming, 2014) }\end{array}$ & Meso \\
\hline & All & $\begin{array}{l}\text { School-wide positive behavior supports } \\
\text { (SWPBIS; Horner \& Sugai, 2015) }\end{array}$ & Exo \\
\hline & Secondary & $\begin{array}{l}\text { Positive youth development multi-tiered } \\
\text { system of supports (PYD-MTSS; Hazel, } \\
2016 \text { ) }\end{array}$ & Exo \\
\hline & Transition & Self-advocacy (Kramer, 2015) & Exo, Macro \\
\hline & Transition & $\begin{array}{l}\text { Transition Planning, Implementation, } \\
\text { and Evaluation (TPIE; Talapatra, } \\
\text { Roach, Varjas, Houchins, \& Crimmins, } \\
\text { 2017) }\end{array}$ & $\begin{array}{l}\text { Micro, meso, } \\
\text { exo }\end{array}$ \\
\hline
\end{tabular}




\section{MANUSCRIPT TWO}

\section{THRIVING WITH DOWN SYNDROME:}

\section{A QUALITATIVE MULTIPLE CASE STUDY}

The vision of the National Association of School Psychologists (NASP) is that all students will thrive in school, at home, and in life (NASP, n.d.). This professional responsibility for school psychologists includes students with significant, pervasive, and lifelong disabilities, such as Down syndrome (DS). Students with DS can benefit from the support of school psychologists through assessments and direct intervention (Davis, 2008), as well as systems-level change and broad advocacy efforts. Further, our field's commitment to social justice (NASP, 2016) and prevention and wellness promotion (NASP, 2014) make school psychologists a natural fit to promote thriving for this student population.

DS is a chromosomal abnormality that is the most common known genetic cause of intellectual disability (ID; Roizen, 2013). In addition to cognitive delays, the disorder is associated with adaptive delays and serious medical complications (Perlman, 2014). Due to the genetic cause and the documented medical complications for individuals with DS, a great deal of information exists concerning the needs and pathology associated with the disorder. These findings often come from a medical deficit model (Dykens, 2006; Roach, 2003). There is markedly less information on those individuals with DS who thrive, or the factors that contribute to well-being and growth in this population. 
Thriving is a multi-faceted positive psychology construct that refers to a state of growth and well-being (Benson \& Scales, 2009; Lerner et al., 2010; Prilleltensky, 2012; Weiss \& Riosa, 2015). Positive psychology is the scientific study of what enables individuals and communities to thrive (International Association of Positive Psychology [IAPP], n.d.). A positive psychology orientation is transformational in nature, allowing practitioners and researchers to recognize assets within a community, thus shifting the focus away from merely fixing problems and more toward building resilience and enhancing outcomes (Mertens, 2009).

The lack of attention given to thriving in the DS population is unfortunate as it ignores a population of people who lead healthy, happy, and fulfilling lives with DS (Alderson, 2001; Skotko, Levine \& Goldstein, 2011). Indeed, the lack of research may even be harmful to the DS population and their families because it can lead to a reduction in educator expectations for achievement, false limitations placed on long-term life goals, and even uninformed termination of pregnancies due to a lack of accurate information (de Graaf, Buckley, Skotko, 2015; Gilmore, Campbell, \& Cuskelly, 2010). Thus, it is critical that research on DS addresses the range of possibilities for life outcomes, including a thorough documentation and analysis of those who are thriving.

\section{Down Syndrome}

Dr. John Langdon Down first identified DS as a specific condition in 1866 (Manfredini, 1988); however, scientists did not discover the underlying genetic cause until the late 1950s. Since then, prenatal screening has enabled doctors to identify the risk of a DS diagnosis as early as the first trimester of pregnancy (Roizen, 2013). However, the disorder is hardly a modern phenomenon. In fact, archeological excavations have 
produced skulls of humans with DS dating as far back as the $7^{\text {th }}$ century (Roizen, 2013). DS has been around for a very long time and is relatively common. Prevalence rates of 1 in 700-800 births in the U.S. indicate that most school psychologists will work with students with DS at some time in their career (de Graaf et al., 2015). To best meet the needs of this student group, it is critical to understand the genetics that cause the disorder, the characteristic strengths and needs associated with the syndrome, and the systems of support relevant to this population.

\section{Genetics}

There are three primary causes of DS, all three of which involve extra chromosomal material (Perlman, 2014). Ninety-five percent of all individuals with DS have trisomy 21 , in which a third copy of human chromosome 21 is formed by nondisjunction (a failure to separate) during mitosis (Bornstein et al., 2010). Far fewer (1$3 \%$ for each type) cases of DS are caused by translocation or mosaic DS. In translocation, the long arm of the $21^{\text {st }}$ chromosome attaches itself to another chromosome, thereby resulting in extra genetic material and a diagnosis of DS (Batshaw, Gropman, \& Lanpher, 2013). Mosaicism occurs when some of the individual's cells possess the extra $21^{\text {st }}$ chromosome and others do not. For example, an individual may have trisomy 21 in his or her blood cells, but not in his or her skin cells. Those with mosaic DS may demonstrate higher cognitive ability, yet tend to have similar medical outcomes to those with translocation and trisomy 21 (Batshaw et al., 2013). Further, the risk of having a baby with DS increases significantly with maternal age (Roizen, 2013). 


\section{Phenotype}

A phenotype is the outward expression, or observable traits, of the interaction of genetics and environment (Batshaw et al., 2013). Characteristics such as behavior patterns, learning styles, communication abilities, growth and motor development, and social and emotional profiles all make up a disability phenotype. In DS, as with many disabilities, the phenotype has variation. Individual characteristics, comorbid conditions, the family and community setting, as well as broad societal influences all impact the profiles of individuals with DS. It is important to note that individuals with DS may closely follow the phenotypic expectations in some domains, yet differ significantly in other ways (Fidler, Hodapp, \& Dykens, 2002; Reilly, 2012). Just as a pathological approach alone will be of little good (Roach, 2003), an overreliance on phenotypic characteristics may result in overgeneralization of DS. It is important for service providers to guard against assuming universality and instead remember each individual brings his or her own strengths and preferences, life circumstances, and relationships to the table.

Physical Attributes. Although there are a wide variety of physical features associated with DS, two attributes are present in all individuals with DS. First, individuals with DS have a developmental delay, resulting in a decreased rate of bone growth (Perlman, 2014). This typically causes individuals with DS to have a shorter stature and decreased size of the head (microcephaly) as compared to others their age. Second, individuals with DS have low muscle tone (hypotonia), causing loose ligaments and hyperextension of the joints (Perlman, 2014). Additional physical features that may be present include upward slanting, almond shaped eyes, a flat nasal bridge, extra skin 
around the neck, and a wide gap between the toes (Perlman, 2014). Individuals with DS also frequently have significant medical needs, such as congenital heart disease, gastrointestinal disorders, thyroid conditions, and autoimmune diseases (Perlman, 2014; Roizen, 2013). Many children with DS will spend a considerable amount of time in hospitals starting at a very young age for corrective heart or gastrointestinal surgeries (Miodrag, Silverberg, Urbano, \& Hodapp, 2013).

Cognitive/Learning Profile. The developmental course of cognitive abilities is unique in the DS community. While infants typically present with average cognitive functioning, skills tend to decline within the first year of life. The average intelligence quotient (IQ) score for an adult with DS is 55, while the average score in the general population is 100 (Perlman, 2014). More specifically, many individuals with DS possess personal cognitive strengths in the areas of visual-spatial processing (Fidler, 2005). This strength appears to be most prominent in skills related to visual memory, visual motor integration, and visual imitation. Further, a pattern of significant relative weaknesses in the areas of verbal processing skills and auditory working memory is common for individuals with DS (Fidler, 2005). A cognitive decline is present in most individuals with DS, with the onset of Alzheimer-like neuropathy by age 45 (Carr, 2012; Fidler, 2005).

Adaptive Skills. In terms of daily functioning, individuals with DS tend to require more assistance than others of a similar age (Roizen, 2013; van Diujn, Dijkxhoorn, Scholte, \& van Berckelaer-Onnes, 2010). Adaptive functioning tends to develop at a rate slower than age equivalent peers and peak at a lower level for individuals with DS (van Diujn et al, 2010). While the range of adaptive functioning is 
broad with the DS community, and varies drastically based on the individual as well as opportunities and supports in the family, school, and community, some specific trends have been noted in the literature. Multiple studies examining adaptive behaviors in individuals with DS have indicated a profile of relative strengths in social skills and daily living skills, as well as relative deficits in communication and motor skills (Fidler, Hepburn, \& Rogers, 2006; van Diujn et al., 2010).

Communication. Individuals with DS tend to have significant communication delays in early childhood, and many do not speak their first words until after 18-monthsof-age (Roizen, 2013). As children gain communication skills, they continue to struggle with articulation and expressive language. For many children with DS, receptive communication skills are a relative strength compared with expressive communication skills (Abbeduto et al., 2003; Fidler, 2005; Kumin, 2001). Additionally, nonverbal communication is a relative area of strength for young adults with DS (Fidler, 2005). However, there is significant variation in communication skills for individuals with DS, and exposure and environment play a significant role in language expression (Deckers, Van Zaalen, Stoep, Van Balkom, \& Verhoeven, 2016). For example, adults with DS in professional and community routines with more complex and novel verbal requests frequently acquire a variety of new vocabulary terms. Furthermore, inconsistencies in speech and language intervention services available in adulthood make it difficult to generalize the receptive/expressive communication gap that is more common during childhood (Kumin, \& Schoenbrodt, 2016).

Social Skills and Behavior. Individuals with DS tend to have personal strengths in social functioning, especially when compared to individuals with other genetic causes 
of ID (Fidler, Most, Booth-LaForce, \& Kelly, 2008). Specifically, results from studies using parent behavior rating forms have indicated higher levels of engagement with caregivers (Fidler et al., 2008), more developed play and leisure skills (Fidler et al., 2006), and higher quality relationships (Rosner, Hodapp, Fidler, Sagun, \& Dykens, 2004) when compared to same-aged peers with ID caused by other genetic disorders.

That is not to say that individuals with DS do not exhibit behavior problems. In fact, social strengths may actually impede on-task behaviors for children with DS. Fidler (2006) noted a "social motivation profile" whereby individuals with DS may compensate for deficits in problem solving abilities with their strengths in sociability. Resulting behaviors have been described as "party trick behaviors" where individuals with DS engage in distracting social behaviors to avoid task completion (Wishart, 1996). Furthermore, although aggression is relatively low for individuals with DS, behavioral concerns associated with rigidity and cognitive inflexibility such as stubborn disobedience, attention seeking, and arguing are relatively common (Dykens et al., 2002). Additionally, more externalizing behaviors (e.g., hyperactivity) are seen in childhood and more internalizing concerns (e.g., social withdrawal) arise in adolescence (Dykens, 2007).

Mental Health. There is a historic and persistent stereotype that individuals with DS are pervasively cheery and pleasant (Gilmore et al., 2003; Roizen, 2013). However, research indicates that this stereotype neglects reality; the mental health of those with DS is more nuanced. Parents of children with DS do consistently report higher levels of joy and happiness in their children than the parents of children with other genetic causes of ID (Rosner et al., 2004). Further, several studies measuring the self-esteem and life 
satisfaction for individuals with DS have found that a sizable proportion of those living with DS enjoy their lives, feel competent, and think highly of themselves (Begley, 1999; Glenn \& Cunningham, 2001; Skotko, et al., 2011). Higher levels of happiness and life satisfaction with DS may be correlated with living situations (e.g., more satisfaction when living with family, independently, and/or with roommates, than when living in a group home), the influence of religion, certain states of residency, and how many parents live in the home (Skotko et al., 2011). However, studies also show that as individuals with DS age, occurrences of smiling decrease (Fidler, Barrett, \& Most, 2005) and parents rate their children as less cheerful and affectionate (Hodapp et al., 2003).

Recent research indicates that individuals with DS have an increased risk of comorbid autism spectrum disorder (ASD) and attention deficit hyperactivity disorder (ADHD) compared with the general population (Oxelgren et al., 2017; Moss, Nelson, Richards, Oliver, 2013). Furthermore, age increases the risk for individuals with DS developing mental health problems (Dykens, 2007). Early onset of Alzheimer's disease is common for adults with DS, starting in the mid-forties (Carr, 2012; Fidler, 2005). Additionally, clinical depression is a particular concern in the DS population. Specific factors associated with DS - high risks of dementia, specific neurological attributes (e.g., reduced levels of neurotransmitters and lower hippocampal volumes), communication deficits, working memory difficulties, and attachment issues with caregivers - place them at an increased risk for developing clinical levels of depression (Walker, Dosen, Buitelaar, \& Janzing, 2011).

To summarize, the positive mental health for those with DS is particularly salient in childhood and adolescence. Dykens (2007) reported that while approximately $30-40 \%$ 
of children with ID have significant signs of psychopathology, only $18-23 \%$ of children with DS have the same levels of mental health problems. While this is an increased risk in comparison with typically developing peers, those with DS are at significantly less risk than those with ID caused by other genetic conditions (Dyken, 2007). The onset of age is a significant risk factor in mental health issues, and service providers must consider mental health supports as individuals with DS enter adulthood.

\section{Systems of Support and Down Syndrome}

The Association for Intellectual and Developmental Disabilities (AAIDD) puts forth a social ecological model for disability, emphasizing the significance of support from an individual's surrounding systems on general human functioning, as a method for contextualizing service delivery models (Buntinx, 2014; Schalock et al., 2010). Outcomes for those with DS can be greatly enhanced by supportive systems that address individual needs adequately and build on strengths (Schalock et al., 2010). Understanding those who thrive with DS requires an understanding of research related to relevant systems of support, including family, friends, school, work, and the community at large.

Home. Within the home context, an individual with DS receives critical supports from parents and immediate family members (Bronfenbrenner, 1979). For many families of children with disabilities, stress levels are higher than those of parents of typically developing children (Peer \& Hillman, 2014). One way researchers have examined the family functioning of children with significant disabilities (e.g. ID) is by measuring the expressed emotion (EE) of parents. EE is a measure of the emotional climate for a family, including the quality of relationship between parent and child and the parent's attitudes about the child (Magana-Amato, 2015). High EE in parents of children with ID may 
interfere with treatment and be associated with negative child behavioral outcomes (Beck, Daley, Hastings, \& Stevenson, 2004; Coleman \& Riley, 2014). Research indicates that over one-third of parents of children with developmental disabilities (DD) have high EE, or an emotionally charged home environment (Thompson, Coleman, \& Olmos, 2017). There is no data at this time regarding EE specific to the population of parents of children with DS.

In terms of family functioning with DS, studies have documented a "DS advantage," in which children with DS are reportedly easier to rear than those with other genetic causes of ID (Hodapp, Ly, Fidler, \& Ricci, 2001; Hodapp, 2007). Research shows that families of children with DS report higher levels of well-being than families of children with other forms of ID (Fidler, Hodapp, \& Dykens, 2000). However, critics of the "DS advantage" call attention to troubles with the metrics used to assess family levels of well-being, the importance of analyzing parent age and support systems when assessing well-being, and the necessity to consider the ages of the children at the time of assessment (Ebensen \& Seltzer, 2011; Glidden, Grein, Ludwig, 2014). Overall, families of children with more developed adaptive behaviors and parents who use adaptive coping strategies for stress (e.g., positive reappraisal of the circumstances) have higher levels of well-being (Abbeduto et al., 2004; Rooke, Pereira-Silva, 2016; van der Veek, Kraaij, \& Garnefski, 2009).

Over the course of the lifespan, parents of children with DS tend to report their highest levels of coping abilities during their children's school aged and adolescent years (Goff et al., 2016). The combination of having time to accept a child's diagnosis of DS coupled with supportive resources from the schools and community during these years 
may contributes to parents' perceived coping abilities. Furthermore, multiple studies have documented that adults with DS may develop additional medical problems and begin significant cognitive declines in their mid-40s (Bittles, Bower, Hussein, \& Glasson, 2006; Carr, 2012; Hodapp, Burke, Finley, \& Urbano, 2016; Tsao, Kindlberger, Freminville, \& Bussy, 2015). This places an increased caregiving burden—-both emotional and economic — on elderly parents. There is a clear need for a supportive system of public services to assist the entire family unit in the elder years of individuals with DS.

Social. In terms of friendships, limited research indicates that young children with DS can and do form true friendships, characterized as reciprocal, warm, and parent validated (Freeman \& Kasair, 2002). In adulthood, limited communication skills, difficulty reading social cues, and challenges with empathy and identifying emotions in others can impact friendships (Watt, Johnson, \& Virji-Babul, 2010; Wishart, 2007). In general, diminished social skills and behavior issues in children with disabilities can lead to long-term social isolation, reduced levels of well-being, and increased mental health problems throughout the lifespan (Guralnick, 2006). Thus, targeted skill building in the development of friendships for children with DS is imperative to encourage the development of mental health and long-term well-being.

Schools. Federal laws support service provision for young children (birth - age three) with disabilities through an Individualized Family Service Plan (IFSP; Individuals with Disabilities Education Act [IDEA], 2004). These early intervention services can start as soon as a diagnosis is made at birth for many children with DS. Indeed, starting early with an individual with DS allows interventionists to target skills that are still developing, and have not begun to differ significantly from peers without disabilities 
(Roberts \& Richmond, 2014). The focus of early intervention is to support the family as primary caregivers. Therefore, therapies and assessments are frequently conducted in the home, with parents learning the methods to support their children in areas relevant to their daily lives. For those with DS, the frequency of early intervention can be critical; children receiving services more frequently demonstrate more significant growth in development (Yoder, Woynaroski, Fey \& Warren, 2014).

At age three, children with DS typically enter their community's school system in preschool settings. Provisions under IDEA (2004) ensure students with DS can be educated in the "least restrictive environment" (LRE) alongside their nondisabled peers per their individualized education program (IEP). Educational inclusion has a rich body of literature to support its use in the school systems (Gargiulo \& Bouck, 2018). Several studies have documented that students with DS who attend school in an inclusive setting demonstrate higher levels of academic achievement than those in segregated learning environments (Turner, Alborz, \& Gayle, 2008). Inclusion practices vary, based on the child's needs and the school's resources. Inclusion outcomes tend to be most successful for children with DS when classroom teachers are active partners in the educational program, working together with the special education team and the family (Fox, Farrell \& Davis, 2004). Successful practices include positive behavior supports (e.g., praise for desired behavior), individual and small group learning arrangements, peer tutoring, and the use of assistive technology (Wolpert, 2001). These provisions and supports are documented in the child's IEP and reviewed on an annual basis.

Starting at age 16, the public schools are responsible for supporting students with disabilities, including DS, as they transition out of public schools and into the community 
through transition services (IDEA, 2004). Transition programming for students with DS must adequately assess and document student needs, strengths, interests, preferences, and goals for after graduation. Furthermore, the plan must document necessary support services, mapping out the coursework, community partnerships, and vocational training that will be implemented to facilitate the student's post-school success (Talapatra, Roach, Varjas, Houchins, \& Crimmins, 2017). For students with DS, the transition plan is a critical path toward independence in adulthood. Many students with DS remain on a transition plan through the age of 21 , receiving supportive transition programming services in the community through the public school districts.

Recently, postsecondary education (PSE) opportunities have become an option for those with ID, including individuals with DS (Grigal, Hart, \& Weir, 2012; Papay \& Bambara, 2011; Plotner \& Marshall, 2016). Some individuals with DS attend PSE programs on a college campus between the ages of 18 and 21 while still enrolled in the K-12 education system, and some individuals attend PSE programs later in adulthood (Grigal et al., 2012). PSE programs tend to differ significantly from traditional postsecondary college programs for students without disabilities. Rather than a traditional degree program, PSE for a student with DS may focus more on specific training for practical employment opportunities (Papay \& Bambara, 2011) and independent living skills (Grigal et al., 2012). Thus, while academic skills are part of the programming, less than one quarter of PSE programs for students with disabilities highlight academic coursework as their primary goal (Grigal et al., 2012). Still, despite modifications to these college curriculums and the lack of traditional degree programs, the inclusion of individuals with DS in the PSE system is a moral imperative (Uditsky \& Hughson, 2012). 
After all, postsecondary inclusion brings people with DS out of the margins of society and into their age appropriate natural settings in the community.

Community. Upon exiting public school services at age 21, adults with DS are faced with a far less inclusive environment than that found in the public schools (Gargiulo \& Bouck, 2018). For many, a self-sustaining and satisfying professional life is hard to come by (Kumin \& Schoenbrodt, 2016). In fact, as of 2012, only 32\% of Americans with ID ages 22-30 were employed, with a mean annual salary of less than \$15,000 (Butterworth, Migliore, Sulewski, \& Zalewska, 2014). Specific to the DS community, a recent nationwide survey showed that a significant number of adults with DS are unemployed (Kumin \& Schoenbrodt, 2016). Those who do have jobs, tend to work in a very limited pool of vocational areas, including food services, landscaping, office work, and janitorial services. Very few report full-time employment, but many are engaged in part-time work and part-time unpaid volunteer work in the community. In fact, over $40 \%$ of respondents indicated they volunteer in their community (Kumin \& Schoenbrodt, 2016).

Limits on paid employment options make it difficult for those with DS to afford independent living without significant support from public services. In addition, reduced capacity in the areas of communication, cognitive problem solving, and adaptive development also impact an individual with DS's ability to live without the support of a family member or caregiver who can provide help with decision making and planning required in daily living (Van Gameren-Oosterom et al., 2013). Although the scholarly literature does not currently detail the lives of those living independently with DS, rather merely captures deficits that make it difficult, there are accounts in the popular press 
media of adults with DS successfully living in the community (Bulman, 2017; Garber, 2013). Clearly, there is a need for more academic research into the topic of independent living with DS.

\section{Outcomes}

Life for individuals with DS has improved drastically in the last half century (Roizen, 2013). As mentioned above, early intervention coupled with inclusive educational practices have enabled those with DS to develop many of the skills required for healthy functioning in our community. Medical advances, such as life-saving heart surgeries, have extended the life expectancies of people with DS several decades (Roizen, 2013). The inclusion of students with DS in public education, with early interventions starting at birth, has resulted in many people with DS developing a number of skills that were not previously thought possible for those with this condition. Opportunities in the community, including inclusive post-secondary options, are beginning to open some job options and are improving the quality of life for adults with DS.

However, despite these improvements in the lives of those with DS there remain significant challenges for adults with DS to pursue independent living in the community. Furthermore, there is a persistent tendency toward termination when prenatal results indicate a child will be born with DS (de Graaf et al., 2015; Natoli, Ackerman, McDermott, \& Edwards, 2011). In fact, current studies in the US estimate that approximately $67 \%$ of women will choose termination when they receive a prenatal diagnosis of DS (Natoli et al., 2011). This has resulted in a reduction of the population of those living with DS in our country by approximately 30\% (de Graaf et al., 2015). 
The AAIDD social ecological model for disability asserts that adequate social supports can improve human functioning for all individuals with disabilities (Buntinx, 2014; Schalock et al., 2010). Perhaps outcomes for those with DS would improve further with more supportive systems of service-delivery that better address the unique phenotypic profiles of strengths and needs of this population. Working within the principles of positive psychology and using a thriving orientation may help school psychologists to operationalize the social ecological model. This information can inform practice and policy, ultimately promoting thriving for all students with DS.

\section{Thriving with Down Syndrome}

The significant majority of individuals with DS report that they are generally happy and satisfied with their lives (Skotko et al., 2011). Perhaps many are, indeed, thriving with DS, however, thriving is a more complex construct than mere happiness. Thriving theory is informed by positive psychology (Peterson \& Seligman, 2004; Seligman \& Csikszentmihalyi, 2000; Seligman, 2011), bioecological systems theory (Bronfenbrenner, 1979), positive youth development (PYD; Benson \& Scales, 2009; Lerner et al., 2013), the social ecological model for human functioning (Buntinx, 2014; Schalock et al., 2010), and quality of life (QOL) concept (Schalock \& Alonso, 2014). Thriving is subjective, in that the individual reports satisfaction and enjoyment of life. Yet thriving is also objective, requiring measurable growth and positive life outcomes.

Thriving occurs when an individual's unique personal characteristics are adequately supported by environmental factors in a series of inclusive and transactional systems of support (see Manuscript 1, Figure 1). Thriving encompasses a variety of concepts and factors. Briefly, one must consider subjective well-being (SWB), or an 
individual's self-reported life satisfaction and affective state or mood (Diener et al., 2016). Thriving also involves an upward developmental trajectory; progress and personal growth in meaningful areas of life (Schalock \& Alonso, 2014). Finally, a series of supportive systems (e.g., family, school, community, and broader societal influences) as well as contribution through meaningful, self-determined social inclusion must be accounted for in the thriving discussion (Lerner et al., 2013; Schalock \& Alonso, 2014). Thus, while simple happiness in the population of those with DS has been documented (Skotko et al., 2011), the field has yet to fully explore the lives of those who truly thrive.

A systematic literature review in the psycINFO and ERIC academic databases revealed a significant gap in the literature in the area of individuals thriving with DS. An initial search with the subject fields "thriving" and "Down syndrome" resulted in zero articles, books, or theoretical papers on this highly specific topic. The addition of other positive psychological research topics related to thriving, including well-being, well being, wellbeing, eudaimon*, happiness, passion, optimal functioning, flourish*, character strengths, and positive youth development significantly expanded results (42 in psycINFO and 46 in ERIC). However, most of these articles referred specifically to the well-being of the mothers, fathers, and siblings of individuals with DS, and did not address the perspectives or experiences of those living with DS themselves.

Those few studies that did specifically examine thriving, happiness, or well-being in the population of those with DS have identified a number of important themes and associations. Thriving and well-being in DS appear to be related to contextual factors such as higher levels of community participation (Lyons, Brennan, \& Carroll, 2016; Scott, Foley, Bourke, Leonard, \& Girlder, 2014; Wuang \& Su, 2012), supportive 
government policies (Jiar, Handavani, \& Xi, 2014), opportunities for physical activity (Love \& Agiovlasistis, 2016), positive interpersonal relationships, independence in the community (Scott et al., 2014), geographic location, and living situations (Skotko et al., 2011). Thriving and well-being may also be related to individual characteristics, such cognitive and motor abilities (Wuang \& Su, 2012) or unique personal attitudes about life (Robison, 2000; Scott et al., 2014).

Another source of data comes from detailed and compelling narrative accounts on those who thrive with DS. Several memoirs (Bérubé, 1996 \& 2016; Estreich, 2011; Kinsgsley \& Levitz, 1994; Wyllie, 2012), children's stories (Kahn, 2016), and documentaries (e.g., films Monica and David and Up Syndrome, and A \& E television series Born This Way) put forth by individuals with DS and their friends and families document rich and meaningful lives, full of purpose, joy, and struggles. Many of those documented in these narratives would likely identify themselves as thriving based on the Transactional Ecological Thriving Model (TET-M; Manuscript 1, Figure 1). However, while some of these authors (see Bérubé, 1996 \& 2016) also include contextual information about historical, theoretical, political, and socio-cultural influences, most focus primarily on textural and emotional descriptions of life with DS. These accounts artfully provide the reader with access to personal experiences, promoting empathy and understanding through the use of story (Estreich, 2011). Perhaps a deep, scholarly investigation relating this type of narrative data to previous research and contemporary theory may contextualize the information and improve utility for service provision and policy development. 


\section{Purpose of Study}

The current study fills some critical gaps in the disability, school psychology, and positive psychology literature bases with in-depth case studies of four young adults who are currently thriving with DS. A focus on those with the highest levels of QOL broadens the phenotype for the disability, alerting service providers (including school psychologists) to the potential of students with DS in our schools and how we can use data-based decision making and design supportive environments to help them thrive in school, at home, and in life (NASP, n.d.). The following research questions guided this study:

1. How do individuals with DS and their families define thriving with DS?

2. What are the individual characteristics that influence thriving, as defined by the TET-M, for individuals with DS?

a. What are the individual psychosocial profiles of those who thrive with DS?

b. How do individuals with DS who thrive experience SWB?

c. In what ways do thriving individuals with DS demonstrate developmental growth?

3. What are the environmental factors that influence thriving, as defined by the TETM, for individuals with DS?

a. What are the major systems of support for individuals who thrive with DS and how do they participate in these systems?

b. What facilitates thriving for individuals with DS?

c. What are some of the barriers to thriving for individuals with DS? 
It is important to note that the first research question aimed to inductively define thriving directly from the participants' experience with the phenomenon. Questions two and three use an a priori definition for thriving outlined in the TET-M (Manuscript 1, Figure 1).

\section{Methodology}

This exploratory research study used a multiple case study methodology in which a phenomenon is studied in depth across multiple natural contexts (Creswell, 2013; Stake, 1995; Yin, 2014). Case study research is particularly useful for studying those who thrive with DS for three main reasons. First, case study allows for research on both individual and contextual factors (Yin, 2014) related to thriving. Second, case study allows for several data collection methods, including interviews, naturalistic observations, documents and other artifacts, and even the use of some quantitative and standardized methods, such as assessment (Creswell, 2013; Yin, 2014). Third, case study can provide naturalistic generalizations, or "vicarious experiences" that help the reader connect with the participants and place themselves in the settings being studied (Stake, 1995, p.85). This is particularly useful when working within a transformative framework focused on power inequities and the strengths of a community (Creswell, 2013; Mertens, 2009), as this study aims to do.

\section{Procedures}

Ethics. I received approval from the University of Denver's Institutional Review Board (IRB) for this study. Per ethical requirements, I sought consent and/or assent from both participants and their parents to ensure that both parties understood the research and willingly agreed to the process (see Appendix A for consent and assent forms).

Historically, many individuals with ID have been left out of research studies due to 
concerns with their ability to willingly consent (Horner-Johnson \& Bailey, 2013), and this results in a lack of direct participation and voice from those with ID (Roach, 2003). In working directly with a vulnerable population, I took special care to ensure participants truly understood the consent process and made an informed choice to engage in the research. For example, I used a conversational approach and checked for understanding of key components of the research process prior to actually requesting consent (Horner-Johnson \& Bailey, 2013). I used a variety of accommodations for consent, including having a caregiver present to assist with comprehension, adapting the consent form, and using more simple language (e.g., shorter sentences and phrases in easy-to-read formats). All four participants were willing and able to provide clear consent/assent according to an assessment from their legal guardians and myself (see Appendix B).

\section{Sample}

Cases. Experts in case study research recommend including between three and ten cases to allow for adequate cross-case analysis without overwhelming the reader (Creswell, 2013; Stake, 2006). For this study, I recruited four different participants (see Table 1 for participant demographics and Table 2 for parent demographics) to allow for participant diversity (e.g., age, gender, family environment, socio-economic status) while still ensuring a manageable solo and high-quality investigation within a reasonable amount of time. In all, 17 participants (individuals with DS, parents, adult siblings, and other supportive adults) signed consent and participated in direct interviewing for the study. 
Table 1

Participant Demographics

\begin{tabular}{|c|c|c|c|c|c|c|c|c|c|c|}
\hline Case \# & Gender & Pseudonym & Age & $\begin{array}{l}\text { Race/ } \\
\text { Ethnicity }\end{array}$ & $\begin{array}{l}\text { Education } \\
\text { Level }\end{array}$ & $\begin{array}{l}\text { Employment } \\
\text { Status }\end{array}$ & $\begin{array}{l}\text { Relationship } \\
\text { Status }\end{array}$ & $\begin{array}{l}\text { Living } \\
\text { Status }\end{array}$ & $\begin{array}{l}\text { Annual } \\
\text { Income }\end{array}$ & $\begin{array}{l}\text { Comorbid } \\
\text { Health } \\
\text { Conditions }\end{array}$ \\
\hline 01 & Female & Angel & 36 & Caucasian & $\begin{array}{l}\text { High } \\
\text { school }\end{array}$ & $\begin{array}{l}\text { Unemployed, } \\
\text { Day program }\end{array}$ & $\begin{array}{l}\text { Committed } \\
\text { relationship }\end{array}$ & $\begin{array}{l}\text { Independent } \\
\text { (no } \\
\text { roommate) }\end{array}$ & $<\$ 10 \mathrm{~K}$ & $\begin{array}{l}\text { History of } \\
\text { hip } \\
\text { necrosis } \\
\text { Type } 2 \\
\text { diabetes }\end{array}$ \\
\hline 02 & Male & Hal & 21 & $\begin{array}{l}\text { Biracial- } \\
\text { African } \\
\text { American and } \\
\text { Caucasian }\end{array}$ & $\begin{array}{l}\text { Some } \\
\text { college }\end{array}$ & $\begin{array}{l}\text { Employed, } \\
\text { part-time, } \\
\text { paid }\end{array}$ & Single & With parents & $\begin{array}{l}\$ 10- \\
20 K\end{array}$ & 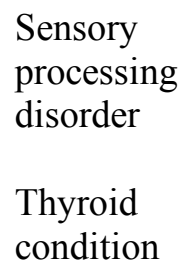 \\
\hline 03 & Male & Clark & 39 & Caucasian & $\begin{array}{l}\text { High } \\
\text { school }\end{array}$ & $\begin{array}{l}\text { Employed, } 2 \\
\text { part-time, } \\
\text { paid }\end{array}$ & $\begin{array}{l}\text { Committed } \\
\text { relationship }\end{array}$ & $\begin{array}{l}\text { With parents } \\
\text { (in between } \\
\text { independent } \\
\text { apartments) }\end{array}$ & $\begin{array}{l}\$ 10- \\
20 \mathrm{~K}\end{array}$ & None \\
\hline 04 & Female & Anita & 31 & Hispanic/Latino & $\begin{array}{l}\text { Some } \\
\text { college }\end{array}$ & $\begin{array}{l}\text { Employed, } \\
\text { part-time, } \\
\text { paid }\end{array}$ & Single & $\begin{array}{l}\text { Independent, } \\
\text { (no } \\
\text { roommate) }\end{array}$ & $\begin{array}{l}\$ 20- \\
40 \mathrm{~K}\end{array}$ & $\begin{array}{l}\begin{array}{l}\text { Celiac } \\
\text { disease }\end{array} \\
\text { Sleep } \\
\text { Apnea }\end{array}$ \\
\hline
\end{tabular}


Table 2

Parent Demographics

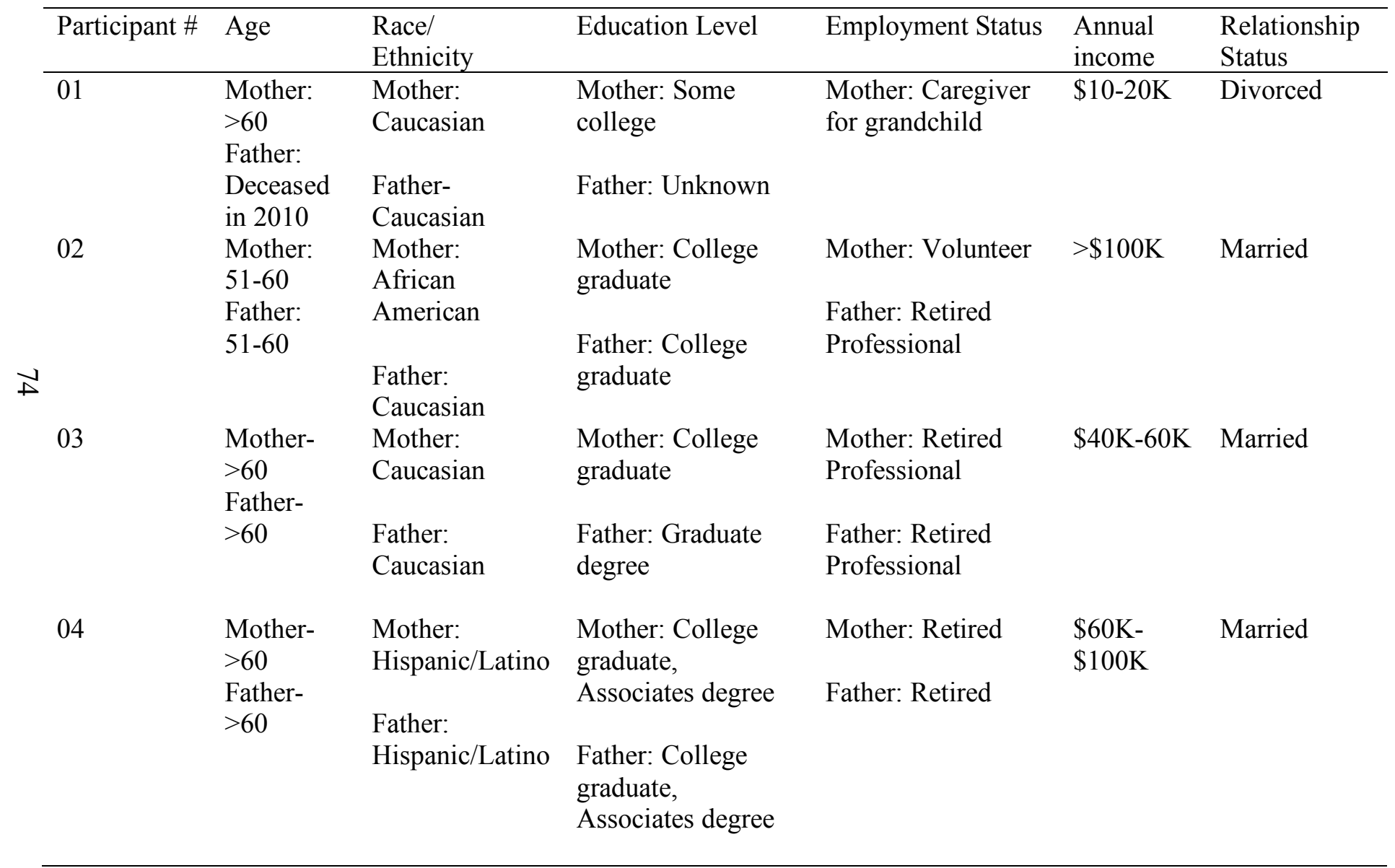


Bounding the cases for this inquiry was critical for planning the scope of data collection (Yin, 2014). Each case was an "integrated system" with clear predetermined boundaries surrounding a collection of working parts (Stake, 1995, p. 2). This included the individual participants themselves as well as their systems of support, including immediate families, community connections, schools or places of employment, systems of transportation, and even broader socio-political influences that arose in the investigation (see Manuscript 1, Figure 1). In terms of chronological boundaries (Yin, 2014), I took a retrospective account, investigating each participant's entire educational history through interviews with parents and a review of educational and medical records when available.

Inclusion criteria for the study included having a diagnosis of DS, being between the ages of 21 and 40 at the time of data collection, and self-identifying as thriving. A definition for thriving was based on the TET-M (see Manuscript 1, Figure 1) as a state of being where SWB is high and the individual demonstrates continued developmental growth. The lower age was limited to 21 -years-old so that a retrospective account could be made about each participant's complete educational history. Limiting the upper range to 40-years-old ensured that participants were not so far removed from their educational history that they did not recall important details. Exclusion criteria included inability or unwillingness of the participant to assent or consent to participate.

A screening process with potential participants and families ensured participants met the inclusion criteria. A brief interview of the individual with DS screened for levels of SWB (see Appendix C). Sample questions included asking participants to rate their satisfaction with life (Diener, Emmons, Larson, \& Griffin, 1985) and general mood 
(Lyubomirsky \& Lepper, 1999). Overall the participant had to express both satisfaction with his or her life (option a or b on first screening question- see Appendix C) and a general positive mood (option a or b on second screening question- see Appendix C) to qualify with high SWB. Further, brief questions with both the participant and family screened for continued developmental growth. This included inquiry about whether or not current activities allowed the potential participants to learn new skills, what specific skills had been learned in the past two years, and whether or not the new skills facilitated increased independence (Gomez, Arias, Verdugo, Tasse, \& Brown, 2015; Schalock \& Alonso, 2014). The individual and his or her family had to indicate that the potential participant was continuing to grow and develop in ways that were meaningful to himself or herself (affirmative response to third participant screening question and first family screening question - see Appendix C).

Recruitment. Recruitment for this study was purposeful in order to gather rich data regarding the phenomenon of thriving for individuals with DS (Stake, 2006). I initiated recruitment through professional networking (convenience sampling) and then used snowball sampling to identify additional cases of interest through these connections (Creswell, 2013). In the end, two participants were individuals with whom I had previously worked in a research capacity while the other two were unfamiliar to me.

\section{Data Collection}

Data collection was collaborative and elicited participants' thoughts, beliefs, experiences, and opinions through interviews, observations, document review, and assessments. See Appendix D for a general timeline of the data collection process for each case and Appendix E for a visual depiction of the ways each piece of the data 
collection process provided data to address the research questions. In order to document the data collection process as a whole, I kept a methodological journal in which I noted my thinking and choices regarding methodological processes and decision-making throughout the study (e.g., reconciling barriers to data retrieval) (Ortlipp, 2008).

Interviews. This study involved 18 total interview sessions (case-study and photo elicitation), for a total of 20 hours. Interviews took place with the participants, parents, and one other significant adult in the participant's life (e.g., boss, friend, partner, teacher). See Table 3 for a summary of interviews, including the types of interviews, the roles of individuals interviewed by each case, number of each interview sessions, and time spent interviewing. Case study interviews must inform the research questions in an approachable and nonthreatening manner (Yin, 2014). Therefore, questions for respondents were open-ended and conversational in tone. I engaged in frequent reflective journaling directly before and after interviews, so that I maintained an awareness of my own subjectivities in the interviewing process and avoided influencing what participants chose to share (Ortlipp, 2008; Tracy, 2010). I employed three types of interviews for this study: traditional case study interviews (open-ended and focused), five-minute speech sample (FMSS) interviews, and photo elicitation interviews. Due to the brevity of FMSS interviews they are not included in the count of interview sessions or total times. 


\section{Table 3}

Summary of Interviews

\begin{tabular}{|c|c|c|c|c|}
\hline Case & Type of Interview & Interviewee Role(s) & $\begin{array}{l}\text { Number of } \\
\text { Interview Sessions }\end{array}$ & $\begin{array}{l}\text { Total } \\
\text { Time } \\
\text { (Hours) }\end{array}$ \\
\hline \multirow[t]{6}{*}{01} & Photo Elicitation & Participant & 2 & 2 \\
\hline & Open-Ended Case & Mother & 2 & 2 \\
\hline & Study & Sister & & \\
\hline & $\begin{array}{l}\text { Focused Case- } \\
\text { Study }\end{array}$ & Boyfriend & 1 & 1 \\
\hline & Five Minute & Mother & N/A & N/A \\
\hline & Speech Session & & & \\
\hline \multirow[t]{6}{*}{02} & Photo Elicitation & $\begin{array}{l}\text { Participant } \\
\text { Sister }\end{array}$ & 1 & 1 \\
\hline & Open-Ended Case & Mother & 2 & 3.5 \\
\hline & Study & Sister & & \\
\hline & $\begin{array}{l}\text { Focused Case- } \\
\text { Study }\end{array}$ & College Professor & 1 & 1 \\
\hline & Five Minute & Father & N/A & N/A \\
\hline & Speech Sample & Mother & & \\
\hline \multirow[t]{4}{*}{03} & Photo Elicitation & Participant & 1 & 1 \\
\hline & Open-Ended Case- & Mother & 2 & 2.5 \\
\hline & $\begin{array}{l}\text { Focused Case- } \\
\text { Study }\end{array}$ & Friend & 1 & 1 \\
\hline & Five Minute & Mother & N/A & N/A \\
\hline \multirow[t]{5}{*}{04} & Photo Elicitation & Participant & 1 & 1 \\
\hline & Open-Ended Case- & Mother & 3 & 3 \\
\hline & Study & Father & & \\
\hline & $\begin{array}{l}\text { Focused Case- } \\
\text { Study }\end{array}$ & Work Supervisor & 1 & 1 \\
\hline & $\begin{array}{l}\text { Five Minute } \\
\text { Sneech Samnle }\end{array}$ & Mother & N/A & N/A \\
\hline Total & & 17 & 18 & 20 \\
\hline
\end{tabular}


Case study interviews. The primary interviews with parents were open-ended, prolonged case study interviews (Yin, 2014). I spoke with parents for extended periods of time, over multiple sessions, with follow up questions over the phone or via email. Interviews with nonfamily supportive adults were focused case study interviews (Yin, 2014) concentrating on topics related to their role in the participant's life. Interviews focused on interpretations of the meaning of thriving as well as facilitators and barriers to thriving. Appendix F provides the open-ended interview protocol I used with parents and other adults in the support system, including a table outlining how each interview question addressed the research questions and the literature to support each probe.

Five-Minute Speech Sample. In addition to the open-ended case study interviews, five parents (all four mothers and one father) also completed brief standardized FMSS interviews (Magana-Amato, 2015) to measure their Expressed Emotion (EE), or the emotional climate for the dyads. The FMSS consists of a brief structured interview, in which the parent responds to a prompt requesting a five-minute uninterrupted monologue about the child and their relationship. Research indicates that useful and valid information regarding EE is often communicated in the condensed timeframe of a fiveminute interview (Magan-Anato, 2015). Per author recommendations (Magana-Amato, 2015), I administered the FMSS interviews prior to other data collection methods, with the exception of one parent who needed to reschedule due to medical issues. Further, one FMSS was collected as part of another research study and was, therefore, administered by a different interviewer.

In the FMSS, a systematic coding process is used to analyze a transcription of each interview for both content and tone. The coding system measures five areas of EE: 
initial statement, relationship, criticism (CRIT), dissatisfaction, and emotional over involvement (EOI). Scores are combined to place each FMSS interview into subgroup categories of low, high, or borderline for CRIT and EOI. Subgroup category ratings are combined to produce an overall EE summary coding of High or Low. Myself and another trained individual coded each sample in order to ensure inter-rater reliability and allow for consensus ratings for analysis.

One goal of this study was to examine the systems of support for those who thrive with DS. A standardized measurement of parent EE provided another useful data point to understand the quality of relationships for each participant and his or her parents. Triangulating EE data with interview and observation data helped to support the credibility of the findings (Tracy, 2010). Furthermore, the results from the FMSS interviews were consistent with other data points in each case indicating that this instrument may be a useful and valid measure of EE for this specific population. Further research could explore the face validity of the FMSS with a larger sample of parents of adults with DS.

Photo-elicitations. Interviews with the participants were open-ended and probebased (Stake, 2006) to encourage friendly inquiry into a complex topic. Probe-based interviewing uses texts, videos, photos, or artifacts to evoke comments and meaning from participants and to elicit deeper discussion (Stake). The probe in this study was photoelicitation, a method that involves participant-generated visual data to be utilized in the interview process (Guillemin \& Drew, 2010; Povee, Bishop, \& Roberts, 2014). Photoelicitation is both empowering and enabling (Guillemin \& Drew, 2010). The method is empowering for participants in that it allows them a voice in the research process. 
Participants themselves can direct the attention of the researcher and initiate conversations about topics they believe are relevant during the interview process. The method is enabling as it can allow the researcher "a different way in" to the phenomenon of interest (Guillemin \& Drew, 2010, p.178). Visual methods may allow the researcher to gather data on a topic that is difficult to express with words, or with a population who struggles to communicate verbally.

Photo elicitation has historically been used in research as a "communicative bridge" for speaking about a sensitive topic with a population of youth who may not have the vocabulary or cognitive maturity to adequately express their thoughts and feelings (Guillemin \& Drew, 2010). The participants in this study all had DS; a syndrome associated with deficits in abstract reasoning and expressive communication abilities (Fidler, 2005). Considering the DS phenotype, photo-elicitation was particularly useful for extracting meaningful and data-rich interviews about the abstract topic of thriving. In fact, visual prompts are frequently used to elicit verbal communication for students with DS in educational settings (Kumin, 2001).

First, participants were provided with a choice of using their own phones or an iPhone $5 \mathrm{~s}$ to borrow for photos. The iPhones did not have a data plan or the ability to connect to the Internet; they only had camera functionality. This method has been used in prior studies with individuals with ID as a method to provide participants with cameras that fit in with their natural environment and are unlikely to draw any unusual attention (Grimmet, 2016). Participants were given 1-2 weeks to photograph the people, places, and things that they believed help to "make their lives good." The term "good life" has been used successfully in focus group research on well-being with adults with DS (Scott 
et al., 2014). The term is useful because it is easy to understand as well as open to interpretation by the individual being interviewed. In particular, this phrase makes an abstract concept such as "thriving" more concrete and accessible to participants with limited communication and abstract reasoning skills. The 1-2 week timeframe allowed enough time to capture key elements in their lives, without the interference of memory concerns that may happen with a longer time span.

After each participant completed taking photos, I met with them to discuss the pictures (see Appendix $\mathrm{G}$ for interview protocol and Appendix $\mathrm{H}$ for a list of open codes from each participant's photo elicitation interviews). We uploaded the photos to a laptop computer and scrolled through each photo to engage in a conversation about what contributes to their "good life." This method was successfully used in a large-scale research study with adults with ID titled 'This is Me' (Povee, Bishop, \& Roberts, 2014). In this project, the authors asked participants, "What made you take this photograph, and what is happening in this photograph?" to elicit meaning about visual data (Povee et al., 2014, p. 899). I used these same two questions for interviewing participants, adding a third question: “How does [item in picture] help to make your life good?” Participants had the choice of who to have present in their interviews. One chose to have his adult sister present for the interview, while the other three preferred to interview alone.

Direct Observations. Observations took place over the course of three months for a total of 35 hours of direct observation. I spent an average of 8.75 hours observing each participant, with an average of 2.25 hours in each home setting, three hours in each community setting, and 3.5 hours in each work/day program setting. See Appendix I for an observation protocol outlining settings and focus areas, how each area contributed to 
answering the research questions, and supporting literature. During each observation, I created field notes (See Appendix J) to capture what I saw in these settings, including aesthetic details that were useful in analysis and representation (Creswell, 2014; Stake, 1995; Yin, 2014). Descriptive "bursts," or short detailed vignettes from the field, provided rich data to use in analysis and representation of what it looks and feels like to thrive with DS (research question \#1) (Wolcott, 1995, p. 98).

My presence undoubtedly affected the setting (Creswell, 2013); it was impossible to blend in for a blind observation. Therefore, I engaged in "participant observation" in which I joined participants in three key life settings, embedding myself into the settings, helping out as needed and engaging as much as was appropriate. Settings for observation included participants' homes, a work/day program setting, and a community setting (see Table 4 for community settings). Community settings were chosen in partnership between the participant, the family, and myself with the criteria they be data-rich, meaningful to the participant, and feasible for observation (e.g., accessible to a researcher, my presence would not disturb or harm anyone in the setting). I participated alongside the participants, as appropriate, while also observing the environment (Wolcott, 1995; Yin, 2014). 
Table 4

Community Settings

\begin{tabular}{lll}
\hline Case & Community Observation Setting & Occurrence \\
\hline 01 & Physical therapy appointment & Biweekly \\
02 & Staff training for Boy Scouts of America (BSA) leadership camp & Monthly \\
03 & Dinner date at the home of girlfriend & Weekly \\
04 & Swim lesson at community recreation center & Weekly \\
\hline
\end{tabular}

Document Review. A review of available and important health and educational documents contributed to the data collection process by providing insights into the participants' medical and educational histories. In case study, reviewing existing documents and records allows the researcher access to historical information that may be critical to the topic of study, but impossible to observe at the current time (Stake, 1995). In the current study, educational and medical records provided by the families shed light on academic growth over time, levels of inclusion in the educational history, major medical procedures, behavioral histories, personal strengths, and relative weaknesses. Documents and other artifacts provided me with information about systems and organizations that I probed further in interviews. Using my research questions, I analyzed these documents for codes and themes related to thriving with DS. In cases where documents were limited, I probed further into educational and medical histories through parent interviews.

Standardized Individual Assessments. Any examination of thriving must involve an examination of what the individual brings to the situation. This allows for a richer understanding of how the systems of support interact and support the individual's 
needs and how the individual uses his or her profile of strengths to contribute to relationships and the community at large (Buntinx, 2014; Gilman, Huebner, \& Furlong, 2014; Lerner et al., 2013). In order to understand and communicate each individual's profiles of strengths and weaknesses, I conducted a total of 9.25 hours of psychoeducational assessments, for an average of 2.3 hours with each participant. Assessments included measurements of cognitive abilities, adaptive functioning, mental health, communication skills, academic achievement, and character strengths. These data allowed for a comparison of scores with prior school and clinical assessment results to examine their growth trajectory at this point in early adulthood. Data from assessments completed within one year of this study were used, as appropriate, with permission from the participant and his or her guardian (see Appendix K for Release of Information form.) Table 5 provides results from standardized assessments. A cross-case analysis of scores is provided in the results section of this paper.

Psychoeducational assessment data included a current measure of IQ using the Stanford-Binet 5 (SB5; Roid, 2003). The SB5 has strong psychometric properties and has been shown to be a useful and valid measure of IQ for individuals with DS (Hessl et al., 2016). The Vineland Adaptive Behavior Scales, Third Edition (Vineland-3; Sparrow, Saulnier, Cicchetti, \& Doll, 2016) was used to measure each participant's overall adaptive functioning and specific skills in the areas of communication, daily living, socialization (including emotional coping skills), and maladaptive behaviors. 
Table 5

Cross-Case Standardized Assessment Results

\begin{tabular}{|c|c|c|c|c|}
\hline $\begin{array}{l}\text { Standardized } \\
\text { Assessments }\end{array}$ & 1 (Angel) & 2 (Hal) & 3 (Clark) & 4 (Anita) \\
\hline \multirow{3}{*}{$\begin{array}{l}\text { Cognitive* } \\
\text { SB5 }\end{array}$} & FSIQ: 52 & FSIQ: 44 & FSIQ: 42 & FSIQ: 68 \\
\hline & Verbal: 57 & Verbal: 43 & Verbal: 44 & Verbal: 62 \\
\hline & Nonverbal: 51 & Nonverbal: 51 & Nonverbal: 46 & Nonverbal: 77 \\
\hline \multirow{12}{*}{$\begin{array}{l}\text { Adaptive* } \\
\text { Vineland-3 }\end{array}$} & Adaptive & Adaptive & Adaptive & Adaptive \\
\hline & Behavior & Behavior & Behavior & Behavior \\
\hline & Composite: 72 & Composite: 30 & Composite: 59 & Composite: 68 \\
\hline & $\begin{array}{l}\text { Communication: } \\
68\end{array}$ & $\begin{array}{l}\text { Communication: } \\
20\end{array}$ & $\begin{array}{l}\text { Communication: } \\
36\end{array}$ & $\begin{array}{l}\text { Communication: } \\
54\end{array}$ \\
\hline & Daily Living: 72 & Daily Living: 49 & Daily Living: 63 & Daily Living: 76 \\
\hline & Socialization: 80 & Socialization: 20 & Socialization: 82 & Socialization:77 \\
\hline & Maladaptive & Maladaptive & Maladaptive & Maladaptive \\
\hline & Behaviors- & Behaviors- & Behaviors- & Behaviors- \\
\hline & Internalizing: & Internalizing: & Internalizing: & Internalizing: \\
\hline & 16, Average & 19, Elevated & 14, Average & 16, Average \\
\hline & Externalizing: & Externalizing: & Externalizing: & Externalizing: \\
\hline & 20, Elevated & 20, Elevated & $\begin{array}{l}21 \text { Clinically } \\
\text { Significant }\end{array}$ & 15, Average \\
\hline \multirow{11}{*}{$\begin{array}{l}\text { Academic* } \\
W J-4\end{array}$} & Brief & Brief & Brief & Brief \\
\hline & Achievement & Achievement & Achievement & Achievement \\
\hline & Cluster Standard & Cluster Standard & Cluster Standard & Cluster Standard \\
\hline & $\begin{array}{l}\text { Letter Word ID- } \\
\text { Grade: } 1.9 \\
\text { Age: } 7-4\end{array}$ & $\begin{array}{l}\text { Letter Word ID- } \\
\text { Grade: } 1.2 \\
\text { Age: } 6-8\end{array}$ & $\begin{array}{l}\text { Letter Word ID- } \\
\text { Grade: } 2.3 \\
\text { Age: } 7-8\end{array}$ & $\begin{array}{l}\text { Letter Word ID- } \\
\text { Grade: } 10.6 \\
\text { Age: } 16-0\end{array}$ \\
\hline & Applied & Applied & Applied & Applied \\
\hline & Problems- & Problems- & Problems- & Problems- \\
\hline & Grade: 1.3 & Grade: $<$ K.0 & Grade: $<$ K.0 & Grade: 2.6 \\
\hline & Age: 6-8 & Age: 4-7 & Age: 4-7 & Age: $8-0$ \\
\hline & Spelling- & Spelling- & Spelling- & Spelling- \\
\hline & Grade: 2.5 & Grade: K.2 & Grade: 1.9 & Grade: 4.6 \\
\hline & Age: 7-11 & Age: 5-7 & Age: 7-4 & Age: $10-0$ \\
\hline
\end{tabular}




\begin{tabular}{|c|c|c|c|c|}
\hline \multirow{2}{*}{$\begin{array}{l}\text { Communication* } \\
P P V T \& E V T\end{array}$} & Receptive: 70 & Receptive: 35 & Receptive: 49 & Receptive: 84 \\
\hline & Expressive: 79 & Expressive: 51 & Expressive: 70 & Expressive: 80 \\
\hline $\begin{array}{l}\text { Mental Health } \\
S L S \& S W L S\end{array}$ & $\begin{array}{l}\text { Life } \\
\text { Satisfaction: } 33 \text {, } \\
\text { Very High }\end{array}$ & $\begin{array}{l}\text { Life } \\
\text { Satisfaction: } 32 \text {, } \\
\text { Very High }\end{array}$ & $\begin{array}{l}\text { Life } \\
\text { Satisfaction: } 34, \\
\text { Very High }\end{array}$ & $\begin{array}{l}\text { Life } \\
\text { Satisfaction: } 35 \text {, } \\
\text { Very High }\end{array}$ \\
\hline & $\begin{array}{l}\text { Happiness scale: } \\
5.75, \text { Above } \\
\text { Average }\end{array}$ & $\begin{array}{l}\text { Happiness scale: } \\
\text { 7, Above } \\
\text { Average }\end{array}$ & $\begin{array}{l}\text { Happiness scale: } \\
\text { 7, Above } \\
\text { Average }\end{array}$ & $\begin{array}{l}\text { Happiness scale: } \\
\text { 7, Above } \\
\text { Average }\end{array}$ \\
\hline $\begin{array}{l}\text { Strengths } \\
\text { (Top 5) } \\
\text { VIA-Youth }\end{array}$ & $\begin{array}{l}\text { 1. Gratitude** } \\
\text { 2. Zest } \\
\text { 3. Love of } \\
\text { Learning } \\
\text { 4. Spirituality** } \\
\text { 5. Appreciation } \\
\text { of Beauty and } \\
\text { Excellence** }\end{array}$ & $\begin{array}{l}\text { 1. Appreciation } \\
\quad \text { of Beauty \& } \\
\quad \text { Excellence** } \\
\text { 2. Humor** } \\
\text { 3. Spirituality** } \\
\text { 4. Zest } \\
\text { 5. Love }\end{array}$ & $\begin{array}{l}\text { 1. Appreciation } \\
\text { of Beauty \& } \\
\text { Excellence** } \\
\text { 2. Perseverance } \\
\text { 3. Spirituality** } \\
\text { 4. Zest } \\
\text { 5. Humor** }\end{array}$ & $\begin{array}{l}\text { 1. Forgiveness } \\
\text { 2. Humor** } \\
\text { 3. Perseverance } \\
\text { 4. Love of } \\
\text { Learning } \\
\text { 5. Spirituality** }\end{array}$ \\
\hline
\end{tabular}

* Scores are standardized with a mean of 100 and a standard deviation of 15 .

** Character strengths under the subcategory of Transcendence (Peterson \& Seligman, 2004)

Measures of mental health provided data on each participant's current levels of

SWB. The Subjective Happiness Scale (SHS; Lyubomirsky \& Lepper, 1999) (see

Appendix L) was used as a global measure of happiness and the Satisfaction with Life

Scale (SWLS; Diener, Emmons, Larsen, \& Griffen, 1985) (see Appendix M) was an

indicator of participant life satisfaction. Both measures are well-validated brief surveys

for the measurement of SWB and have been used successfully in prior research with the population of adults with ID (Rey, Extremera, Duran, Ortiz-Tallo, 2013).

Participant communication skills were measured directly with the Peabody

Picture Vocabulary Test, Fourth Edition (PPVT-4; Dunn \& Dunn, 2007) and the Expressive Vocabulary Test, Second Edition (EVT-2) (Williams, 2007). Both have been 
used extensively with individuals with DS in both research and clinical settings (Finestack, Sterling, \& Abbeduto, 2013; Loveall et al., 2016). The Woodcock-Johnson Tests of Achievement (Brief Achievement Cluster), Fourth Edition (WJ-4; Schrank, McGrew, Mather, 2014) was used to measure basic academic achievement, including reading, writing, and math skills. Finally, I conducted an analysis of each participant's self-reported individual character strengths using the Values in Action (VIA) Inventory of Strengths for Youth (VIA-Youth; Park \& Peterson, 2006) with recommended accommodations and cognitive supports for enhancing validity with individuals with ID (Shogren, Wehmeyer, Forber-Pratt, \& Palmer, 2015).

\section{Data Analysis}

Data analysis in case study is an inductive and iterative process in which meaning is derived from raw data collected from each case (Creswell, 2013; Stake, 1995; Yin, 2014). For this study, both interviews and field notes were transcribed into Microsoft Word documents. I completed all field note transcriptions and eight of the 19 interview transcriptions, including all four of the participant photo elicitation interviews. The other 11 interviews were completed by a transcription service to ensure a timely analysis process. I also engaged in frequent memo writing (Creswell, 2013) to capture initial thoughts on data and emergent themes throughout the data collection phase. All data (memos, transcribed interviews, field notes, notes on educational and medical documents, and standardized assessment results) were then uploaded into a qualitative data analysis software program (ATLAS.ti) to assist in organization, storage, and analysis.

After data collection for each case was complete, I conducted within-case analysis starting with open coding across all data points for each participant (interviews, 
observations, document review, and standardized assessments) to identify basic categories related to the research questions (Creswell, 2013, p. 86). Open codes were both inductive (emergent from the data) and deductive (based on thriving literature and the TET-M; see Manuscript 1). Next, I looked for patterns in the codes as well as categorical aggregations, or repeated instances of occurrences (Stake, 1995). From these patterns I created broader categories and then several themes related to each case. Finally, I wrote several vignettes about each case to provide the reader with a detailed understanding of what it looks and feels like to thrive with DS. The iterative nature of qualitative research was particularly salient for the within-case analytic process. Following data collection and analysis for each case, I revisited the previous case(s), renaming and collapsing open codes and categories to maintain consistency in the coding system for cross-case analysis.

After within-case analysis was complete for all four cases, I conducted a crosscase analysis to identify similarities and differences between the cases, as well as crosscase categories and themes related to the research questions (Creswell, 2013; Stake, 2006; Yin, 2014). Here, I analyzed within-case categories and themes that appeared redundant across the four cases, or that contained significant overlap of similar open codes. This resulted in the creation of several specific cross-case categories that answered aspects of all three major research questions. Then, I looked for relationships between cross-case categories to develop seven broad and emergent cross-case themes about the phenomenon of thriving with DS. See Figure 1 for a visualization of data collection and qualitative analysis including specific tasks for each phase of the process. 
Participants' parents were asked to review transcripts and discuss emerging within-case themes to assure that data were collected accurately, and that their beliefs and opinions were correctly expressed (Carlson, 2010; Creswell, 2013). Three of the four parents reported reading their transcripts and one intended to read the information at a later date. All three who reviewed transcripts confirmed their accuracy. This process of member checking honors the experience and perspectives of a population of individuals who have been historically marginalized (Wehmeyer, 2013).

\section{Author's Biography}

Qualitative researchers are the "key instrument" in a qualitative study (Creswell, 2013, p. 45). In qualitative research, rather than striving to be an objective and unbiased, invisible researcher, the voice and perspectives of the researcher are openly disclosed. Sincerity is a noteworthy criterion for excellent qualitative research and entails "honesty and transparency about the researcher's biases, goals, and foibles as well as about how these played a role in the methods, joys, and mistakes of the research" (Tracey, 2010, p. 841). Therefore, it is appropriate for me to provide an honest appraisal of my own subjectivities that affect the ways in which I designed this study, interacted with participants, and interpreted data. By positioning myself in this study, readers will be better able to interpret and evaluate my findings. I undertook reflexivity during data collection and analysis through personal journaling to document the ways in which I believed my subjectivities influenced my interpretations of the data, as well as questions that arose and critical decision-making processes throughout the research process (Ortlipp, 2008; Tracy, 2010). 


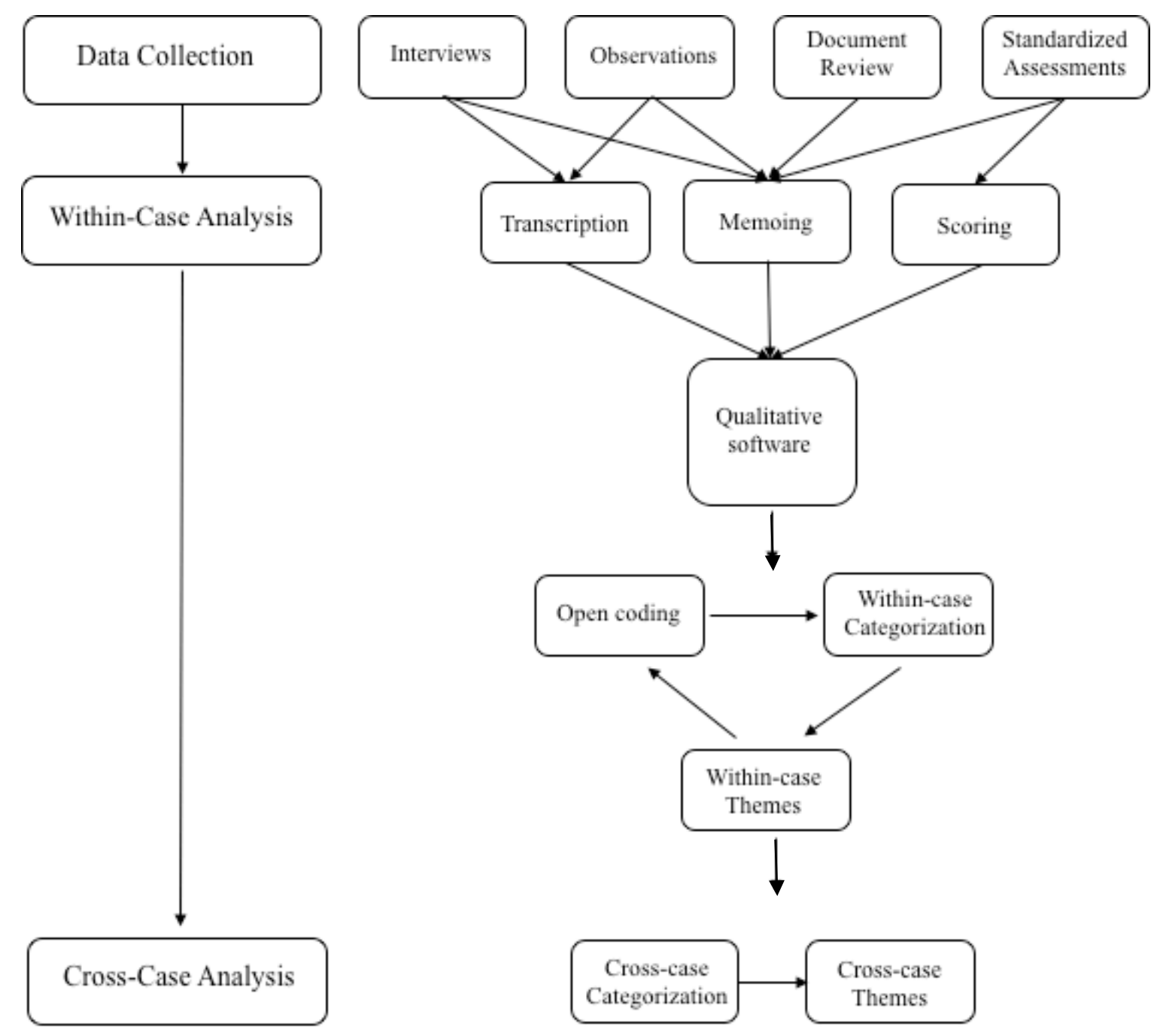

Figure 1. Analytic Process

Professionally, I am a licensed school psychologist who has worked in public schools, charter schools, and private schools. Throughout my career, I have supported the mental health and well-being of many students, including those with ID. In my own practice, I worked from a positive psychology framework, building capacity by focusing on student strengths and healthy school communities. A major part of my work with students with ID, including those with DS, was to conduct psychoeducational assessments to support their learning. I have conducted, scored, and analyzed the data 
from countless IQ tests, parent rating forms, and student observations with the goal of identifying each student's strengths and needs to inform the placement and intervention decision-making process.

For the past two years, I have been working as a research assistant on a National Institutes of Health (NIH) funded grant research project (Hessl et al., 2016). Our goal is to validate a new cognitive assessment in the population of individuals with ID, including a sub-population of participants with DS. As part of the study, I have had the opportunity to meet over 40 individuals with DS and their families through two-day visits and onemonth follow up visits to our university clinic. I have interviewed many of the parents of these individuals with DS and have heard personal accounts of their lives. I have also conducted many hours of cognitive assessments with these individuals and provided feedback sessions with test results to their families. The families who have participated in our research have openly shared some of the most poignant stories I have ever heard about living with a disability.

Some of the most intriguing stories have been from those individuals whom I began to consider were "thriving with DS." Dozens of individuals entered our clinic and immediately brightened the days of our entire staff by sharing their joys with our team. These participants described meaningful lives, filled with healthy interpersonal relationships and personal growth. Some of these individuals were learning lines for theater productions or song lyrics for choir performances, others were in college programs earning certificates in athletic training or early childhood teaching, some were dating, others were leading church youth groups, some had successful jobs, and others were learning to drive. I was impressed by their life stories and surprised that I had not 
considered such positive outcomes before for students with DS when I was working in the schools. In particular, I was startled to notice that whenever I provided feedback sessions, there was an almost complete dismissal of these standardized results by parents of our participants. Many explained to me that these results meant little to them. They understood that quantitative assessment results almost always placed their children at or below the $1^{\text {st }}$ percentile when compared with their chronological aged peers (Roizen, 2013). However, they were more concerned with understanding their child's unique profile of strengths so they could help them navigate their school and the community. These interactions with individuals who were thriving with DS inspired me to more thoroughly investigate this phenomenon. I wanted to understand what thriving was like for those individuals with DS and why they were able to thrive.

On a personal level, I am a white, heterosexual woman. I am married to a publicschool art teacher who has been working in inclusive teaching settings for over 15 years. Our two children attend a local, inclusive public elementary school. While both of my children have unique learning needs in the classroom, neither receives specialized instruction at this time. I do not have any family members or close friends with significant disabilities. My interest and relationships with this population began entirely through my professional life. Through the years, working in this community, I have begun to form friendships with the parents of children with a variety of disabilities.

It is important, however, that I make clear my own personal distance from DS. I entered this community as an outsider with a professional interest and warmth. However, I have never personally experienced the struggles or joys related to DS. When I hear parents describe their infants' open-heart surgeries, watching their child finally learn to 
walk, the social stigma of not getting invited to birthday parties, or teachers saying they are scared to have their child in their class, I can only muster empathy and compassion. While I cannot ever truly know the experience of these families as an insider, I hoped to use my status as an outsider to notice patterns and processes that might be overlooked by those living within the system. Perhaps my distance allowed me to reveal some nuances and assets that have been taken for granted by those living the phenomenon.

\section{Rigor}

Qualitative research methods have a unique set of guidelines for rigor (Creswell, 2013; Tracy, 2010). In this study, I focused on Tracy's (2010) eight suggested criteria for high quality qualitative research: worthy topic, rich rigor, sincerity, credibility, resonance, significant contribution, ethics, and meaningful coherence. Throughout the study I aimed to meet these quality indicators through intentional and reflective research practices.

Tracy (2010) states that qualitative research must focus on worthy topics that are timely, significant, and relevant. Using a positive psychology approach with the population of individuals with DS meets all three of these criteria (Dykens, 2006). Increased life expectancies and social inclusion for the population of individuals with DS (Roizen, 2013) compels us to examine QOL issues and gain a further understanding of facilitators and barriers to thriving. Rich rigor for this study was achieved by using a strong theoretical framework for the study (see Manuscript 1), the recommended data collection and analysis processes outlined by case study experts in the field (Stake, 1999; Yin, 2014), and spending adequate time in the field with each participant (Tracy, 2010). Sincerity was achieved through reflexive journaling (Ortlipp, 2008) in which I 
acknowledged my own subjectivities (see author's biography above) and reflected thoughtfully on methods and challenges in the study.

Case study methodology is particularly useful in establishing credibility for a study on thriving. Specifically, the use of multiple data collection methods (e.g., interviews, field observation, review of documents, and standardized assessments) allowed for triangulation (Creswell, 2013), or crystallization (Tracy, 2010) of the data, in which I was able to examine topics from multiple angles and perspectives to substantiate information and establish trustworthiness. This in-depth examination also provided thick descriptions of each case's context so that readers could draw their own conclusions about what it means to thrive with DS. Further, member checking of transcripts and emerging within-case themes was conducted with the parents of each participant to examine accuracy of transcription as well as consistency of my interpretations with the experiences of participants (Carlson, 2010). I also provided descriptive vignettes for each case to promote resonance by evoking empathy through transferable and naturalistic generalizations (Wolcott, 1995).

This study provides a significant contribution to the field of school psychology by extending our thinking about students with DS and providing reflections on ways to improve service delivery to this student population. Ethical practices were established for procedures through the IRB process (see above). However, situational and relational aspects of ethics (Tracy, 2010) were also prioritized, guided by recommended practices in ethical research with vulnerable populations (Horner-Johnson \& Bailey, 2013). Finally, meaningful coherence was achieved by using a methodological approach (qualitative multiple case study) that aligned well with the research questions and by accomplishing 
the intended purpose of the study: to elucidate the lives of those who thrive with DS and to identify the facilitators and barriers to their thriving.

\section{Findings}

In this study, I explored the phenomenon of thriving with DS across the contexts of four young adult lives. Each context is described, including details regarding each participant's home, employment, social life, and educational history. Additionally, each context includes excerpts from field observations in two major life areas: the home setting and another setting or event in which the individual thrives. Following these contextualizing narratives, a cross-case analysis presents seven key emergent themes identified across all four cases: a supportive social ecology, creating family, high expectations for independence, vulnerability in adulthood, advocacy, a focus on physical health, and limited utility for traditional assessments. Themes are supported with participant quotes to capture the thoughts, voices, and opinions of those directly experiencing the phenomenon of thriving with DS.

\section{Contexts}

Case 1. Angel is a 36-year-old Caucasian woman with DS. She lives independently in an inclusive apartment complex, with supports from a local government funded agency. A full-time rotating staff in her apartment complex supports approximately 12 residents receiving publicly-funded disability services for daily living. Her individualized support plan provides help for budgeting, grocery shopping, medication oversite, and transportation to appointments and social outings. She is responsible for decorating and cleaning her home, doing laundry, cooking her own meals, completing personal-care tasks, and using transportation to and from her day program. 
I observed Angel on a weekday morning preparing to leave her apartment for her day program. She independently navigated her morning routine despite a painful ankle injury that slowed her down:

I knock on her door at 7:45 am. A welcome mat sits in front of the door, sporting several smiling snowmen. Angel takes a few minutes to answer. As I wait, I hope she hasn't left already, or that she hasn't overslept. Finally, she opens the door, using the safety chain to allow her to peek out at me. When she sees its me, she closes the door, unlocks it, and welcomes me in. "Good morning. Sorry I'm just getting ready... I hurt my ankle. Slept on it weird." She is wearing an ankle wrap and limping badly.

She limps into her bedroom and closes the door. The apartment is softly lit with lamps. Her shades are drawn. The walls are covered in artwork including a pencil drawing of a horse, a small canvas painted with the word LOVE, a photo of Elvis, a wooden cross, and a picture of angels. I sit on a fuzzy cheetah print chaise lounge, piled with several cheetah print throw pillows, and sitting atop a cheetah print area rug. Multiple chairs are clustered in the living room area to create a seating area. One chair is hand painted with butterflies and flowers. Her mother proudly explained during my last visit that Angel had painted it herself while in a day program. A thick, plastic binder filled with pictures and instructions for exercises rests on a brown, leather ottoman. Sitting slumped to one side, in a folding camp chair, is a baby doll. The doll is realistic in size and color, dressed in cheetah print pajamas. Another chair hosts an infant car seat- not a toy, but a real car seat with a pink, knit blanket draped across. It looks as if a real baby was recently plucked up and carried out into the apartment. 
Angel walks out a few minutes later and asks, "Everything okay?" She is wearing a purple t-shirt, faded black jeans, sneakers, and brightly colored striped socks. Her long, brown hair is in a low bun at the nape of her neck with a hot pink headband at the hairline. Her skin is pale and smooth, with rosy cheeks and shapely eyebrows above wide eyes and a dainty chin. She talks quietly to herself as she takes food and a bottle of juice from the refrigerator. She grabs a bottle of water, then sets it down and mutters, "Don't need this. I have my juice." She puts on a bright blue hooded sweatshirt with the statement "Get Moving" in bold, white letters and places a plaid cap over her hair. She explains to me that we are going to see someone in the staff office, so she can get her medicine before heading to the bus stop. After locking up her apartment, we begin to walk through the large and sprawling complex.

It is a cold morning in January. We are wearing light layers, but we can see our breath. Angel wears a small backpack and carries a Lion King shoulder bag. She asks if I can hold the shoulder bag as she is limping on her hurt ankle. We walk at an incredibly slow pace. When we arrive at the staff apartment to pick up her medicine, Angel turns the knob and pushes the door open without knocking. Angel introduces me to the staff on duty, "This is the lady I told you about. The one who's gonna follow me around." We briefly say hello. The staff tells Angel she is late and that she needs to take her pills earlier in the day. He uses an authoritative tone with her and explains that someone will be calling her mother to let her know the rule. He says she must take her medicine one hour before the bus comes. She nods, "OK." She placates him with her tone. She is not defensive at all, nor does she explain her injury. She simply agrees with him. She grabs a 
baggie with a half a dozen pills of various shapes, colors, and sizes, and we leave the apartment without any more discussion. - Field Notes, 1/9/18.

Angel is highly independent; she lives in an apartment that reflects her aesthetic preferences, lifestyle, and hobbies. She navigates self-care routines herself, accessing help as needed from support staff. Despite this independence, she receives reprimands from staff when her behavior is not in line with their wishes.

Employment. Angel is currently unemployed. Four days a week, she attends a daily program for adults with ID where she is learning prevocational skills to prepare her for employment in the community. Each day, her class begins with a lesson on functional living, such as money skills or social etiquette. The lessons use a combination of direct instruction, modeling, role playing, and Socratic questioning. After lunch, the teacher takes her class out into the community for outings where they can practice their newly learned skills, applying their lessons to real-world situations. The school climate is warm and encouraging, and she has close relationships with teachers and classmates.

Social Life. Angel is supported by a close-knit social network. Her immediate family includes her mother and several adult siblings. Her mother is the live-in care provider for one brother's young daughter. Angel enjoys playing with her niece and helping her mother with caretaking responsibilities such as changing her diaper, playing, and watching her as needed. Her most significant personal relationship is with her loving boyfriend, Ike, of eight years. Ike has a diagnosis of cerebral palsy (CP) and lives in a supported group home with two male roommates. Ike spends the night at Angel's apartment several times per week and the two enjoy going on dates in the community and 
speaking on the phone multiple times each day. I observed Angel and Ike on a Friday evening at her apartment:

"I have a surprise for you!" Angel says excitedly. She leads me to the door of her laundry closet and knocks dramatically. She is giggling, and I can hear a man giggling from inside the door. Ike jumps out and shouts, "Surprise!" He is tall with a dark, curly mop of uncombed hair. He is wearing a maroon Gryffindor shirt from Harry Potter, light-colored khaki pants, and black socks. He wears a wide, silver band on his left ring finger. It is decorated with Celtic designs; two hands holding a heart. Ike eagerly shakes my hand, making intense and prolonged eye contact.

The two lead me to a chair in Angel's living room, encouraging me to sit. Ike offers me water and then proceeds to walk around the living room pointing out items and labeling them for my benefit, “These are board games, you can see this poster I made her...” Angel limps over to the corner of the couch and asks Ike to help her sit down. He rushes to her side and holds her elbow as she plops down. Her ankle is injured, and she winces in pain asking him to bring her an ice pack. He runs quickly to the kitchen and grabs one from the freezer, returning to gently place it on her injury.

Ike begins to read aloud a story he has written. Angel moves from the couch to sit on a leather ottoman, holding a baby doll on her lap. She snuggles it into her body and rubs her cheek on the top of its head. She places its head into the crook of her neck, gently and absentmindedly playing with its feet, staring off while Ike reads aloud. Rubbing the baby's hands, Angel lifts it up above her head smiling at its face, then sets it down, propping it against a pillow. - Field Notes, 1/12/18. 
Ike's attentive and loving behavior toward Angel regarding her injury is characteristic of their relationship. He supports her as needed and provides her with joy, entertainment, and laughter on a regular basis. Her family describes her healthy and reciprocal relationship with Ike as one of her major achievements in adulthood. The couple has several baby dolls or "pretend children" with whom they roleplay typical parenting tasks such as dressing, bathing, and comforting.

Angel also has several long-term friendships, including Ranger, a young man with vision impairment who lives in her apartment complex. She and Ranger cook together and engage in roleplaying games with Ike every weekend. She has also maintained a long-term friendship another young woman with DS, for over twenty-five years. The two women enjoy seeing each other daily at their day program and getting together to watch movies and bake. Her life is busy with social engagements, many of which take place in her apartment, including playing video games, role playing Ike's stories, watching movies, eating meals, and hosting parties. She also goes on frequent excursions out into the community with support from family and service agencies for both transportation and funding.

Educational History. Angel received most of her education in self-contained instructional settings. From ages five to ten, she attended a private, faith-based school specifically designed to support students with significant needs. Within this setting she received small group, full-day instruction from a special educator as well as two hours per week of speech and language therapy. Instruction was individualized to Angel's learning needs. At age 11, Angel transferred to the public schools, where she was educated in self-contained classrooms for functional academic skills and continued to 
receive speech and language therapy on a weekly basis. In high school, she participated in general education elective courses with support for inclusion from a paraprofessional. After graduation, Angel attended a transition program for one year before aging out of public school services at twenty-one. The focus of the program was to build independence and improve post-secondary outcomes for students with disabilities.

Case 2. Hal is a 21-year-old biracial man with DS living with his mother, father, and older sister. His older brother lives in a different state where he is stationed for the Air Force. Hal has his own room in his parents' two-story suburban home. He is responsible for feeding, walking, and providing daily care to his service dog, Captain. At home he enjoys watching television shows and movies, eating home-cooked meals with his family, creating Lego construction projects with his father, and spending time in his bedroom singing songs from musicals and perusing social media.

I observed Hall in his home one evening while his parents were out of town. This was the family's first time leaving Hal without his parents. He was in the shared care of his sister and several respite care providers. He proudly showed me his personal space and belongings:

Hal walks in to the house holding a plastic lidded cup. "Strawberry lemonade!" he shouts out with a wide smile. He and his respite care provider have just returned from a burger shop for dinner. He has short, cropped, wavy black hair and warm, medium brown skin. His wide set, dark brown eyes are surrounded by rectangular, wire rimmed glasses. A blue striped polo shirt is neatly tucked into a pair of jeans, cinched with a leather belt at the waist. He joins me at the dining room table to discuss our plan. I explain that we will be going through his photos for an interview, seeing his room, and completing a strengths 
survey. I ask if he is still interested in participating in the study. He claps his hands, smiles, and stands up. He appears willing and excited to participate.

Hal's room is at the top of the stairs. A bunk bed and ladder take up one wall. The bed is neatly made, and a pair of flannel pajama pants and a black winter hat are laid carefully on top of the covers. I ask him if he makes his bed every day. "Yes. I make at night," he replies. His sister chimes in that he often makes his bed at night and then sleeps on top of his blankets, so he doesn't have to make it in the morning. A desk sits under windows facing the backyard, covered with neatly stacked yearbooks, a laptop computer, a small plastic set of drawers, and a model airplane. Several stickers of the local football team, Harry Potter, and the Incredible Hulk decorate the area. Next to the desk sits a shelf filled with books, sports hats, trophies, and boxes.

Hal shows me around his room. He points out each item on his walls and explains them to me. Five calendars are hung up for display; all but one are from years prior, yet all are flipped to the current month. Each calendar is different: two display pictures of scantily clad football cheerleaders, one has Legos, another shows a picture of a European city, and one has a decorative tree on the top. I ask about the quantity of calendars and he replies, "Uh, just make you happy 2018. Yeah! This month."

Hal's handwriting covers a large whiteboard in green marker. He has written the upcoming few months of the year alongside shows he would like to watch in theaters, on stage, or on television with his family. A work schedule is framed in plastic and hangs next to his door. The schedule is several weeks old. When I inquire, Hal says, "Yeah. It's old. That's okay." A meticulous spreadsheet with hot pink highlighting is hung on the closet door. The spreadsheet outlines who will provide care to him for each moment that 
his mother and father are out of town. Specific details are included, such as the days, times, tasks, whether or not care providers are confirmed, locations, transportation issues, and the service type (e.g. overnight respite, volunteer, hourly respite, N/A). - Field Notes $2 / 12 / 18$

Hal's room is personalized with his favorite icons and teams; he has surrounded himself with sources of happiness. His calendars and schedules help him to look forward to fun upcoming events and keep track of his daily life.

Employment. Hal works as a stocker for the local Army and Air Force base retail store. He works three five-hour shifts per week, to which he commutes independently using public transportation. At work he is responsible for removing items from packaging, placing items on shelves in the store, breaking down cardboard boxes, and completing some cleaning tasks. He brings a warm and flexible attitude to his job, greeting colleagues and customers with a friendly and helpful demeanor. He struggles at times with signing in and out at the correct time, staying on task for the entire shift, and transitioning back from his break in a timely manner. A job coach funded by the local disability supports agency visits him on a weekly basis to observe, check in with supervisors and colleagues, and provide on-site training as needed.

Social life. Hal has an active social life in organized activities. He is an acolyte in his church and meets with the church men's group twice a month for happy hour. He is a member of Toastmasters International, where he practices public speaking skills, and volunteers for the Lions Club International, sorting donated eye glasses. His largest social commitment is to Boy Scouts of America (BSA). Hal belongs to two troops: one in his neighborhood with local peers and one for scouts with a variety of special needs. He is 
actively moving toward his Eagle scout status by accumulating merit badges. Further, he was recently hired on as staff for a BSA youth leadership summer camp. I observed Hal in a BSA staff training session:

Hal joins a group of 20 scouts standing in a large circle at one end of the spacious indoor archery range. Several scouts take turns leading the group in songs. They are joyful and loud; the songs are familiar to everyone. Hal sings along, missing several words but beaming and bouncing as he sings. The team leader interrupts the songs to start a name game. She explains the rules of the 'Who me?' game. Each scout will state his or her name and something he or she likes or enjoys. The next person in line will need to recall each previous person's information and state it aloud. Hal is situated near the end of the circle. He will be required to remember approximately 15 names and preferences. A small group of adult staff members, including Hal's troop leader, stand drinking coffee and chatting at the side of the room. Hal has no support for this activity; it is expected he will complete this task independently.

As the team progresses through the circle, Hal's troop leader turns his attention to the activity. He leaves his small group and begins pacing outside the circle. He approaches me, sitting on the side of the room and states, "This might be hard for him." His brow is furrowed and he watches Hal intently. Hal is smiling and nodding as each person shares. He claps occasionally when he shares a preference with a teammate. The young man directly before Hal is confident in his recall. He goes quickly through the circle, correctly and loudly naming each teammate and their unique penchants.

When it is Hal's turn several adults walk closer to the circle. The team in the room next door is loud and it is becoming difficult to hear the 'Who Me?' players. Hal 
begins without skipping a beat. He has been waiting for this moment and appears excited and happy to have a turn. He steps into the circle, reaches out his arm and points to the first person in the circle, correctly naming him. He continues, pointing and shouting out as many names as he can remember, only occasionally recalling a preference. He smiles broadly as he speaks, laughing when he forgets. "You're Sam, you like movies. You're Joe, I don't know what you like. I don't remember you..." He misses more than half of the names and almost all of the preferences. The group laughs and encourages him. People shout out their own names when he forgets. Hal finishes naming the group and moves on to introducing himself. "I'm Hal and I like acting and Disney, like Cinderella. And Newsies. Yeah, Newsies!” He jumps up and down and shakes his hands above his head with excitement. Everyone in the group cheers loudly. The adults look at each other, smiling, and back away from the group. - Field Notes 1/19/18.

Hal's eager approach to life is contagious to those in his community. His deficits in working memory make a task such as 'Who Me?'nearly impossible to complete correctly without significant accommodations. However, the essence of the task introducing himself to a team - is natural for him. His enthusiasm and positive attitude allow him to easily embed himself into the inclusive BSA setting.

Educational history. Hal's education began in an inclusive, faith-based preschool setting, where his private speech language pathologist and physical therapist provided services in and out of school and consulted with his teachers. Upon transferring to a public elementary school, he began spending time in self-contained classrooms for students with significant needs. In kindergarten, he spent half the day in general education and half the day in a developmental kindergarten class. By third grade, he 
received most of his academic instruction in a self-contained classroom yet was included with his general education peers for physical education, art, music, recess, and lunch. In middle school, he spent the majority of his school day in a self-contained classroom, with instruction for science and drama in the general education setting. In high school, his family advocated for him to be in several general education classes, including poetry and science, two areas of particular interest and strength. The school was not receptive to these ideas, reportedly for safety and comprehension concerns. His parents actively pursued education in these two areas outside of the public schools via theater programs and BSA.

After graduating from high school, Hal did not attend a formal transition program with his public school district. Rather, he attended a 2-year inclusive college program for students with IDD at a local, public university. He was required to take public transportation to and from the school and received extensive individualized training to complete this task. His initial coursework at the college was designed to prepare him for college classes by teaching digital literacy, communication, and self-monitoring skills. Eventually, he took general education college level classes in physical education and Taekwondo and graduated with a certificate of completion at age 20 .

Case 3. Clark is a 39-year-old Caucasian man with DS. He currently lives with his parents, Martha and Jonathan, in the basement of their urban home. His three adult siblings are all married with children and live outside the home. Prior to his current living arrangement, Clark lived independently in a two-bedroom apartment for two years. However, finding a suitable roommate proved difficult. Therefore, his family purchased a single bedroom unit in the same complex to allow him to live on his own. He has moved 
back in with his parents while waiting for the apartment to become available. Although his parents purchased the apartment upfront, he plans to pay the monthly mortgage payment with combined income from work wages and social security. He is financially independent from his parents and pays for all his own food and daily living expenses.

I observed Clark early on a typical weekday morning as he prepared for a day of work. On the day I observed Clark, his mother was recovering from brain surgery and awaiting results from the biopsy of a malignant tumor:

Clark greets me at the door of his parent's home and invites me to join him at the dining table. He has dark brown hair neatly combed and slicked back from his face, brown eyes, pale skin, and a wide warm smile. His green striped button-down shirt is tucked into jeans and covered by a black apron with his work restaurant's logo. He places a plate on the table with a breakfast burrito and banana next to a cup of black coffee. His father is sitting across the table, reading the newspaper. Morning sun is streaming in through a window that faces out to a park with large trees shading a playground, grassy fields, and a historic stone library. Paintings cover the sage green walls, including a copy of The Last Supper. He cuts his burrito in half to cool and begins to eat his banana.

As he eats, he mentions he can't wait for his apartment to open back up. His father explains he wants to "get away from mom and dad." Clark makes intense eye contact with me and nods seriously in agreeance. He mentions that his burrito is vegetarian. It is a Friday during Lent and he will not eat meat in observance of the holiday. He plans for his lunch aloud, deliberating between ordering tofu or shrimp with his salad after his shift at the restaurant. After he finishes breakfast, he heads downstairs to prepare for work. 
His room is in the basement. A twin sized bed is pushed against one wall, covered in a bright red comforter, with framed photos of his girlfriend along the headboard shelf. A television sits on a table near the door, with a gaming console and several controls. Two chairs draped with superhero tee shirts are pushed into the table. Sitting in separate corners of the room are two dressers, each covered with different "shrines." The first has a statue of Jesus in the center behind an open bible covered in rosary beads. White pillar candles, a teddy bear, and a small Christian themed snow globe are interspersed with a framed photo of Mother Theresa and a plastic figurine of the Madonna. Three color photos of Jesus, Mary, and a temple with a golden dome are taped to the wall above. A three-foot cement garden statue of Jesus sits next to the dresser. The second "shrine" is dedicated to Superman. A Superman costume with built-in padded muscles is pinned to the wall behind the dresser next to a Superman apron. Three Superman mugs, a Superman comic, five Superman figurines, and several stickers are displayed on top of the dresser.

Clark grabs his coat hanging from a hook on his door, delicately pulling up the hood over his hair. He places a lanyard with keys and his bus pass over his head and around his neck, then carefully puts the hood back down. His puts on a pair of brown, rectangular framed glasses sitting on the Superman shrine. He takes out a Spiderman lunch box and packs it with a carefully rolled necktie (to wear to his second job at a university later in the day), his cell phone, and charger. He pours his remaining breakfast coffee from a ceramic Harry Potter mug into a Superman travel mug from the dresser and then checks his hair one last time in the mirror. Throughout this routine, he speaks to himself, "Charger. Tie. Oh yeah. Ready. Last time for hair and go." 
Back upstairs, his mother is now seated in the dining room with his father, wearing a brown terry cloth robe over her pajamas. She looks up at Clark and smiles. He hugs her tightly goodbye and she responds with, "I love big hugs from you. Your hugs give me strength." - Field notes, 3/2/18.

Clark leads an independent life, even while living with his parents. His mornings are busy; he must complete his personal care and use public transportation to arrive early each morning to his job. He has created a space for himself within his parent's home that reflects his personal preferences and brings him joy. His presence is a comfort to his mother in the difficult time after her surgery.

Work. Clark has two part-time stocking and cleaning jobs in the community: at a healthy fast food chain restaurant and a local private university in their college of education. In the restaurant, he works five days a week for two-and-a-half-hour early morning shifts prior to the restaurant opening. He is responsible for preparing the restaurant for customers. Each morning, he brews iced tea, stocks the drink and condiment stations, sweeps the dining area, shakes rugs, wipes tables, places chairs, and cleans the restrooms. Three days a week, he leaves the restaurant job and travels directly to the university where he is the assistant to the Assistant of the Dean. His shifts at the university vary in length from two to four hours, depending on his arrival time and the assigned duties for each day. His college work tasks are similar to the restaurant; he is responsible for stocking the break rooms on each floor of the four-story building, minor cleaning of banisters and doorknobs, and delivering packages from the Dean's office to various staff and faculty. Clark receives support for successful employment through a publicly funded job coach. 
I observed Clark one morning as he travelled independently to work and completed a shift at the restaurant:

We come to a busy intersection and he presses the pedestrian crossing button. A neon sign lights up and flashes brightly, but the cars do not slow down. Clark forcefully marches out into the street as the cars barrel toward him, holding his hand out in a stop position and pointing vehemently at the pedestrian crossing sign. The drivers slow and eventually stop. He shouts "Stop!" toward the cars, and then turns to me saying, "I want to say [to the drivers], 'Did you saw the light?' I can't say it 'cause their stupid window is shut." Later in our trip, we come to the intersection of two more busy streets with four lanes of traffic in each. He tells me, “These people, I don't trust them. That's why I don't want to work at [the restaurant]. Traffic." Again, he sticks out his hand like a stop sign, and marches fiercely across the road, stopping drivers from turning right on a red light into our cross walk.

At work, Clark uses his fingerprint to sign in at the register. His shift starts at 8:00am and ends at 10:30am, right before the restaurant opens for customers. He sets his lunch box down, hangs his jacket near the condiment station and immediately begins the process of making iced tea. He grabs scissors from behind the counter and cuts open a tea bag. He places a coffee filter and dumps in the leaves. He says aloud, "Make the tea. Taste good for the customers." After pressing the on button, he leaves to sweep the floor next to the door, pushing large piles of dust into a dustpan. He tells me, "A lot of dust. From the customer's shoes." He returns to check on the tea, peering over the top to make sure it is still brewing. He sets out rope barriers to create a place for customers to line up at the register. He takes down chairs and wipes tables with hot soapy water from a red 
plastic bucket his boss has prepared for him. He folds the cloth, wipes, and refolds for each table. He methodically wipes each table with a clean portion of the rag and then returns to check on the tea brewing. He taps the side of the machine to make it drip faster.

One coworker is talking incessantly as she prepares salad greens. He tells me, "They talk too much. Distracting. They not talk with self. They talk each other. I talk to myself. But not about the Holy Land anymore. Got be respectful. They not listen to Jesus!" and points to his colleagues. He moves into the other dining area to take down chairs and wipe more tables. He returns to check the tea again, dumping the spent tea leaves into a trash can and beginning his third batch. He returns back to the chairs, taking them down and setting them all at exactly the same angle. He takes the soiled rag back to the kitchen to wash it clean. When he returns, he goes back to wiping the tables. He scrubs at a persistent spot on the table, smiling as he wipes. He notices a small spot on a bench and wipes it clean. - Field Notes, 3/2/18.

Clark does not hesitate to meet a challenge; he is willing to persevere to complete a task and get a job done. This determination makes him a reliable employee who can complete tasks independently. His bold attitude keeps him safe as he travels independently through a busy urban environment.

Social life. Clark has an active social life in the community with a variety of friends and social activities. His most significant relationship is with his girlfriend, Lois. Lois is twelve years older than Clark. She also has DS and she lives independently in a condominium in a neighboring suburb. At age 51, Lois is experiencing some significant cognitive decline with memory loss and confusion, forcing her to stop working at her long-time job with a local grocery store. She and Clark have been dating for over ten 
years. In prior years, the two enjoyed going out to movies, attending local picnics and dances, and visiting amusement parks. Recently, they have settled into a routine of seeing each other each Friday afternoon and evening. After completing his shift at the university, Clark takes two public buses directly from work to visit Lois. She prepares a dinner and the two enjoy talking, laughing, eating together, watching TV, and being intimate. He leaves her apartment for the bus at 7:20pm and arrives home to his parents' house before 8:30. Clark reports that they had some sleepovers when he lived in his own apartment, but they have stopped this practice since he moved back home, as he does not think his parents would approve.

In addition to his romantic relationship, Clark has several close friendships. His friend Bruce is an older adult without disabilities. Nearly seven years ago, the two met in the community and became fast friends. Now, they meet at least once a week for meals or community outings and communicate daily with phone calls and text messages. When Bruce travels internationally, they speak two to three times per week via Facetime. Clark is also a member of a group of men who became friends through a local DS adult education group. This group of young men meet weekly for class, as well as regular social outings such as birthday parties and movies.

Educational history. Clark was primarily educated in self-contained classroom settings with other students with significant disabilities. His mother, Martha, recalled that this placement decision was due primarily to his behavior. She reports that, starting early in elementary school, he was disruptive in the large inclusive classroom setting and benefited from small, structured classrooms with low student to teacher ratios. He switched junior high schools midway through seventh grade. His parents report that his 
relationship with the teacher was poor, and he needed a more warm and flexible environment. A review of report cards from this time revealed low grades in the fall of seventh grade and mostly negative teacher comments focused on deficits. After transferring to a new school, report cards from the spring of seventh grade had high marks and many positive comments, such as "Doing a great job. Good participation. Super student!' In high school, he took functional academic classes within the special education department as well as general education elective coursework in sculpture, choir, and broadcast production. Teacher comments from high school were positive with statements on his report cards such as, "Positive attitude toward classwork. Cooperative student. Pleasure to have in class." After high school, he attended two-years of transition programming through his public school district in which he learned life skills and received prevocational training.

Case 4. Anita is a 31-year-old Hispanic woman with DS living independently in a suburban condominium. Her parents, Juanita and Poncho, live a few miles away in her childhood home. Her older brother lives in Europe with his wife. Anita has lived on her own for ten years in a variety of apartments. Her parents purchased her current home by supplying the down payment. Anita pays for her monthly mortgage, home owner's association (HOA), and all living expenses using combined funds from her part-time job and social security income benefits. She is responsible for all daily living tasks, including cleaning, cooking, and self-care. She receives supports from a publicly funded personal assistant, Susan, for shopping, paying bills, and completing weekly chores. Susan has been Anita's personal assistant for over nine years. 
I observed Anita and Susan on a typical weekday after work. After picking Anita up from work, Susan drove them to a grocery store and then home where they completed their weekly deep cleaning of the apartment:

Anita walks out of the middle school where she works to meet us in the parking lot. Her petite four-foot-six-inch frame is loaded down with a purse and a heavy cloth bag carrying a work uniform and shoes. Her zip-up hooded sweatshirt sparkles on the back with the local football team's logo. She wears stretchy, black yoga pants, a navy blue ribbed tank top, and sporty sandals over socks. Her chin length dark brown hair is pushed away from her forehead by a pair of oversized tortoiseshell sunglasses with gold embellishments at the corners. She has a broad smile, dark brown eyes, and tan skin. She sees us waiting in the parking lot and cheerfully exclaims, "It's a beautiful day for World Down Syndrome Day!”

I follow in my car as Susan drives Anita to the grocery store near her apartment. We park and slowly navigate the busy parking lot on foot. Anita slings her purse over her shoulder while Susan carries several reusable grocery bags. Susan asks, "Anita, you checking for traffic?" She replies, "Yep. I was wondering if you were, Susan?” The two giggle together as they enter the store and retrieve a shopping cart. While shopping, Susan provides frequent prompts asking if she needs specific food items or toiletries.

At the check-out lines, they look around for a favorite cashier. Another employee sees them looking and calls out, "He's here! Look in number 11!" As they walk toward the line, a middle-aged man working register 11 shouts, "Well it's about time you got in here!" He smiles broadly at Anita and the two banter back and forth about her mother's health and the weather. She tells him that it is World Down Syndrome day, and he thanks 
her for telling him. They high five and give each other fist bumps. He says, “Anita, I'll see you next week!”

After shopping, we head to Anita's apartment. She lives in a row of tan, two-story units surrounded by parking spaces. The condo has an open floor plan with living areas on the main floor. A single, small, black leather chair sits facing a large TV next to a fireplace. A soft, overstuffed couch sits against the wall flanked by tables. In the center of the room, a dining table is pushed against the wall surrounded by chairs and a small exercise bike. A station for contact lenses is set up with a large magnifying light-up mirror, a tray with bottles of contact solution, and multiple small, plastic contact lens cases. Kitchen counters are cluttered with dishes, spices, papers and appliances such as a high-tech coffee machine, blender, toaster, and microwave.

Susan and Anita head upstairs to clean the bedroom and bathroom. She tells me, "I'm a pink girl! You gotta know that about me!" Her bedroom has high, vaulted ceilings. Pale pink letters spell out her name on a hot pink wall. Pink sheer curtains hang from the windows filling the room with a soft pink glow. A hot pink dresser sits against one wall, covered in jewelry boxes and a hanging display of necklaces. Another shelf hosts several framed photos of Anita dressed in gowns at local dance parties. A Continuous Positive Airway Pressure (CPAP) machine sits on the side table next to her bed with several jugs of distilled water below.

Anita turns on the stereo and loud salsa music fills the room. She begins to shake her hips, walking toward the bathroom, smiling as she watches herself in the mirror. She dances into the bathroom and removes a red apron from under the sink, tying it around her waist, shimmying and shaking to the beat. She puts on a pair of small latex gloves 
and begins to scrub the toilet with a brush, singing along to the Spanish lyrics and swaying as she cleans.

When Anita is done in the bathroom, Susan joins her in the bedroom, dancing along while they change her sheets. They work together to pull off the quilt and strip the bed. They comment on how much they both enjoy the music playing. It is a CD that Susan purchased for Anita while on vacation in the Dominican Republic. Anita loves the music and already knows some of the words to the songs. They explain to me that there are several albums they enjoy playing while they clean, including gospel music that reflects their shared Christian faith. - Field Notes, 3/21/18.

Anita has a close, familiar, and warm relationship with her personal assistant. The two work easily together to help her maintain a clean and pleasant personal space that reflects her preferences. She uses her love of dance and music to help make daily chores more enjoyable.

Employment. Anita has worked in the same job for 10 years. She is an assistant in the cafeteria at the public middle school she attended in childhood and is responsible for preparing meats and cheeses on platters for sandwiches, wrapping cookies, washing dishes, putting dishes away, sanitizing tables, serving breakfasts to classrooms each morning, and fulfilling a variety of needs as they arise each day. She works five days a week for four-hour shifts and gets off immediately before the cafeteria serves lunch to students. Anita finds her work to be rewarding and meaningful. She gets along well with her coworkers in a supportive and warm work environment. Her supervisors provide detailed checklists of job duties for all employees. The team eats lunch together chatting 
about their personal lives each day while on break, and regularly celebrates birthdays together.

Social. Anita's parents describe her as a quiet young woman with a limited social life. However, she is engaged in several structured social events where she regularly connects with friends and meets new acquaintances. Once a week, Susan and another client pick up Anita from work for a social outing. The three women frequently go bowling, out for coffee, or have lunch together at a restaurant. She also attends a Christian church each week with a long-term friend she met at a local DS event in childhood. The church has a focus on fellowship, and Anita enjoys socializing with her faith community. She also is a member of the local therapeutic recreation adaptive sports program. Through this program, she participates in bowling, softball, swimming, Zumba, and any other recreational offerings. A core group of young adults with disabilities attend many of these events and she has developed some long-term friendships with other members. I observed Anita at a swim team practice for special Olympics at her local recreation center pool:

Anita and five other women with a variety of disabilities hop into a swim lane. After a brief talk from the coach, the swimmers set out into the water. Anita pulls on a swim cap and a pair of goggles and pushes off the side of the pool with a backstroke. When she gets to the far wall, she stops briefly, and then turns around to return to the coach, gazing upward at the ceiling as she swims. Her coach sits crossed legged on the side of the pool and shouts, "Looking good Anita!" She is watching each swimmer's movement and shouting out encouragement. Several adolescent volunteers join the team 
in the water, swimming behind tentative members, providing support as needed. Anita doesn't need the support; she swims independently.

The parents fill a small set of metal bleachers on the side of the pool, chatting and watching one mother's videos of her daughter's cheerleading team who recently competed in a national tournament. They laugh and joke about their own children's swimming styles and remark on each team member's growth in specific strokes this season. The parents are familiar and comfortable with each other; their children have participated in sports together for decades.

After 45 minutes of swimming, the coach announces, “OK, so we've done all four strokes. It's time for a medley!” Anita grins. When it's her turn, the coach prompts her, "Okay Anita, go!" She hesitates a moment and the coach reiterates, "Go!" She pushes off from the side of the pool into a butterfly stroke. She pops up and out of the water with each push, swinging her arms out and up over her head, kicking like a dolphin. At the end of the lane, she moves into a backstroke and returns to the coach, her toes pointed and her arms flapping up and over. She pauses briefly at the wall and her coach shouts, "Go Anita go! Go, go go, go! Breaststroke! Go!" She calmly pushes away from the wall into a breaststroke, her arms pushing water away from her midline, her legs kicking like a frog, and her head bobbing in and out of the water. She returns on the final lap in free style, gracefully cutting through the water and coming up for a breath every four strokes. After their first pass of medleys, the coach shouts at the team, "Ladies, are we supposed to stop in the middle? No! Can you do this? Oh yeah!” They complete 2 more medleys, ending with loud cheers from the coach and the volunteer helpers. Anita removes her goggles and props her arms up on the side of the pool, hanging her head back and breathing 
heavily. The coach encourages the swimmers to lower their heart rates with a cool down lap. She chooses a breast stroke, moving slowly through the water to finish her lesson. She is the last remaining team member in the pool at the end of the hour. - Field Notes, $3 / 12 / 18$.

Anita has been swimming since age four, when she started taking lessons at a local fitness center. She completed all seven levels of swimming lessons and then participated on a swim team with daily practices each summer for most of her childhood. In middle and high school she swam with her general education peers on the school swim teams. In adulthood she swims for the local Special Olympics team every spring. Swimming provides Anita with opportunities to exercise, socialize, and achieve personal goals.

Educational history. Anita was educated entirely in inclusive school settings from elementary school through high school. She received small group special education services for study skills, math, and reading comprehension. Study skill classes were particularly helpful in middle and high school, where teachers helped to modify her assignments, support her organization of work, and allow her extra time to complete written work. She also received weekly supports from a speech language therapist throughout her education to support deficits in articulation and language. She graduated from high school with honors and received many accolades from teachers. For example, her English teacher wrote a letter of recommendation stating, "[Anita] is the example of what is possible by every student that passes through the halls of high schools in this country because she will never cheat herself out of excellence or experiences that she believes are her right." Her parents note that this inclusive educational history provided 
Anita with background knowledge required for living in an inclusive setting in adulthood. For example, she can discuss current events because she has been exposed to world and U.S. history courses. However, they also admit that attending classes purely in the general education setting limited her ability to connect socially with classmates. After high school, Anita attended a two-year transition program in which she received prevocational and life skills training with other students with disabilities.

After exiting the public school system at age twenty, she attended a two-year certificate program at a university in a neighboring state. The program was specifically designed to provide occupational training for students with developmental disabilities. She lived in a dorm on campus and was responsible for getting herself to her classes and completing all self-care and health related tasks. She graduated with a certificate in food services, where she learned a variety of skills in food preparation, hygiene, and kitchen safety. This training was instrumental in obtaining her current job in a school cafeteria.

\section{Cross-Case Analysis}

An analysis across each of the four cases revealed seven key themes related to thriving with DS: a) a supportive social ecology, b) creating family, c) high expectations for independence, d) vulnerability in adulthood, e) advocacy, f) a focus on physical health, and g) limited utility for traditional assessments.

A supportive social ecology. Each of the thriving young adults in this study benefit from a supportive social ecology including close and caring immediate relatives, community connections, and publicly funded agencies.

Close and caring immediate relatives. Each participant in this study is surrounded by a close-knit family of parents and siblings. Participants rely on their families for 
emotional encouragement, financial support, access into the community, and help developing skills in adulthood. For Hal, the youngest of the four participants, his relationship with his parents is still highly dependent. His sister, Saoirse described her mother's role in her brother's life, "Mama the driver, mama the chef, mama the schedule planner, mama the secretary." However, the older three participants, Angel, Clark, and Anita, are more independent from their parents. Angel described her current relationship with her mother:

Well, I know her since I was a baby... Anytime she sees me growing she says, "I wanna put a block on your head." Keep me from growing. [giggle] We do a lot of stuff together. She's always there for me when I need help. And sometimes she's like, "You can do it yourself. It's okay." For each of the participants, parent support is evolving as they age and relationships are becoming less dependent and more reciprocal.

In many ways, the three older participants, Angel, Clark, and Anita, are financially independent from their parents for major daily living expenses. Although Clark and Anita's parents both supplied the down payments for their apartments, both pay their own monthly mortgages and groceries. Angel relies entirely on government assistance for her housing and her groceries; her mother is not involved in her finances at all at this life stage. However, all four participants rely heavily on their parents for extraneous purchases that they cannot cover themselves. Clark described this relationship with his parents: "We go out for dinner. Movies. 'Buy something for your son. Please buy something for me!' I tell my mom that. 'Buy a movie. Mom buy me frosty. Mom. Mom!' [She says,] 'Ok, Ok!'” Thus, while the bulk of financial support is transferred to 
public funding and personal income in adulthood, limited government subsidies and low earning potential lead to a reliance on parents for spending money.

Each of the parents reported that relationships with their children are mutually enjoyable; participants in this study provide their parents with joy and purpose. FMSSs for each of the parents were coded as positive or neutral for the quality of their relationships. These warm and reciprocal emotional climates in the immediate family appear to support the role of a healthy transactional microsystem presented in the TET-M (see Manuscript 1). For example, Angel's mother enjoys helping her host holiday parties in her apartment. Hal's father loves to build large and complicated Lego creations with his son. Clark's mother enjoys their tradition of going out for Chinese food when her husband travels for work. Anita's mother described the enjoyable morning routine of driving her daughter from her condo to the school where she works:

We take her to work every morning and that's our fun time. Whoever gets to take her, we trade off, and she's always in a good mood in the morning. She's just a joy. It's just fun to be around her. I don't think she is ever at a loss for topics to talk about. Like I said, it's fun when it's our turn, we look forward to it, we don't say, "Oh, I got to take Anita this morning." These dynamic, warm and supportive relationships with parents persist well into adulthood for all four participants.

Siblings for all four participants are a source of joy as well as a mechanism for participation in the community. The adult sisters and brothers of each participant were observed to facilitate meaningful life experiences through outings and family events, such as vacations, birthday parties, the births of nieces and nephews, and holiday celebrations. 
Angel and Hal both enjoy eating out at restaurants and seeing movies with their siblings. Anita's family travels to see her brother who lives in a different country and described these trips as a highlight of her life. Clark's mother reported that his older brother had recently volunteered to care for Clark if and when his parents were no longer able. For young adults who are unable to drive and have a limited income, adult siblings can provide transportation, enjoyable company for safe social inclusion, and supervision as needed.

Community connections. Inclusive and organized programming in the community provides opportunities for each participant to connect with peers outside of their families. For Hal, a variety of real-world venues such as Lions Club, Toastmasters International, his church men's group, and BSA provide natural settings where he makes friends and builds life skills. Anita benefits from a local therapeutic recreation program within the public parks, where she connects with friends through sports and social functions multiple days a week. Angel sees her best friend from childhood each day at her local day program, where they chat over lunch or catch up in the coat room before class. Clark participates in a weekly life skills class for young adults with DS which has provided him with a long-term group of young male friends with whom he regularly socializes in the community. For each participant, friendships are sustained through regular meetings with peers in a structured and encouraging exosystem.

Publicly funded supports. A supportive macrosystem provides a number of critical government funded resources for all four participants. These supports include healthcare through Medicaid, monthly Social Security Income (SSI) checks, and a Medicaid waiver program which provides funding for respite care providers, personal 
assistants, subsidized public transportation services, supervised day programming, and supported employment (job coaches). The young adults all access these resources, tapping into as many supports as available. Hal's mother described her desire to maximize support services:

They're using the same money for respite care that they use to pay the job coach. So, I have to choose. Do I want an hour off while somebody else takes him to the movies? Or, do I want a job coach to follow him for a half day of work? I choose it all. I choose everything. I am trying to do everything for Hal. Because there is no way one of them isn't important. These publicly funded supports are invaluable to the developmental growth of these young adults as they aim to function independently in the community.

Creating family. The participants in this study are at various stages of creating their own families in adulthood through intimacy and generativity.

Intimacy. A common developmental experience for young adults is the shift away from parents as the primary relationship and toward close and intimate partnerships (Erikson, 1950). The young adults with DS in this study are experiencing a variety of intimate relationships. At age 21, Hal desires a girlfriend but has never dated. Starting in college, Anita had a six-year relationship with a boyfriend who she planned to marry; however, after a rough breakup due to vast differences in independent living skills she prefers to be single at this point in her life. Both Angel and Clark are currently in longterm relationships. Clark and his girlfriend, Lois, plan to be married someday. Clark has a ring he is saving to present to Lois for a proposal and is working hard to save money for a wedding. In contrast, Angel and her boyfriend, Ike, have committed to each other with 
promise rings but do not plan to get married. Ike explained their connection despite a formal marriage:

We're married in our hearts forever. Don't you ever forget that. She's married in my heart. I'm married in hers. We just wanna connect. You know. So, yeah, I live a great life with her. And she with me.

Both Angel and Clark's connections with their long-term partners are a primary source of joy, purpose, and emotional support at this stage in their lives.

Generativity. Generativity refers to the act of establishing and guiding the next generation, frequently by creating a family with one's own children (Erikson, 1950). Although reproduction is physically possible for some individuals with DS, it is a quite rare phenomenon (Bovicelli et al., 1982). The participants in this study are experiencing generativity in several ways.

Hal expressed a strong desire to have a daughter in the near future who he plans to take for walks, change diapers, and give baths. When his sister asked what he would do if he had a boy, Hal responded with:

I don't know what's a boy! [disgusted face] I don't know. Baby girl. Yeah. It's better girl. It be younger for me. Its name is Ana Beth. Her just a super star. A angel [he grins and closes his eyes]. Yes, a cutie angel. It's like, 'ahhhhhhh!' [makes sing-song angel sound].

Although Hal is nowhere near the point of partnership and raising a child, the idea of having a baby girl brings him joy and purpose. He speaks of his desire to earn enough money for a car and an apartment where he can, someday, live with his future wife and baby. On the other hand, Anita does not currently have a desire to have children of her 
own, although she and her ex-boyfriend had planned for parenthood when they were together. Rather, she currently speaks about generativity in creating a new family through her church: "Believe it or not, we are a huge family. A huge church family. In God's Kingdom.”

Angel and Clark have adult siblings with children of their own who they are helping to raise in a peripheral way. Both participants included photographs of their nieces and nephews in the photo elicitation interviews and described an immense sense of pleasure and connection as they help to nurture these young family members. Clark described the birth of his niece as a moving and meaningful experience: "She born Christmas Day. She smiled at me, 'cause she a tiny baby. Make me tears on my face." Angel described her relationship with her niece: "She always make me laugh. I change her diaper. Stuff like that. She needs some help. She'll say, [in a small, high-pitched voice] 'Help!'” These nieces and nephews provide them with immense pleasure and also a chance to nurture by helping with childcare duties.

Additionally, Angel and her boyfriend, Ike, consider themselves to be a family and are raising "pretend children" together. Their "pretend children" are baby dolls that they have purchased or received as gifts. Ike described their babies:

We pretend that her baby is one of the baby dolls. Or she's a girl that's pregnant. Since we don't have babies for real, we just pretend that we have. Angel does the voice of the baby dolls. So, she's a role player for fun. It's like our own story pretty much.

Angel and Ike are "creating their own story," experiencing the joys of adulthood through the developmental stages of intimacy and generativity. When asked what she likes best 
about her baby dolls, she replied, "I feel like I'm a real mama to them." Her experience of being a "real mama" facilitates happiness and meaning in her life.

High expectations for independence. Hal's father Robert stated, "We kind of have a philosophy of we don't know what he's incapable of, so we keep on pushing him to see what he can do." The families in this study all have high expectations for their adult children's independence including key factors such as moving out, transportation, and employment as contribution.

Moving out. Independent living is a major consideration for all of the young adults in this study. Angel's mother described the benefit of her living alone as, "the ownership of her activities of her life." For Hal, at age 21, moving out of his parent's home is a long-term goal. His desire to live in his own apartment is not yet accompanied by adequate adaptive skills for independent living (see Table 5). For now, he has his own space in his parents' home to which he retreats for privacy. Clark is anxiously waiting for the day he will move back into his own apartment, where he looks forward to cooking meals of his choice, having quiet time to read and pray, and watching his favorite TV shows uninterrupted by family.

Angel and Anita both live alone and are responsible for all of their own self-care and domestic tasks. A review of educational records indicates that both have made tremendous growth in daily living skills since the end of high school, specifically in the areas of personal care and domestic skills (see Table 5). Both receive support from their personal assistants for chores, such as grocery shopping, budgeting, and paying bills. Anita also receives weekly help with cleaning her apartment while Angel completes cleaning tasks on her own. Angel receives help from staff with taking daily medications, 
while Anita is independent in her daily medications. Both women are responsible for all of their own laundry.

Each woman learned skills for independent living through structured support programing. Anita learned skills in college where she was required to prepare herself for class, make sure she had a clean uniform each day, and use public transportation to her work study job. University staff provided direct instruction and supervision in this skill development. Angel developed most of her domestic and self-care skills after moving away from home, while living in host-home and group home settings. Care providers and live-in staff modeled and supported daily living skills until Angel was self-sufficient enough to warrant living in her own apartment.

Public transportation. The participants in this study use public transportation to facilitate their independence in the community. For Anita and Angel this involves using a curbside bus service for individuals with disabilities to bring them directly from their homes to their daily destinations. While chronic unpredictability in exact drop-off times forced Anita's parents to start driving her to work each day to ensure she is on time, she continues to take the bus home when the timing is not as critical. Hal and Clark both use the traditional fixed-route transportation system of buses and light rail trains. Hal received formal training for independent transportation from a local nonprofit agency working with his college program. Transportation trainers provided direct instruction with a slow fading of supports until he was entirely independent in the process. Years later, they completed a retraining for navigating to his new employment location on the military base, which involves taking a train downtown where he transfers to a city bus that drives him onto the base. Clark takes a variety of city buses to work, his girlfriend's 
apartment, and to social events around the community. He deftly navigates the city's public transportation application on his smartphone and frequently transfers between multiple buses while on route to his destinations. His mother attributes his comfort with public transportation to his first real job in young adulthood which required him to transfer between three buses. Although this was cumbersome at the time, she believes it helped him solidify his skills and his confidence.

Employment as contribution. For the young adults with DS in this study, meaningful work is a way to contribute to their community. The participants have a range of employment statuses. Angel is currently unemployed although she would like to work with young children in a preschool or daycare setting and hopes to graduate from her vocational training program in the near future. Hal, Clark, and Anita all work part-time in the community. Field observations revealed some key supports in the work setting that facilitate success. Publicly funded job coaches are one such support used by Clark and Hal. These employment specialists helped each young man obtain their jobs by assisting with applications and interviewing. Further, they support employers with training and by addressing any work issues that arise over time, acting as a liaison between the individual, the family, and supervisors. Both Hal and Clark have solid work skills; however, behavioral concerns such as off-task behavior or inappropriate conversations with colleagues have caused supervisors to be concerned in the past. Their job coaches have helped to create task-lists, retrain in how to take timely breaks, and review proper coworker conversation topics.

Anita no longer uses a job coach as she has worked in the same school cafeteria for ten years. She explained her joy with her job, "I never thought I'd get such a great job 
right out of college!" Similar to Hal and Clark, she uses a task list with explicit instructions for what to do if she finishes all of her daily tasks before her shift is finished. Her supervisor describes her as a wiling and helpful employee who enjoys feeling useful: If you make her feel important, she does things a lot quicker and nicer... All around, she's just so happy and so nice to work with. She's willing to help out anywhere. That is a really great strength, especially in the areas we work in and how we do things. She's willing to help out with breakfast. She's willing to do anything any of the girls ask her to do if I'm not there. Helpful and productive behavior executed in a work setting allows these young adults an opportunity to contribute their strengths to their community and feel a pride of accomplishment.

Vulnerability in adulthood. Although these young adults are developing skills for independence, they present with a persistent vulnerability well into adulthood. This requires families to have the courage to risk and develop safety strategies.

Courage to risk. The parents in this study all expressed the need for courage to allow their children to move toward an independent life. Clark's mother, Martha, reported:

There is a lot of fear with parents. But once Clark could do something, then I felt more comfortable. I think you have to do that. You have to allow them to take on the freedom, so that they can feel successful and then you feel confident with [them] getting out. 
Hal's mother described this parenting process with regards to her son's use of public transportation and his tendency to talk to strangers. Hal's open and receptive attitude is accompanied by a social vulnerability that concerns his family. His mother reported:

So very scary, but I figure that's courage to risk. You have to be, in a way, putting yourself out there. He has to learn street smarts. If I don't ever let him do it, he won't ever learn it.

True inclusion in the community requires some risk from families to allow for skill development and ultimate independence.

Safety strategies. Strategies to ensure safety were evident in each of the four cases for this study. Tactics ranged from low-tech options, such as Angel's consistent use of a safety chain on the locked door of her apartment, to Anita's tech-savvy applications on her phone. Specifically, Anita's parents have equipped her apartment with a doorbell video camera connected to a web-based application accessed by both Anita and her parents on their smart phones. They are able to see anyone who approaches her door or rings her doorbell. Further, she and her parents track each other's geographic location with an application on their smart phones that alerts them each time someone in the family leaves their respective home or is in transit. Hal's family has adopted a service dog to act as a companion while in public. Additionally, Hal's mother drives him to the light rail station each morning and observes him with binoculars from the top level of the parking structure to ensure he boards the correct train. His transit support trainers have instructed him to text his mother as soon as he sits down on the train, to sit in the front car near the driver, and to avoid speaking with strangers. As the eldest of the participants, Clark has developed his own personal strategies for maintaining his safety while in transit 
in the community. While crossing streets, Clark purposefully chooses intersections with pedestrian walkways. Knowing his rights as a pedestrian, he bravely holds out his hand to stop traffic and marches across the road when needed. Like Hal, he has been taught to avoid speaking with strangers on public transportation: "My heart tells me I can't talk to strangers. [My girlfriend] said that. And my class.”

Advocacy. Examples of advocacy are present in all four of the cases in this study, including pioneering parents who consistently discover and try new methods and programs for their children, and the fostering of self-advocacy to help participants continue this legacy for themselves.

Pioneering parents. The parents in this study are pioneers for their children. They do not wait for instruction or follow the first service plans outlined by providers. Rather, they initiate the care and services they want for their children through relentless advocacy; paving a path forward. Angel's mother pushed for her to be included in every afterschool program and summer camp that her siblings attended. Clark's family switched him to a new junior high school when they believed his teacher was not providing the flexibility he required as a student. Hal's parents pressed for him to attend a new, inclusive post-secondary program for students with disabilities rather than the selfcontained transition program offered by the school district. Anita's parents demanded she be educated in an entirely inclusive setting and shut down a meeting when the school team suggested a more restricted learning environment:

They called us in for a meeting with the principal from [another] middle school where all the special needs kids went. They called us in to meet the principal, and the vice principal, and the special needs teacher. But they 
didn't tell us what the meeting was about. We go in and when I found out what it was about, I said, "You know what? You might as well leave because she's staying here." So, they did.

This parent advocacy is driven, primarily, by their adamant belief that their children are capable and that they deserve a fair and equitable life. As parents, they refuse to adhere to prescribed limitations based on the diagnosis of DS and prefer to continue to push for growth and achievement.

Fostering self-advocacy. In addition to parent advocacy, the young adults with DS in this study are building their own capacity through self-advocacy. For example, Angel's day program taught self-advocacy skills by encouraging students to speak up and remove themselves from peers who may be a bad influence. Angel put these skills into practice later that day by assertively ensuring that her personal assistant would not smoke in front of her. I observed Clark as he boldly insisted his employer supply the correct sized gloves for him to wear as he cleaned the bathrooms in the restaurant. In my observation of Anita on March $21^{\text {st }}$, she alerted several people in the community about the significance of the day by brightly announcing that it was World Down Syndrome Day. In high school, Hal's parents helped him create notecards with key information about his strengths and educational needs to read aloud at the beginning of his own IEP meetings. Thus, the young adults in this study are learning to communicate their needs and to tell their story. Hal wrote a recent blog post on the subject: "I am learning how to Learn and Self Advocacy, that's a big word. I learn how to talk about disabilities. My disability is Down syndrome. I learn to talk for myself." 
A focus on physical health. In all four cases, there is a strong focus on physical health, including prioritizing weight loss and exercising for connection, achievement, and joy.

Prioritizing weight loss. Each of the four young adults in this study are actively working to lose weight or stay fit. In interviews, participants and their families spoke frequently about healthy eating choices and monitoring weight gain to avoid obesity commonly associated with the DS phenotype. Hal enjoys eating with his family; many of his photographs for this study were of healthy food being prepared by his parents. His mother fears weight gain and limits his intake of junk food. The older three participants are more self-aware and self-monitor their habits. Angel struggles to avoid overeating and those in her microsystem help her to make good choices. Her sister, Gretchen reported:

Eating is a big challenge for Angel. I mean being able to understand the thing of not over eating. Angel is one of those people who you could give her the biggest jar of peanut butter that you can buy in the grocery store and she would literally sit there and eat the whole thing in a day. No problem. She would eat and not be able to really hold herself back from doing that.

Angel's family, personal assistants in her apartment complex, and her boyfriend all support her healthy food choices by taking her grocery shopping for better options, cooking healthy meals together, and encouraging self-restraint when it comes to treats. Anita uses an application on her phone to monitor her daily eating habits which she reviews monthly with a nutritionist to help meet her weight loss goals. She stated, "Well, 
I'm trying to lose weight. But it's been kind of a roller coaster ride. You gotta have a really good diet. Basically, it's a lot of fruits and vegetables and a lot of good meat." Clark researches and takes photographs of healthy recipes that he looks forward to cooking when he moves back into his own apartment. He described his goals for healthy food choices:

Eat good meals. Not grain. Vegetable fruit. That's it. What I have today? I have a wrap and chips. Chips, I have to skip it. I have fruit. Not other stuff. Not grain. A little bit meat. Yes. Very important about vegetable and fruit.

Thus, a focus on maintaining a healthy weight through healthy eating is a persistent focus for these thriving young adults with DS.

Exercise for connection, achievement, and joy. The participants in this study are physically active with regular exercise. In addition to promoting health, the exercise also provides social and emotional benefits. Angel's favorite service provider is her physical therapist. Although their sessions are focused on strength building to address an injured hip, they also enjoy talking about Angel's life goals and laughing together. Hal's most meaningful classes in college were inclusive taekwondo courses where he felt immense pride from earning belts to mark his physical growth and achievement. Clark participated in swimming for many years through the Special Olympics, earning medals for his skills and building friendships on his swim team. He currently engages in weekly exercise with his personal assistant through hikes in the mountains and by playing football in the park near his parents' home. Anita is the most physically active of all the participants. She participates in sports every season, is a junior cheerleader for the local professional 
football team, and does weekly weight training and cardio workouts (e.g., Zumba) between seasons. Further, she regularly attends parties where she dances for hours on the dancefloor. Her mother, Juanita, described her ability to get lost in the moment while dancing:

The DJ keeps it going all night long, man. It never quits. Last time, she was out there dancing two hours before she even sat down. She just loved all the songs and she practices all the time with her dance [video] games [at home]. She knows all the moves and she's just out there.

Physical movement and exercise provide pleasure, achievement, and social connections with peers and support staff.

Limited Utility in Traditional Assessments. For each of the four participants in this study, traditional standardized assessments are limited in utility. Two major findings emerged from assessments in this study: participants all have a profile of normative deficits and character strengths facilitate SWB.

A profile of normative deficits. All four of the young adult participants in this study self-identify as thriving in life. Nevertheless, they all demonstrate a shared profile of normative deficits on standardized assessments measures. Table 5 indicates that all four participants score two or more standard deviations below the mean for both general cognitive abilities and adaptive skills. Further, while Anita has a wide range of academic abilities, such as math skills at the second grade level, spelling skills at the fourth grade level, and basic decoding skills at the tenth grade level, the other three participants all possess basic academic achievement skills at or below the second grade level (See Table 5). Communication scores for all four participants are also compromised. While Angel 
and Anita possess higher communication skills than would be predicted by cognitive abilities (see Table 5), they still demonstrate lower skills than similar aged peers. Hal and Clark performed similarly on communication assessments to their performance on cognitive measures, scoring well below the first percentile (see Table 5). In all, standardized measures indicate a profile of normative weaknesses in psychoeducational functioning for all four participants, despite their status of thriving in life.

The parents interviewed in this study all described a futility in using standardized measures to understand their children. Anita's mother, Juanita, explained her reaction to hearing about these deficits from school psychologists throughout her daughter's education:

We used to go to the IEP meetings when she was in grade school and they'd go, "Well, she only did in the $17^{\text {th }}$ percentile of this and the $25^{\text {th }}$ percentile of this." I finally said, "You know what? I don't want to hear what she can't do anymore." I said, "I want you to tell me what she can do this time that she couldn't do last time." Because they used to depress the heck out of me.

Hal's mother, Lucky, described her frustration with culturally biased assessments that were unable to accurately capture her son's knowledge:

Child Find would give him a test, and they would show him a comb and he didn't know what a comb was. If you have African American hair, maybe you don't use a comb, you use a pic. So, whatever they showed him, he had no clue what it was. We had been struggling to increase vocabulary and learn sign language, and Child Find is going to ding him 
for not knowing what a comb is! But they didn't ask him, "What is a printer? What is a computer?" 'Cause that was his world. They didn't ask him "What is that?"

Thus, while standardized assessments are a primary source of data used in educational planning, for students with DS results may be limited to capturing normative weaknesses. The standardized nature of many assessments fails to allow for variability in culture or experience and to accurately measure growth and development.

Strengths facilitate subjective well-being. Strengths-based assessment (SBA) in this study revealed more useful and meaningful results than traditional assessments, including the ways in which exercising personal assets contributes to SWB. An analysis of top self-reported strengths (see Table 5), triangulated by interviews, field observations, and a review of educational records indicates that all four participants share two common and influential assets: transcendence and zest.

Transcendence is generally defined as a connection to the wider world and a sense of meaning and purpose (Peterson \& Seligman, 2004). Transcendence strengths include spirituality, an appreciation of beauty and excellence, humor, and gratitude. All four participants in this study identify spirituality as a top character strength (see Table 5). Three of the participants (Hal, Clark, and Anita) attend church on a weekly basis with family or friends. Angel explained that she does not attend church but she prays regularly by speaking directly with God and with the spirits of family members who have died. Clark described the meaning of his spirituality:

I like church. I study. I listen. My mouth is shut. Because I listen what Father says about the Bible. And [we sing] the song "Blessed are your 
poor.” If I sing, I say a prayer. Say prayers first, silence for my heart. I

want to sing this song because how much I love this earth.

A spiritual practice, including attending a place of worship, meditation, reflection, speaking to spirits, and prayer, connects all four participants to others while providing meaning and guidance.

A strong appreciation for beauty and excellence, or a sense of awe (Peterson \& Seligman, 2004), is another character strength associated with transcendence. All four participants in this study self-identify with this strength and speak openly about their passion for their preferred music, musicians, movies, actors, activities, and settings. Angel illustrated the nature of this asset when she described her love of Elvis Presley's music. "It touch me. [She taps her chest.] He touch me in my heart." The participants in this study all have strong favorites with which they surround themselves in their personal living spaces. Angel's home is filled with posters and statues of Elvis. Hal's room hosts costumes for his favorite musical characters as well as several calendars where he makes plans for attending beloved musical productions with his family. Clark's bedroom has a shrine for superheroes he deems the most excellent. Anita's condo is filled with photos of herself dressed in beautiful gowns and tiaras she wears to dances. Filling their lives with items, music, events, and places they find most beautiful and excellent provides a reliable source of joy and ultimately enhances their well-being.

Humor is a sub-category of transcendence, in which an individual can see the light side of a situation and make others experience joy. Three of the four participants (Hal, Clark, and Anita) identify their humor as a notable asset. Although Angel does not self-identify humor as one of her top strengths, I observed her frequently joking and 
playing with friends and classmates. Further, she reports her favorite characteristic of several friends and family members is their ability to make her laugh. Clark's friend, Bruce, described the ways in which his humor contributes to their relationship: [Clark's] a comedian. He likes to make jokes. I keep all of his texts and stuff that he sends. He was having problems with his Xbox. He couldn't get the Xbox working, and he was mad at it. He said, "I think I'm going to take it outside and pee on it. That's supposed to make it work." I go, "Clark, you can't do that!" He goes, "I'm just pulling your leg!" Bruce saves his written communications with Clark because their humor brightens his life. Humor allows the participants in this study to connect with others and contribute to the lives of those in their systems of support.

In addition to transcendence strengths, all four participants possess an enthusiasm and excitement for life, a strength termed zest in the positive psychology literature (Peterson \& Seligman, 2004). Zest is one of the character strengths most frequently associated with life satisfaction (Park, Peterson, \& Seligman, 2004). Three of the four participants (Angel, Hal, and Clark) ranked zest in their top-five on a strengths survey, while Anita's responses placed zest as her sixth highest character strength (see Table 5). Further, self-report measures of SWB indicate above average levels of happiness and very high life satisfaction for all participants (see Table 5). I observed zest frequently as all four participants engaged in their daily lives with a marked eagerness and zeal. Hal's college professor, Katia described his zest:

This man is so happy. He is happy to be on the planet. He is happy to be with others. He is happy to take every single breath in his day, just an 
amazing person and uplifting and so much fun to be around. He tries so

hard to do whatever is required of him, and really goes above and beyond.

Hal's uplifting and magnetic personality, as with all of the participants in this study, facilitates his relationships and inclusion in the community.

\section{Discussion}

The four participants in this study are thriving with DS in adulthood. They have rich, complicated, and meaningful lives filled with joyful relationships and activity. As outlined in the TET-M (see Manuscript 1, Figure 1), a series of reciprocal and supportive systems facilitate high levels of SWB and a trajectory of continued personal development. Using a thriving framework for this study provided new insight as to what is possible for students with DS and the facilitators and barriers to positive outcomes. Implications for school psychology can be addressed by answering the three main research questions for this study: (1) How do individuals with DS and their families define thriving with DS? (2) What individual characteristics influence thriving? (3) What environmental factors influence thriving?

\section{How do Individuals with DS and Their Families Define Thriving with Down}

\section{Syndrome?}

In this study, individuals with DS and their families defined thriving as supported independence; joyful lives filled with both connection and autonomy. School psychologists can support this notion of thriving by holding high expectations for postgraduation independence with adequate supports for success. High educator expectations can inform appropriate educational goals and programming (Jorgenson \& Lambert, 2012). School psychologists can inform teachers about opportunities for students with DS 
to participate in post-secondary college opportunities, live independently in the community, and work in meaningful paid positions. This may help shift educator perceptions about the potential roles of those with DS in our community. Rather than assuming students will demonstrate lifelong dependency, educators may see their students as helpful and meaningful community contributors. Parents should be considered partners in the educational process and can provide advocacy and resources to support student development (Neece, Kraemer, \& Blacher, 2009). Fostering self-advocacy skills (Anderson \& Bigby, 2017) and directly teaching self-determination (Shogren, Palmer, Wehmeyer, Williams-Diehm, \& Little, 2012) can enhance student self-concept and encourage them to set personal goals for independence and to engage in purposeful behavior to achieve academic and post-school ambitions.

\section{What Individual Characteristics Influence Thriving?}

Findings from this study indicate several areas to target for specific individual skill development and assessment. While examples cited here are specific to the population of students with significant learning needs, such as those with DS, or other causes of ID, it is important to note that these suggestions are considered best practice for all students at different points in the developmental lifespan.

Contribution through work was a major source of SWB for these young adults. School psychologists can facilitate a successful transition process that prepares students for meaningful work in which they can make a genuine contribution to their community (Talapatra et al., 2017). Additionally, participants in this study all had a focus on physical health. School psychologists can encourage a healthy lifestyle, weight management, and exercise by partnering with nurses, coaches, occupational and physical therapists, and 
physical education teachers to provide universal and targeted supports for healthy eating choices and the many benefits of physical exercise (Savina, Garrity, Kenny, \& Doerr, 2016). Further, school psychologists should be aware that individuals with DS may seek out the very normative psychosocial developmental stages of intimacy and generativity as adults (Morales et al., 2015). Schools can prepare students by providing direct instruction in healthy relationship development and sexual health (Tice \& Hall, 2008). Finally, service providers should be aware of the persistent vulnerability experienced by some individuals with DS, even into adulthood. Practitioners can empathize with parent fears or reticence to allow for independence and can directly teach personal safety skills to address concerns about student welfare (Spivey \& Mechling, 2016).

Additionally, many individual characteristics that influence thriving for participants in this study were identified through the direct measurement of self-reported character strengths. School psychologists can focus on identifying character strengths for this student population to supplement more traditional batteries of standardized assessments (e.g., cognitive, adaptive, academic) that may produce limited data for educational decision-making. Cognitive accommodations such as simplified instructions and the use of concrete examples can be useful with this student population (Shogren et al., 2015). Strengths-based assessments for students with DS may aid in the development of educational plans that allow for the expression and development of strengths throughout the school day perhaps enhancing student SWB in the school setting (Proyer, Ruch, \& Buschor, 2013). Further, communicating strengths to a school-based support team may encourage a more hopeful picture of a student's educational future (Donavan \& Nickerson, 2007). 


\section{What Environmental Factors Influence Thriving?}

School psychologists can directly impact environmental factors that influence thriving for students with DS by using an ecological lens in their work with this population. Participants in this study had close and warm relationships with parents and siblings. Rather than focusing solely on individual strengths and needs, a systems-level assessment approach coupled with family focused interventions may enhance student relationships with immediate relatives and overall family well-being (Head \& Abbeduto, 2007). Additionally, participants in this study benefited from peer connections made through structured activities in the community. Connecting families with school-based or community programs that are designed for students with disabilities (e.g., therapeutic recreation programs) or that have inclusive and supportive policies for students with DS (e.g., scouting organizations, local churches) may help students build close and meaningful lifelong friendships (Siperstein, Glick, \& Parker, 2009). Finally, each participant in this study benefited significantly from publicly funded supports. School psychologists should be aware of local disability support agencies and work to connect families, provide relevant assessment data to help them qualify for services, and collaborate with case managers to ensure students are receiving adequate services across multiple settings (Rizzolo, Friedman, Lulinski-Norris, \& Braddock, 2013).

\section{Assumptions}

While assumptions are present in any research, a key assumption was present in this study. Criteria for determining a status of thriving was based on the definition of thriving from the TET-M: high levels of SWB coupled with a state of continued developmental growth (Manuscript 1, Figure 1). Purposeful recruitment and individual 
screenings were used to ensure participants demonstrated the phenomenon in question (Creswell, 2013; Stake, 2006). However, the screening process was inherently subjective and did not involve a pre-determined standardized assessment or checklist.

Determining the presence of DS is a simple and concrete process, easily proven with results from karyotype testing or by simply noting the presence of the physical features most commonly associated with the phenotype (Roizen, 2013). However, thriving is a more subjective term that can be more difficult to measure than the presence of DS. Few studies have used standardized measures of thriving with the population of individuals with DS and no validation studies to this date have proven the utility of such measures in this population (Weiss \& Riosa, 2015). Furthermore, the act of determining whether or not someone is thriving is fraught with power dynamics. Having strict quantitative cut-off scores for meeting the criteria of thriving may interfere with an authentic initial investigation of the phenomenon. This might narrow the scope of inquiry thereby ignoring critical information about the processes involved with thriving (Massey, Cameron, Oulette, \& Fine, 1998). Therefore, while participants were recruited for this study via referrals based on a clear set of indicators of thriving (SWB and developmental growth trajectory), the final determination of thriving status came from each participant and his or her family and was highly subjective in nature.

\section{Limitations}

There are some limitations to this study. First, there were a limited number of cases in this analysis. This small sample size allowed for an in-depth and rich description and analysis; however, it precludes the reader from generalizing data to all others with DS. While there was some diversity in terms of gender, socioeconomic status, race, 
and/or ethnicity, all four cases were from the same geographical region - one state in the mountain west region of the United States. Thriving is contextual and dependent on systems of care (Prilleltensky, 2012); therefore, an investigation limited to a single region is not able to compare and contrast the impact of certain systems on thriving for individuals with DS. Future research can extend this study by broadening the number of individuals studied and the areas in which they reside.

Furthermore, the subjectivity mentioned in the assumptions section above can also be considered a potential limitation to the study. Much of the data gathered came directly from the participants and the families (e.g., rating forms, interviews). This was intentional to bring the voices of those who thrive with DS directly into the scholarly discussion concerning their well-being (Roach et al., 2009). However, a history of persistent marginalization for individuals with ID (Dykens, 2006; Wehmeyer, 2013), as well as statistics regarding termination rates after a prenatal diagnosis of DS (Natoli et al., 2011), may have (intentionally or subconsciously) caused participants and their families to want to skim over challenges and highlight successes. After all, the DS advocacy community has put forth a concerted effort to change public perceptions of the disability and highlight progress (Global Down Syndrome Foundation, n.d.; GDS \& National Down Syndrome Congress, 2017). Further, self-reporting in research can result in social desirability bias, in which participants prefer to present themselves in a positive light regardless of the accuracy of their responses (Paulhus, 2002).

A number of methods were employed to triangulate data and represent each case as truthfully and comprehensively as possible, including direct observation through immersive field work and document review for a more objective perspective of 
educational history. Further, my status as an outsider allowed me insight without the personal subjectivities that can present for those living with DS. However, a key element of qualitative research is to understand a phenomenon from the perspective of those most impacted, including the subjective, multiple truths that can emerge from this type of inquiry (Creswell, 2013). Therefore, all self-reporting in this study was examined from multiple perspectives, using triangulation to expand, elucidate, and clarify the data. Ultimately the subjective self-reporting on thriving with DS was documented, analyzed, and represented in this study in order to share a perspective that has historically been sidelined in the DS literature and merits the attention of researchers and practitioners.

Finally, using a multiple case-study design with a cross-case analytic process allowed for the reporting of general findings on the phenomenon across a variety of contexts. However, in so doing, some of the detailed within-case categories and themes were not reported in the findings of this dissertation. While this was intentional to avoid redundancy and to follow recommendations from experts in the methodology (Stake, 2006; Yin, 2014), it can be considered a limitation of this study. Future publications could provide more explanation of within-case categories and themes for each case in addition to the cross-case findings presented in this dissertation.

\section{Future Directions}

This in-depth multiple case study revealed several topics worthy of further exploration to refine the TET-M as a conceptual framework and to further explore its utility with other student populations. For example, a large-scale quality of life survey based on the TET-M components of SWB and developmental growth (see Manuscript 1) could reveal rates of thriving in the national DS population. Similar to prior research 
examining levels of life satisfaction and self-concept (Skotko et al., 2011) this research could examine the associations between individual factors (e.g. character strengths, physical health) and environmental factors (e.g., warm relationships with parents, access to publicly funded supports) identified in this study and in prior research as possible correlates with positive post-school outcomes (e.g., meaningful employment, independent living). Further research is also warranted in the use of SBA for students with DS. An examination of how service providers perceive and plan for students with DS when presented with character strengths data in addition to traditional psychoeducational assessment data could inform the field of the utility of this practice for this student population. The specific character strengths of transcendence and zest were identified across all four cases in this small-scale study. A wider-scale probe into these particular character strengths for individuals with DS may improve our understanding of the DS character phenotype and help inform the creation of etiologically based interventions for the promotion of mental health and SWB. Finally, the use of qualitative research methods (e.g., photo elicitation and field observation) proved to be useful and novel methodological approaches to thriving research. The school psychology research community should consider approaching underexplored topics with this empowering approach in order to highlight the experiences, voices, and perspectives of historically disenfranchised student populations. 


\section{CONCLUSION}

Individuals with intellectual disabilities (ID) have historically been measured and conceptualized by their known deficits (Dykens, 2006). Diagnostic criteria outline the ways in which people with ID differ statistically from the general population (Schalock et al., 2010). Service delivery models have used a medical perspective focused on remediating pathology; removing the effects of the disabling condition (Dunn \& Andrews, 2015). Further, current research focuses on the fact that students with ID have fewer school experiences linked with positive post-school outcomes (e.g. employment during high school, participation in extracurricular activities) than any other student population (Lipscomb et al., 2017). Regardless, with advances in medical and educational interventions and improvements in quality of life through social inclusion, many individuals with ID are living longer, more meaningful and satisfying lives (Roizen, 2013; Skotko et al., 2011). Research must keep pace with progress in this population, documenting successes in order to better understand the supportive systems that facilitate positive outcomes.

This dissertation builds on existing positive psychology and disability studies literature to examine the construct of thriving for those with significant life-long disabilities. Manuscript One presents the TET-M, a newly proposed conceptual model for thriving with ID (See Manuscript 1, Figure 1). By synthesizing current psychological thriving models with relevant models in disability studies, the TET-M provides practicing 
school psychologists with a new framework for conceptualizing student cases and planning service delivery. Further, the TET-M provides the school psychology research community with a novel perspective on investigating topics in this student population. The TET-M encourages both practitioners and researchers to examine areas such as character strengths, subjective happiness, personal development, and contribution. This innovated approach to the population of students with ID encourages equity and social justice.

Manuscript Two applies this conceptual model to an empirical study examining the lives of four individuals thriving with Down syndrome (DS) in adulthood. Using innovating methods such as photo elicitation, field observation, and the self-reporting of character strengths, this study gives voice to a population that is typically left out of school psychology literature (Roach et al., 2009). Focusing on the well-being, developmental growth, and systems of support of these four young adults provides a unique insight as to what is possible for students with DS after they graduate school, and the reciprocal processes that occur in order for individuals with disabilities to thrive.

Cross-case thematic findings from this multiple case-study support existing literature as well as introduce new topics of inquiry regarding the well-being of individuals with DS. All four participants had supportive social ecologies, including close and caring immediate families, structured activities in the community, and a broad network of publicly funded supports. At the developmental stage of young to middle adulthood, all four participants were contemplating or actively creating their own families through intimate relationships with partners and the process of generativity with children or community. Parents had high expectations for independence for their adult children, as 
all four families aimed for independent living, navigation of public transportation, and employment as a way to contribute to their community. Despite relatively high levels of independence, all four families were concerned with a persistent vulnerability in adulthood requiring parents to have the courage to risk and to develop strategies to maintain safety. Advocacy was also present among all four cases, both in pioneering parents who were consistently seeking new and innovative services for their adult children as well as the development of self-advocacy strategies for the individuals with DS themselves. All four individuals with DS had a strong focus on physical health, including a priority on weight loss and the use of physical exercise for connection, achievement, and joy. Finally, the utility of standardized assessments was limited for all four participants, as they merely reported a profile of normative deficits, while character strength assessments provided useful data on SWB for these individuals.

The data reported in Manuscript Two supports the utility of the TET-M presented in Manuscript One in two major ways. First, using the TET-M as a conceptual framework encouraged ethical and meaningful research practices with individuals with ID. The focus on subjective emotional experiences, unique individual strengths, and personal growth trajectories supports the QOL concepts outlined as best practices in disability studies (Schalock \& Alonso, 2014). Second, the cross-case themes from Manuscript Two support some major tenants of the TET-M, including the critical importance of a supportive social ecology, the transactional nature between the thriving individual and his or her systems (both support and contribution), high expectations for growth, and the uniquely individual and personal nature of SWB for those with ID. Ultimately, the TET-M showed 
promise for future work in both research and service delivery for students with disabilities.

When combined, these manuscripts move the field of school psychology forward in our understanding of how to best support a student population that has historically been marginalized in our schools (Wehmeyer, 2013). Future researchers may utilize the TET-M to conceptualize the construct of thriving for other marginalized populations such as students with other rare genetic disorders, those experiencing homelessness, refugees, students in the foster system, transgender students, or those with social-emotional disorders. The TET-M's unique focus on subjective experiences of happiness and life satisfaction encourages our field to examine and honor the internal experiences of all students. Further, the model's emphasis on growth trajectories, rather than cut-point standardized scores, encourages a developmental perspective that is individualized and hopeful; focusing on personal progress rather than normative expectations. Every student deserves to thrive. This dissertation provides a framework for school psychologists to encourage thriving for all students, including those with the most significant educational needs. 


\section{REFERENCES: INTRODUCTION}

Lipscomb, S., Haimson, J., Liu, A.Y., Burghardt, J., Johnson, D.R., \& Thurlow, M.L. (2017). Preparing for life after high school: The characteristics and experiences of youth in special education. Findings from the National Longitudinal Transition

Study 2012. Volume 2: Comparisons across disability groups: Executive summary (NCEE 2017-4019). Washington, DC: U.S. Department of Education, Institute of Education Sciences, National Center for Education Evaluation and Regional Assistance.

Roizen, N. (2013). Down syndrome (Trisomy 21). In M. Batshaw, N. Roizen, \& G. Lotrecchiano (Eds.), Children with disabilities, Seventh ed. (pp. 307-319). Baltimore, MD: Paul H. Brookes Publishing Co.

Skotko B. G., Levine, S. P., Goldstein R. (2011). Self-perceptions from people with Down syndrome, American Journal of Medical Genetics Part A, 155, 2360-2369. 


\section{REFERENCES: MANUSCRIPT ONE}

Adelman, H. S., \& Taylor, L. (2013). Mapping a school's resources to improve their use in preventing and ameliorating problems. In C. Franklin, M. B. Harris, P. AllenMeares, C. Franklin, M. B. Harris, P. Allen-Meares (Eds.), The school services sourcebook: A guide for school-based professionals (pp. 837-852). New York, NY, US: Oxford University Press.

Angelou, M. (2011, July 4). My mission in life is not merely to survive, but to thrive; and to do so with some passion, some compassion, some humor, and some style [Facebook status update]. Retrieved from https://www.facebook.com/MayaAngelou/posts/10150251846629796

Magana-Amato, A.B. (2015). Manual for coding expressed emotion from the FiveMinute Speech Sample, Revised. Los Angeles: UCLA Family Project.

Benson, P., \& C. Scales, P. (2009). The definition and preliminary measurement of thriving in adolescence. The Journal of Positive Psychology, 4(1), 85-104.

Blatt, B., \& Kaplan, F. (1966). Christmas in Purgatory. Boston, MA: Allyn \& Bacon.

Boström, P., \& Broberg, M. (2017). Protection and restriction: A mixed-methods study of self-reported well-being among youth with intellectual disabilities. Journal of Applied Research In Intellectual Disabilities, doi:10.1111/jar.12364.

Boyd, N. (2015). Introducing thriving at work to the field of community psychology. Journal of Community Psychology, 43(6), 794-809.

Bozic, N. (2013). Developing a strength-based approach to educational psychology practice: A multiple case study. Educational and child psychology, 30(4). 18-29. 
Bradshaw, C. P., Waasdorp, T. E., \& Leaf, P. J. (2015). Examining variation in the impact of school-wide positive behavioral interventions and supports: Findings from a randomized controlled effectiveness trial. Journal of Educational Psychology, 107(2), 546-557.

Bronfenbrenner, U. (1979). The ecology of human development: Experiments by nature and design. Boston, MA: Harvard University Press.

Brunwasser, S. M., Gillham, J. E., \& Kim, E. S. (2009). A meta-analytic review of the Penn Resiliency Program's effect on depressive symptoms. Journal of Consulting and Clinical Psychology, 77(6), 1042-1054.

Bryck, R. L. \& Fisher, P. A. (2012). Training the brain: Practical applications of neural plasticity from the intersection of cognitive neuroscience, developmental psychology, and prevention science. American Psychologist, 67(2), 87-100.

Buettner, D. (2011). Thrive: Finding happiness the blue zones way. Washington, DC: National Geographic.

Buntinx, W. H. E. (2014). Understanding disability: A strengths-based approach. In M. L. Wehmeyer (Ed.), The oxford handbook of positive psychology and disability, (pp. 7-18). New York, NY: Oxford University Press.

Carter, E.W., Boehm, T.L., Biggs, E.E., Annandale, N.H., Taylor, C.E., Loock, A.K., \& Liu, R.Y. (2015). Known for my strengths: Positive traits of transition-age youth with intellectual disability and/or autism. Research and practice for persons with severe disabilities, 40(2). 101-119. 
Diener, E., Heintzleman, S. J., Kushlev, K., Tay, L, Wirtz, D., Lutes, L. D., \& Oishi, S. (2016). Findings all psychologists should know from the new science on subjective well-being. Canadian Psychology, 58(2), 87-104.

Doll, B., Kurien, S., LeClair, C., Spies, R., Champion, A., \& Osborn, A. (2014). The ClassMaps survey: A framework for promoting positive classroom environments. In M. J. Furlong, R. Gilman, \& E. S. Huebner(Eds.), Handbook of positive psychology in schools (pp. 278-297). New York, NY: Routledge/Taylor \& Francis Group.

Doll, B., Spies, R. A., LeClair, C. M., Kurien, S. A., \& Foley, B. P. (2010). Student perceptions of classroom learning environments: Development of the ClassMaps survey. School Psychology Review, 39(2), 203-218.

Donovan, S.A. \& Nickerson, A.B. (2007). Strength based versus traditional socialemotional reports: Impact on multidisciplinary team members' perceptions. Behavioural Disorders, 32(4), 228-237.

Durlak, J. A., Weissberg, R. P., Dymnicki, A. B., Taylor, R. D., \& Schellinger, K. B. (2011). The impact of enhancing students' social and emotional learning: A metaanalysis of school-based universal interventions. Child Development, 82, 405432.

Dykens, E.M. (2006). Toward a positive psychology of mental retardation. American Journal of Orthopsychiatry, 76(2), 185-193.

Erikson, E. H. (1950). Childhood and society. New York, NY: Norton.

Fagan, T. K. \& Wise, P. S. (2007). School psychology: Past, present and future. Bethesda, MD: National Association of School Psychologists. 
Foley, K. R., Blackmore, A. M., Girdler, S., \& Leonard, H. M. (2012). To feel belonged: The voices of children and youth with disabilities on the meaning of wellbeing. Child Indicators Research 5. 375-391.

Fredrickson, B. L. (2001). The role of positive emotions in positive psychology: The broaden-and-build theory of positive emotions. American Psychologist, 56 (3), 218-226.

Froh, J. J., Huebner, E. S., Youssef, A. J., \& Conte, V. (2010). Acknowledging and appreciating the full spectrum of the human condition: School Psychology’s (limited) focus on positive psychological functioning. Psychology in the Schools, 48(2), 110-123.

Furlong, M. J., Gilman, R., \& Huebner, E.S. (2014). Handbook of positive psychology in schools, Second Edition. New York: Taylor and Francis.

Gallup (2009). World Poll Methodology. Technical Report. Washington, DC.

Gargiulo, R. M. (2018). Special education in contemporary society: An introduction to exceptionality, Sixth edition. New York, NY: Sage Publications.

Gilman, R., Huebner, E. S., \& Furlong, M. J. (2014). Toward a science and practice of positive psychology in schools: A conceptual framework. In M. J. Furlong, R. Gilman, \& E. S. Huebner (Eds.), Handbook of positive psychology in schools, Second Edition, (pp. 3-11). New York, NY: Taylor and Francis.

Gomez, L., Arias, B., Verdugo, M., Tasse, M., Brown, I., \& Gomez, L. E. (2015). Operationalisation of quality of life for adults with severe disabilities. Journal of Intellectual Disability Research, 59(10), 925-941. 
Hagerman, R. J. (2006). Lessons from fragile X regarding neurobiology, autism, and neurodegeneration. Journal Of Developmental And Behavioral Pediatrics, 27(1), $63-74$.

Haigh, A., Lee, D., Shaw, C., Hawthorne, M., Chamberlain, S., Newman, D. W., \& ... Beail, N. (2013). What things make people with a learning disability happy and satisfied with their lives: An inclusive research project. Journal Of Applied Research In Intellectual Disabilities, 26(1), 26-33.

Hart, K. E. \& Sasso, T. (2011). Mapping the contours of contemporary positive psychology. Canadian Psychology, 52(2), 82-92.

Hazel, C. E. (2016). Empowered learning in secondary schools: Promoting positive youth development through a multitiered system of supports. Washington, DC: American Psychological Association.

Horner, R. H., \& Sugai, G. (2015). School-wide PBIS: An example of applied behavior analysis implemented at a scale of social importance. Behavior Analysis In Practice, 8(1), 80-85. doi:10.1007/s40617-015-0045-4

Huebner, E. S. (1991). Initial development of the student's life satisfaction scale. School Psychology International, 12(3), 231-240.

Huebner, E. S., Zulig, K., \& Saha, R. (2012). Factor structure and reliability of an abbreviated version of the multidimensional student's life satisfaction scale. Child Indicators Research, 5(4), 651-657.

Huebner, E. S. \& Furlong, M. (2016). Measuring student's well-being. In S. Suldo (Ed). Promoting student happiness: Positive psychology interventions in schools, (pp.15-27). New York, NY: The Guilford Press. 
Hurwitz, J. T., Kratochwill, T. R., \& Serlin, R. C. (2015). Size and consistency of problem-solving consultation outcomes: An empirical analysis. Journal Of School Psychology, 53(2), 161-178.

Individuals With Disabilities Education Act, 20 U.S.C. $§ 1400$ (2004).

International Positive Psychology Association (n.d.). [webpage]. Retrieved from https://www.ippanetwork.org/

Jayawickreme, E., Forgeard, M. J. C. \& Seligman, M.E.P. (2012). The engine of wellbeing. Review of General Psychology, 16, 327-342.

Jimerson, S.R., Sharkey, J.D., Nyborg, V., Furlong, M.J. (2004). Strength-based assessment and school psychology: A summary and synthesis. The California school psychologist, 9, 9-19.

Klotz, M. B. (2016). Improving School Climate: New Resources From the Department of Education, Communiqué, 44(8), 27.

Kramer, J. M. (2015). Identifying and evaluating the therapeutic strategies used during a manualized self-advocacy intervention for transition-age youth. Occupational Therapy Journal of Research: Occupation, Participation And Health, 35(1), 2333.

Lavy, S., Littman-Ovadia, H., \& Bareli, Y. (2014). Strengths deployment as a moodrepair mechanism: Evidence from a diary study with a relationship exercise group. Journal of Positive Psychology, 9, 547-558.

Lerner, J. V., Bowers, E. P., Minor, K., Boyd, M. J., Mueller, M. K., Schmid, K. L., \& ... Lerner, R. M. (2013). Positive youth development: Processes, philosophies, and programs. In R. M. Lerner, M. A. Easterbrooks, J. Mistry, I. B. Weiner, R. M. 
Lerner, M. A. Easterbrooks, ... I. B. Weiner (Eds.), Handbook of psychology: Developmental psychology (pp. 365-392). Hoboken, NJ, US: John Wiley \& Sons Inc.

Lerner, R. M., Lerner, J. V., Almerigi, J., \& Theokas, C. (2006). Dynamics of individual $\longleftrightarrow$ context relations in human development: A developmental systems perspective. In J. C. Thomas, D. L. Segal, M. Hersen, J. C. Thomas, D. L. Segal, M. Hersen (Eds.), Comprehensive Handbook of Personality and Psychopathology, Vol. 1: Personality and Everyday Functioning (pp. 23-43). Hoboken, NJ, US: John Wiley \& Sons Inc.

Lerner, R. M., von Eye, A., Lerner, J. V., Lewin-Bizan, S., \& Bowers, E. P. (2010). Special issue introduction: The meaning and measurement of thriving: A view of the issues. Journal of Youth and Adolescence, 39(7), 707-19.

Lipscomb, S., Haimson, J., Liu, A.Y., Burghardt, J., Johnson, D.R., \& Thurlow, M.L. (2017). Preparing for life after high school: The characteristics and experiences of youth in special education. Findings from the National Longitudinal Transition Study 2012. Volume 2: Comparisons across disability groups: Executive summary (NCEE 2017-4019). Washington, DC: U.S. Department of Education, Institute of Education Sciences, National Center for Education Evaluation and Regional Assistance.

McNicholas, P. J., Floyd, R. G., Woods, I. L., Singh, L. J., Manguno M. S., \& Maki, K. E. (2017). State special education criteria for identifying intellectual disability: A review following revised diagnostic criteria and Rosa's law. School Psychology Quarterly, Advance online publication. http://dx.doi.org/10.1037/spq0000208 
Merydith, S. P., Bamonto, S., Stalker, E., \& Larkin, J. (2017). Mental testing of Ellis Island immigrants: A distant mirror. Communiqué, 45(7), 1, 31.

Miller, D. N., Nickerson, A. B., \& Jimerson, S. R. (2014). Positive psychology and school-based interventions. In M. J. Furlong, R. Gilman, \& E. S. Huebner (Eds.), Handbook of positive psychology in schools (pp. 478-494). New York, NY: Routledge/Taylor \& Francis Group.

Miller, G. Lines, C., \& Fleming, M. (2014). Best practices in family-school collaboration for multitiered service delivery. In P. L. Harrison \& A. Thomas (Eds.), Best Practices in School Psychology, (pp. 491-504). Bethesda, MD: National Association of School Psychologists.

National Association of School Psychologists (2016). Affirming the right to safe and supportive schools and communities for all students [Resolution]. Bethesda, MD: Author. Retrieved from https://www.nasponline.org/research-andpolicy/professional-positions/resolutions

National Association of School Psychologists (2010). Model for comprehensive and integrated school psychological services [PDF document]. Retrieved from http://www.nasponline.org/standards/2010standards/2_PracticeModel.pdf National Association of School Psychologists (n.d.). Vision, mission, core values, and priorities [webpage]. Retrieved from https://www.nasponline.org/utility/aboutnasp/vision-mission-core-values-and-priorities

Nes, R. B. \& Roysamb, E. (2015). The heritability of subjective well-being: Review and meta-analysis. In M. Pluess (Ed.) The Genetics of Psychological Well-Being: The 
Role of Heritability and Genetics in Positive Psychology, (pp.75-96). New York, NY: Oxford University Press.

Nickerson, A. B. (2007). The use and importance of strength-based assessment. School Psychology Forum: Research in Practice, 2, 15-25.

Palmer, S. B., \& Wehmeyer, M. L. (2003). Promoting self-determination in early elementary school: Teaching self-regulated problem-solving and goal-setting skills. Remedial and Special Education, 24, 115-126.

Parker, R. I., Vannest, K. J., Davis, J. L., \& Clemens, N. H. (2012). Defensible progress monitoring data for medium- and high-stakes decisions. The Journal of Special Education, 46(3), 141-151.

Perry, B. D. (2009). Examining child maltreatment through a neurodevelopmental lens: Clinical applications of the neurosequential model of therapeutics. Journal Of Loss And Trauma, 14(4), 240-255.

Peterson, C. \& Seligman, M.E. (2004). Character strengths and virtues: A handbook and classification, Washington, DC: American Psychological Association.

Piaget, J. (1954). The construction of reality in the child. New York: Basic Books.

Prilleltensky, I. (2012). Wellness as fairness. American Journal of Community Psychology, 49, 1-21.

Proctor, C., Tsukayama, E., Wood, A. M., Maltby, J., Fox, Eades, J., \& Linley, P. A. (2011). Strengths Gym: The impact of a character strengths-based intervention on the life satisfaction and well-being of adolescents. Journal of Positive Psychology, 6(5). 377-388. 
Proyer, R. T., Gander, F., Wellenzohn, S., \& Ruch, W. (2015). Strengths-based positive psychology interventions: A randomized placebo-controlled online trial on longterm effects for a signature strengths vs. a lesser strengths-intervention. Frontiers in Psychology, 6, 456. DOI:10.3389/fpsyg.2015.00456

Proyer, R. T., Wellenzohn, S., Gander, F., Ruch, W. (2014). Toward a better understanding of what makes positive psychology interventions work: Predicting happiness and depression from the person $\times$ intervention fit in a follow-up after 3.5 years. Applied Psychology: Health and Well-Being. doi:10.1111/aphw.12039

Quinlan, D. M., Swain, N., Cameron, C., \& Vella-Brodrick, D. A. (2015). How “other people matter" in a classroom-based strengths intervention: Exploring interpersonal strategies and classroom outcomes. Journal of Positive Psychology, 10, $77-89$.

Rey, L., Extremera, N., Duran, A., \& Ortiz-Tallo, M. (2013). Subjective quality of life of people with intellectual disabilities: The role of emotional competence on their subjective well-being. Journal of Applied Research in Intellectual Disabilities, 26, 146-156.

Roach, A. T. (2003). In search of a paradigm shift: What disability studies can contribute to school psychology. Disability Studies Quarterly, 23(3).

Roizen, N. (2013). Down syndrome (Trisomy 21). In M. Batshaw, N. Roizen, \& G. Lotrecchiano (Eds.), Children with disabilities, Seventh ed. (pp. 307-319). Baltimore, MD: Paul H. Brookes Publishing Co. 
Rosa, E. M. \& Tudge, J. (2013), Urie Bronfenbrenner's theory of human development: Its evolution from ecology to bioecology. Journal of Family Theory and Review, 5, 243-258. doi:10.1111/jftr.12022

Roth, R., Suldo, S. M., \& Ferron, J. (2017). Improving middle school students's subjective well-being: Efficacy of a multicomponent positive psychology intervention targeting small groups of youth. School Psychology Review, 46(1), 21-41.

Ryff, C. D. (2014). Psychological well-being revisited: Advances in the science and practice of eudaimonia. Psychotherapy and Psychosomatics, 83, 10-28.

Salvia, J., Ysseldyke, J., \& Witmer, S. (2013). Assessment in special and inclusive education, $12^{\text {th }}$ edition. Belmont, CA: Wadsworth, Cengage Learning.

Satler, J. M. \& Hoge, R. D. (2006). Assessment of children: Behavioral, social, and clinical foundations (5 $5^{\text {th }}$ ed.). San Diego, CA: Jerome M. Sattler, Publisher, Inc.

Schalock, R. L. \& Alonso, M. A. V. (2014). The impact of quality of life concept on the field of intellectual disability. In M. L. Wehmeyer (Ed.), The oxford handbook of positive psychology and disability, (pp. 37-47). New York, NY: Oxford University Press.

Schalock, R. L., Borthwick-Duffy, S. A., Bradley, V. J., Buntinx, W. H. E., Coulter, D. L., Craig, E. M., et al. (2010). Intellectual disability: Definition, classification, and systems of supports. Washington, DC: American Association on Intellectual and Developmental Disabilities.

Schonert-Reichel, K. A., Oberle, E., Lawlor, M. S., Abbott, D., Thomson, K., Oberlander, T. F., et al. (2015). Enhancing cognitive and social-emotional development through a simple-to-administer mindfulness school program for 
elementary school children: A randomized controlled trial. Developmental Psychology, 51(1), 52-66.

Schonfeld, D. J., Adams, R. E., Fredstrom, B. K., Weissberg, R. P., Gilman, R., Voyce, C., \& ... Speese-Linehan, D. (2015). Cluster-randomized trial demonstrating impact on academic achievement of elementary social-emotional learning. School Psychology Quarterly, 30(3), 406-420.

Scott, M., Foley, K.R., Bourke, J., Leonard, H., Girdler, S. (2014). "I have a good life”: The meaning of well-being from the perspective of young adults with Down syndrome. Disability and Rehabilitation, 36(15), 1290-1298.

Seligman, M.E. (2011). Flourish, New York, NY: Simon and Schuster.

Seligman, M.E. \& Csikzentmihalyi, M. (2000). Positive psychology: An introduction. American Psychologist, 55(1), 5-14.

Shogren, K. A. (2014). Positive psychology and disability: A Historical analysis. In M. L. Wehmeyer (Ed.), The oxford handbook of positive psychology and disability, (pp. 19-36). New York, NY: Oxford University Press.

Shogren, K. A., Wehmeyer, M. L., Forber-Pratt, A. J., \& Palmer, S. B. (2015). VIA Inventory of Strengths for Youth (VIA-Youth): Supplement for use when supporting youth with intellectual and developmental disabilities to complete the VIA-Youth. Lawrence, KS: Kansas University Center on Developmental Disabilities.

Shogren, K. A., Wehmeyer, M. L., Pressgrove, C. L., \& Lopez, S. J. (2006). The application of positive psychology and self-determination to research in 
intellectual disability: A content analysis of 30 years of literature. Research and Practice for Persons with Severe Disabilities, 31, 338-345.

Shonkoff, J. P., Phillips, D. A., \& National Research Council (U.S.). (2000). From neurons to neighborhoods: The science of early child development. Washington, D.C: National Academy Press.

Shriberg, D., Bonner, M., Sarr, B., Walker, A. M., Hyland, M., Chester, C. (2008). Social Justice through a school psychology lens: Definition and applications. School Pychology Review, 37(4), 453-468.

Smart, J. (2012). Disability across the developmental life span for the rehabilitation counselor. New York, NY, US: Springer Publishing Co.

Spreitzer, G., Sutcliffe, K., Dutton, J., Sonenshein, S., \& Grant, A. M. (2005). A socially embedded model of thriving at work. Organization Science, 16(5), 537-549.

Suldo, S. M., Savage, J. A., \& Mercer, S. (2014). Increasing middle school student's life satisfaction: Efficacy of a positive psychology group intervention. Journal of Happiness Studies, 15(1), 19-42

Talapatra, D., Roach, A. T., Varjas, K., Houchins, D. E., \& Crimmins, D. B. (2017). Promoting school psychologist participation in transition services using the TPIE model. Contemporary School Psychology, doi:10.1007/s40688-017-0159-5.

Thrive. (2010). In Oxford English Dictionary online (2 $2^{\text {nd }}$ edition). Retrieved from http://www.oxfordreference.com/view/10.1093/acref/9780199571123.001.0001/ m_en

Trawick-Smith, J. (2014). Early childhood development: A multicultural perspective, $6^{\text {th }}$ edition. Upper Saddle River, NJ: Pearson Education. 
U.S. Department of Education (2015). Thirty seventh annual report to Congress on the implementation of the Individuals with Disabilities Education Act, 2015.

Washington D.C.: U.S. Government Printing Office.

Utley, C. A. \& Obiakor, F. E. (2015). Special issue: Research perspectives on multitiered system of support. Learning Disabilities: A Contemporary Journal, 13(1), $1-2$.

Vallerand, R. J. \& Carbonneau, N. (2013). The role of passion in optimal functioning in society. In D. M. McInerney, H.W. Marsh, R.G. Craven, \& F. Guay (Eds.), Theory driving research: New wave perspectives on self-processes and human development, (pp. 53-82). Charlotte, NC: IAP Information Age Publishing.

Vella-Brodrick, V. A. (2016). Optimizing the art and science of well-being in schools. Communiqué, 45(1).

Verdugo, M. A., Navas, P., Gomez, L. A., \& Schalock, R.L. (2012). The concept of quality of life and its role in enhancing human rights in the field of intellectual disability. Journal of Intellectual Disability Research, 56(11). 1036-1045.

Volpe, R. J., DiPerna, J. C., Hintze, J. M., \& Shapiro, E. S. (2005). Observing Students in Classroom Settings: A Review of Seven Coding Schemes. School Psychology Review, 34(4), 454-474.

Vos, P., De Cock, P., Petry, K., Van Den Noortgate, W., \& Maes, B. (2013). Investigating the relationship between observed mood and emotions in people with severe and profound intellectual disabilities. Journal Of Intellectual Disability Research, 57(5), 440-451. 
Vos, P., De Cock, P., Petry, K., Van Den Noortgate, W., \& Maes, B. (2010). What makes them feel like they do? Investigating the subjective well-being in people with severe and profound disabilities. Research In Developmental Disabilities, 31(6), $1623-1632$.

Wehmeyer, M. L. (2013). The story of intellectual disability: An evolution of meaning, understanding, and public perception. Baltimore, MD: Brookes Publishing.

Wehmeyer, M. L. (2014). Beyond pathology: Positive psychology and disability. In M. L. Wehmeyer (Ed.), The oxford handbook of positive psychology and disability, (pp. 3-6). New York, NY: Oxford University Press.

Wehmeyer, M.1., Shogren, K. A., Palmer, S. B., Williams-Diehm, K., Little, T. D., \& Boulton, A. (2012). Impact of the self-determined learning model of instruction on student self-determination: A randomized-trial placebo control group study. Exceptional Children, 78, 135-153.

Weiss, J., \& Riosa, A. (2015). Thriving in youth with autism spectrum disorder and intellectual disability. Journal of Autism and Developmental Disorders, 45(8), 2474-2486.

Werner, S., \& Shulman, C. (2013). Subjective well-being among family caregivers of individuals with developmental disabilities: The role of affiliate stigma and psychosocial moderating variables. Research In Developmental Disabilities, 34(11), 4103-4114. 


\section{REFERENCES: MANUSCRIPT TWO}

Abbeduto, L., Seltzer, M. M., Shattuck, P., Krauss, M. W., Orsmond, G., \& Murphy, M. M. (2004). Psychological well-being and coping in mothers of youths with autism, Down syndrome, or fragile X syndrome. American Journal on Mental Retardation, 109(3), 237-254.

Alderson, P. (2001). Down's syndrome: Cost, quality and value of life. Social Science \& Medicine, 53(5), 627-638.

Anderson, S., \& Bigby, C. (2017). Self-advocacy as a means to positive identities for people with intellectual disability: 'We just help them, be them really'. Journal of Applied Research in Intellectual Disabilities, 30(1), 109-120.

doi:10.1111/jar. 12223

Batshaw, M. L, Gropman, A., \& Lanpher, B. (2013). Genetics and developmental disabilities. In M. Batshaw, N. Roizen, \& G. Lotrecchiano (Eds.), Children with disabilities, Seventh ed. (pp. 3-24), Baltimore, MD: Paul H. Brookes Publishing.

Beck, A., Daley, D., Hastings, R. P., \& Stevenson, J. (2004). Mothers expressed emotion towards children with and without intellectual disabilities. Journal of Intellectual Disability Research, 48(7), 628-638.

Bérubé, M. (1996). Life as we know it: A father, a family, and an exceptional child. New York, NY: Vintage Books.

Bérubé, M. (2016). Life as Jamie knows it: An exceptional child grows up. Boston MA: Beacon Press.

Benson, P., \& C. Scales, P. (2009). The definition and preliminary measurement of thriving in adolescence. The Journal of Positive Psychology, 4(1), 85-104. 
Bittles, A. H., Bower, C. Hussain, R., \& Glasson, E. J. (2006). The four ages of Down syndrome. European Journal of Public Health, 17(2), 221-225.

Bornstein, Lenchner, Donnenfeld, Jodicke, Keeler, Kapp, \& Divon. (2010). Complete trisomy 21 versus translocation Down syndrome: A comparison of modes of ascertainment. American Journal of Obstetrics and Gynecology, 203(4), 391.e1391.e5.

Bovicelli, L., Orsini, L.F., Rizzo, N., Montacuti, V. \& Bocchetta, M. (1982). Reproduction in Down syndrome. Obstetrics and Gynecology, 59,13S-17S.

Bronfenbrenner, U. (1979). The ecology of human development: Experiments by nature and design. Boston, MA: Harvard University Press.

Bulman, M. (2017, February 24). Down Syndrome couple celebrate 22 years of happy marriage. Retrieved from http://www.independent.co.uk/news/uk/homenews/down-syndrome-couple-maryanne-tommy-pilling-essex-22-years-marriagecelebrate-a7597146.html

Buntinx, W. H. E. (2014). Understanding disability: A strengths-based approach. In M. L. Wehmeyer (Ed.). The oxford handbook of positive psychology and disability, (pp. 7-18), New York, NY: Oxford University Press.

Butterworth, J., Migliore, A., Sulewski, J., S., Zalewska, A. (2014). Trends in employment outcomes of young adults with intellectual and developmental disabilities 2004-2012. Boston, MA: University of Massachusetts Boston, Institute for Community Inclusion.

Carlson, J. A. (2010). Avoiding traps in member checking. The Qualitative Report, 15(5), 1102-113. 
Carr, J. (2012). Six weeks to 45 years: A longitudinal study of a population with Down syndrome. Journal of Applied Research in Intellectual Disabilities, 25(5), 414422.

Carter, E.W., Boehm, T.L., Biggs, E.E., Annandale, N.H., Taylor, C.E., Loock, A.K., \& Liu, R.Y. (2015). Known for my strengths: Positive traits of transition-age youth with intellectual disability and/or autism. Research and practice for persons with severe disabilities, 40(2). 101-119.

Coleman, J., \& Riley, K. (2014). The expressed emotion of mothers of children with fragile x syndrome. Lifespan and Disability, XVII(1), 59-88.

Creswell, J. W. (2013). Qualitative inquiry and research design: Choosing among five approaches ( $3^{\text {rd }}$ Ed.). Thousand Oaks, CA: Sage.

Davis, A. S. (2008). Children with down syndrome: Implications for assessment and intervention in the school. School Psychology Quarterly, 23(2), 271-281.

de Graaf, G., Buckley, F. F., Skotko. B. G. (2015). Estimates of the live births, natural losses, and elective terminations with Down syndrome in the United States. American Journal of Medical Genetics, Part A, 167A(4), 756-767.

Deckers, S. M., Van Zaalen, Y., Stoep, J., Van Balkom, H., \& Verhoeven, L. (2016). Communication performance of children with Down Syndrome: An ICF-CY based multiple case study. Child Language Teaching And Therapy, 32(3), 293311.

Diener, E., Emmons, R. A., Larsen, R. J., \& Griffin, S. (1985). The Satisfaction with Life Scale. Journal of Personality Assessment, 49, 71-75.

Diener, E., Heintzleman, S. J., Kushlev, K., Tay, L, Wirtz, D., Lutes, L. D., \& Oishi, S. 
(2016). Findings all psychologists should know from the new science on subjective well-being. Canadian Psychology, 58(2), 87-104.

Down syndrome, American Journal of Medical Genetics Part A, 155, 2360-2369.

Donovan, S.A., \& Nickerson, A.B. (2007). Strength based versus traditional socialemotional reports: Impact on multidisciplinary team members' perceptions. Behavioural Disorders, 32(4), 228-237.

Dunn, L. M., \& Dunn, D. M. (2007). Peabody Picture Vocabulary Test, Fourth Edition. Minneapolis, MN: Pearson Publishing.

Dykens, E. M. (2007). Psychiatric and behavioral disorders in persons with Down syndrome. Mental Retardation and Developmental Disabilities Research Reviews, 13. $272-278$.

Dykens, E. M., Shah, B., Sagun, J., Beck, T., \& King, B. H. (2002). Maladaptive behaviour in children and adolescents with Down's syndrome. Journal of Intellectual Disability Research, 46(6), 484-492.

Dykens, E.M. (2006). Toward a positive psychology of mental retardation. American Journal of Orthopsychiatry, 76(2), 185-193.

Esbensen, A. J. \& Seltzer, M. M. (2011). Accounting for the "Down syndrome advantage". American Journal on Intellectual and Developmental Disabilities, 116(1), 3-15.

Estreich, G. (2011). The shape of an eye: A memoir. New York, NY: Penguin.

Erikson, E. H. (1950). Childhood and society. New York, NY: Norton.

Fidler, D. J. (2005). The emerging Down syndrome behavioral phenotype in early childhood: Implications for practice. Infants \& Young Children, 18(2), 86-103. 
Fidler, D. J. (2006). The emergence of a syndrome-specific personality profile in young children with Down syndrome. Down Syndrome Research and Practice, 10(2), $53-60$.

Fidler, D. J., Barrett, K. C., \& Most, D. E. (2005). Age related difference in smiling and personality in Down syndrome. Journal of Developmental and Physical Disabilities, 17(3), 263-280.

Fidler, D. J., Hepburn, S., \& Rogers, S. (2006). Early learning and adaptive behavior in toddlers with Down syndrome: Evidence for an emerging behavioural phenotype? Down Syndrome Research and Practice, 9(3), 37-44.

Fidler, D. J., Hodapp, R. M., \& Dykens, E. M. (2000). Stress in families of young children with Down syndrome, Williams syndrome, and Smith-Magenis syndrome. Early Education and Development, 11(4), 395-406.

Fidler, D. J., Hodapp, R. M., \& Dykens, E. M. (2002). Behavioral phenotypes and special education: Parent report of educational issues for children with Down syndrome, Prader-Willi syndrome, and Williams syndrome. Journal of Special Education, 36(2), 80-88.

Fidler, D. J., Most, D. E., Booth-LaForce, C., \& Kelly, J. F. (2008). Emerging social strengths in young children with Down syndrome. Infants \& Young Children, 21(3), 207-220.

Finestack, L.H., Sterling, A.M., \& Abbeduto, L. (2013). Discriminating Down syndrome and fragile X syndrome based on language ability. Journal of Child Language, 40, 244-265.

Fox, S., Farrell, P., \& Davis, P. (2004). Factors associated with the effective inclusion of 
primary-aged pupils with down's syndrome. British Journal of Special Education, 31(4), 184-190.

Freeman, S. N., \& Kasari, C. (2002). Characteristics and qualities of the play dates of children with Down syndrome: Emerging or true friendships. American Journal on Mental Retardation, 107(1), 16-31.

Garber, B. J. (2013, March 20). Ben Garber's Quora answer to: What's the best-case scenario for a person with Down's Syndrome living independently? Retrieved from https://www.quora.com/Whats-the-best-case-scenario-for-a-person-withDown\%E2\%80\%99s-Syndrome-living-independently

Gargiulo, R. M. \& Bouck, E. (2018). Special education in contemporary society: An introduction to exceptionality, Sixth edition. New York, NY: Sage Publications.

Gilman, R., Huebner, E. S., \& Furlong, M. J. (2014). Toward a science and practice of positive psychology in schools: A conceptual framework. In M. J. Furlong, R. Gilman, \& E. S. Huebner (Eds.). Handbook of positive psychology in schools, Second Edition, (pp. 3-11), New York, NY: Taylor and Francis.

Gilmore, L., Campbell, J., \& Cuskelly, M. (2010). Developmental expectations, personality stereotypes, and attitudes towards inclusive education: Community and teacher views of Down syndrome. International Journal of Disability, Development and Education, 50(1), 65-76. 515-529.

Glenn, S. \& Cunningham, C. (2004). Self-awareness in young adults with Down syndrome. International Journal of Disability, Development and Education, 51. $363-381$.

Glidden, L. M., Grein, K. A., \& Ludwig, J. A. (2014). The Down syndrome advantage: It 
depends on what and when you measure. The American Journal on Intellectual and Developmental Disabilities, 119(5), 389-404.

Global Down Syndrome Foundation (n.d.). Down Syndrome Misconceptions Vs. Reality [Webpage]. Retrieved from https://www.globaldownsyndrome.org/about-downsyndrome/misconceptions-vs-reality/

Global Down Syndrome Foundation \& National Down Syndrome Congress (2017). Prenatal Testing Pamphlet [PDF document]. Retrieved from http://www.globaldownsyndrome.org/prenatal-testing-pamphlet/

Goff, B. S., Monk, J. K., Malone, J., Staats, N., Tanner, A., \& Springer, N. P. (2016). Comparing parents of children with Down syndrome at different life span stages. Journal of Marriage and Family, 78(4), 1131-1148.

Gomez, L., Arias, B., Verdugo, M., Tasse, M., Brown, I., \& Gomez, L. E. (2015).

Operationalisation of quality of life for adults with severe disabilities. Journal of Intellectual Disability Research, 59(10), 925-941.

Grigal, M., Hart, D., \& Weir, C. (2012). A survey of postsecondary education programs for students with intellectual disabilities in the United States. Journal of Policy and Practice in Intellectual Disabilities, 9(4), 223-233. doi:10.1111/jppi.12012

Grimmet, K. D. (2017). Examining the quality of life of young adults with intellectual disability: Using photo elicitation to empower an unknown voice. Dissertation Abstracts International Section A, 78.

Guillemin, M. \& Drew, S. (2010) Questions of process in participant-generated visual methodologies, Visual Studies, 25(2), 175-188.

Guralnick, M. J. (2006). Peer relationships and the mental health of young children with 
intellectual delays. Journal of Policy and Practice in Intellectual Disabilities, 3(1), 49-56. doi:10.1111/j.1741-1130.2006.00052.x

Head, L. S., \& Abbeduto, L. (2007). Recognizing the role of parents in developmental outcomes: A systems approach to evaluating the child with developmental disabilities. Mental Retardation And Developmental Disabilities Research Reviews, 13(4), 293-301. doi:10.1002/mrdd.20169

Hessl, D., Sansone, S., Berry-Kravis, E., Riley, K., Widaman, K., Abbeduto, L., . . . Gershon, R. (2016). The NIH Toolbox Cognitive Battery for intellectual disabilities: Three preliminary studies and future directions. Journal of Neurodevelopmental Disorders, 8.

Hodapp, R. M. (2007). Families of persons with Down syndrome: New perspectives, findings, and research and service needs. Mental Retardation and Developmental Disabilities Research Reviews, 13(3), 279-287.

Hodapp, R. M., Burke, M. M., Finley, C. I., \& Urbano, R. C. (2016). Family caregiving of aging adults with Down syndrome. Journal of Policy and Practice in Intellectual Disabilities, 13(2), 181-189. doi:10.1111/jppi.12153

Hodapp, R. M., Ly, T. M., Fidler, D. J., \& Ricci, L. A. (2001). Less stress, more rewarding: Parenting children with Down syndrome. Parenting: Science and Practice, 1, 317-337.

Hodapp, R. M., Ricci, L., Ly, T., et al. (2003). The effects of the child with Down syndrome on maternal stress. British Journal of Developmental Psychology, 22. $137-151$.

Horner-Johnson, W., \& Bailey, D. (2013). Assessing understanding and obtaining 
consent from adults with intellectual disabilities for a health promotion study. Journal of Policy and Practice in Intellectual Disabilities, 10(3), 260-265.

Individuals With Disabilities Education Act, 20 U.S.C. § 1400 (2004).

International Positive Psychology Association (n.d.). [webpage]. Retrieved from https://www.ippanetwork.org/

Jiar, Y. K., Handayani, L., \& Xi, L. (2014). The role of government and NGO in promoting wellness of people with Down syndrome. International Journal of Evaluation and Research in Education, 3(3), 175-186.

Jorgensen, Cheryl M., \& Lambert, Laurie. (2012). Inclusion means more than just being "in:" Planning full participation of students with intellectual and other developmental disabilities in the general education classroom. International Journal of Whole Schooling, 8(2), 21-36.

Kahn, T. (2016). Hope. Cambridge: Still Designing Publishing. Kingsley, J. \& Levitz, M. (1994). Count us in: Growing up with Down syndrome. New York, NY: Harcourt Brace.

Kumin, L. (2001). Classroom language skills for children with Down syndrome: A guide for parents and teachers. Bethesda, MD, US: Woodbine House.

Kumin, L. \& Schoenbrodt, L. (2016). Employment in adults with Down syndrome in the United States: Results from a national survey. Journal of Applied Research in Intellectual Disabilities, 29(4), 330-345.

Lerner, J. V., Bowers, E. P., Minor, K., Boyd, M. J., Mueller, M. K., Schmid, K. L., \& ... Lerner, R. M. (2013). Positive youth development: Processes, philosophies, and programs. In R. M. Lerner, M. A. Easterbrooks, J. Mistry, I. B. Weiner, R. M. 
Lerner, M. A. Easterbrooks, ... I. B. Weiner (Eds.). Handbook of psychology: Developmental psychology (pp. 365-392), Hoboken, NJ, US: John Wiley \& Sons Inc.

Lerner, R. M., von Eye, A., Lerner, J. V., Lewin-Bizan, S., \& Bowers, E. P. (2010). Special issue introduction: The meaning and measurement of thriving: A view of the issues. Journal of Youth and Adolescence, 39(7), 707-19.

Love, A., \& Agiovlasitis, S. (2016). How do adults with down syndrome perceive physical activity? Adapted Physical Activity Quarterly, 33(3), 253-270.

Loveall, S. J., Channell, M. M., Phillips, B. A., Abbeduto, L., \& Conners, F. A. (2016). Receptive vocabulary analysis in Down syndrome. Research in Developmental Disabilities, 55, 161-172.

Lyons, R., Brennan, S., \& Carroll, C. (2016). Exploring parental perspectives of participation in children with Down syndrome. Child Language Teaching and Therapy, 32(1), 79-93.

Lyubomirsky, S., \& Lepper, H. (1999). A measure of subjective happiness: Preliminary reliability and construct validation. Social Indicators Research, 46, 137-155.

Manfredini, D. (1988). Down syndrome. ERIC Digest. Retrieved from ERIC database. (ED457).

Magana-Amato, A.B. (2015). Manual for coding expressed emotion from the FiveMinute Speech Sample, Revised. Los Angeles: UCLA Family Project.

Massey, S., Cameron, A., Ouellette, S., \& Fine, M. (1998). Qualitative approaches to the study of thriving: What can be learned? Journal of Social Issues, 54(2). 337-355.

Mertens, D. M. (2009). Transformative research and evaluation. New York, NY: 


\section{Guilford Press.}

Miodrag, N., Silverberg, S. E. Urbano, R. C., \& Hodapp, R. M. (2013). Deaths among children, adolescents, and young adults with Down syndrome. Journal of Applied Research in Intellectual Disabilities, 26(3), 207-214.

Moss, J., Richards, C., Nelson, L., \& Oliver, C. (2013). Prevalence of autism spectrum disorder symptomatology and related behavioural characteristics in individuals with Down syndrome. Autism, 17(4), 390-404.

National Association of School Psychologists (2010). Model for comprehensive and integrated school psychological services [PDF document]. Retrieved from http://www.nasponline.org/standards/2010standards/2_PracticeModel.pdf

National Association of School Psychologists (2014). Prevention and wellness promotion [Position Statement]. Bethesda, MD: Author. Retrieved from https://www.nasponline.org/research-and-policy/professional-positions/positionstatements

National Association of School Psychologists (2016). Affirming the right to safe and supportive schools and communities for all students [Resolution]. Bethesda, MD: Author. Retrieved from https://www.nasponline.org/research-andpolicy/professional-positions/resolutions

National Association of School Psychologists (n.d.). Vision, mission, core values, and priorities [webpage]. Retrieved from https://www.nasponline.org/utility/aboutnasp/vision-mission-core-values-and-priorities

Natoli, J., Ackerman, D., McDermott, S., \& Edwards, J. (2012). Prenatal diagnosis of Down syndrome: A systematic review of termination rates (1995-2011. Prenatal 
Diagnosis, 32(2), 142-153.

Neece, C. L., Kraemer, B. R., \& Blacher, J. (2009). Transition satisfaction and family well being among parents of young adults with severe intellectual disability. Intellectual and Developmental Disabilities, 47, 31-43.

Ortlipp, M. (2008). Keeping and using reflective journals in the qualitative research process. The Qualitative Report, 13(4), 695-705.

Oxelgren, U. W., Myrelid, Å., Annerén, G., Ekstam, B., Göransson, C., Holmbom, A., \& ... Fernell, E. (2017). Prevalence of autism and attention-deficit-hyperactivity disorder in Down syndrome: A population-based study. Developmental Medicine \& Child Neurology, 59(3), 276-283.

Papay, C. K. \& Bambara, L. M. (2011). Postsecondary education for transition-age students with intellectual and other developmental disabilities: A national survey. Education and Training in Autism and Developmental Disabilities, 46(1), 78-93.

Park, N. \& Peterson, C. (2007). Methodological issues in positive psychology and the assessment of character strengths. In A. D. Ong \& M. H. M. van Dulman (Eds.). Oxford Handbook of Methods in Positive Psychology, (pp. 292-305). New York, NY: Oxford University Press.

Park, N., \& Peterson, C. (2006). Moral competence and character strengths among adolescents: The development and validation of the Values in Action Inventory of Strengths for Youth. Journal of Adolescence, 29, 891-905.

Park, N., Peterson, C., \& Seligman, M. E. P. (2004). Strengths of character and wellbeing. Journal of Social and Clinical Psychology, 23(5), 603-619.

Paulhus, D. L. (2002). Social desirable responding: The evolution of a construct. In H. I. 
Brown, D. N. Jackson, \& D. E. Wiley (Eds.), The role of constructs in psychological and educational measurement (pp. 49-69). Mahwah, NJ: Erlbaum.

Perlman, S. L. (2014). Down's syndrome. In M. J. Aminoff \& R. B. Daroff (Eds.). Encyclopedia of the neurological sciences, (pp. 1026-1028), London: Elsevier Inc.

Peterson, C. \& Seligman, M.E. (2004). Character strengths and virtues: A handbook and classification, Washington, DC: American Psychological Association.

Plotner, A. J., \& Marshall, K. J. (2015). Postsecondary education programs for students with an intellectual disability: Facilitators and barriers to implementation. Intellectual and Developmental Disabilities, 53(1), 58-69. doi:10.1352/1934$9556-53.1 .58$

Povee, K., Bishop, B., \& Roberts, L. (2014). The use of photovoice with people with intellectual disabilities: Reflections, challenges and opportunities. Disability \& Society, 29(6), 893-907.

Proyer, R. T., Ruch, W., \& Buschor, C. (2013). Testing strengths-based interventions: A preliminary study on the effectiveness of a program targeting curiosity, gratitude, hope, humor, and zest for enhancing life satisfaction. Journal of Happiness Studies, 14(1), 275-292. doi:10.1007/s10902-012-9331-9

Prilleltensky, I. (2012). Wellness as fairness. American Journal of Community Psychology, 49, 1-21.

Reilly, C. (2012). Behavioural phenotypes and special educational needs: Is aetiology important in the classroom? Journal of Intellectual Disability Research (56)10, 929-946. 
Rey, L., Extremera, N., Duran, A., \& Ortiz-Tallo, M. (2013). Subjective quality of life of people with intellectual disabilities: The role of emotional competence on their subjective well-being. Journal of Applied Research in Intellectual Disabilities, 26, 146-156.

Rizzolo, M. C., Friedman, C., Lulinski-Norris, A., \& Braddock, D. (2013). Home and Community Based Services (HCBS) Waivers: A nationwide study of the states. Intellectual and Developmental Disabilities, 51(1), 1-21. doi:10.1352/1934-9556-51.01.001

Roach, A. T. (2003). In search of a paradigm shift: What disability studies can contribute to school psychology. Disability Studies Quarterly, 23(3).

Roach, A. T., Wixson, C. S., Talapatra, D., \& LaSalle, T. (2009) Missing voices in school psychology research: A review of the literature 2002-2007. The School Psychologist, 63, 6-10.

Roberts, L. V., \& Richmond, J. L. (2014). Preschoolers with down syndrome do not yet show the learning and memory impairments seen in adults with down syndrome. Developmental Science, 18(3), 404-419.

Roid, G. H. (2003). Interpretive manual: Expanded guide to the interpretation of SB5 test results, Stanford-Binet Intelligence Scales, Fifth Edition. Rolling Meadows, IL: Riverside Publishing.

Roizen, N. (2013). Down syndrome (Trisomy 21). In M. Batshaw, N. Roizen, \& G. Lotrecchiano (Eds.), Children with disabilities, Seventh ed. (pp. 307-319), Baltimore, MD: Paul H. Brookes Publishing Co.

Rooke, M. I. \& Pereira-Silva, N. L. (2016). Indicators of family resilience in families of 
children with Down syndrome. Estudos de Psicologia, 33(1), 117-126.

Rosner, B. A., Hodapp, R. M., Fidler, D. J., Sagun, J. N., \& Dykens, E. M. (2004). Social competence in persons with Prader-Willi, William and Down's syndromes. Journal of Applied Research in Intellectual Disabilities, 17(3), 209-217.

Roulston, K., deMarrais, K., \& Lewis, J. B. (2003). Learning to interview in the social sciences. Qualitative Inquiry, 9(4). 643-668.

Sansone, S., Schneider, A., Bickel, E., Berry-Kravis, E., Prescott, C., \& Hessl, D. (2014). Improving IQ measurement in intellectual disabilities using true deviation from population norms. Journal of Neurodevelopmental Disorders, 8(6).

Savina, E., Garrity, K., Kenny, P., \& Doerr, C. (2016). The benefits of movement for youth: A whole child approach. Contemporary School Psychology, 20, 282-292.

Schalock, R. L. \& Alonso, M. A. V. (2014). The impact of quality of life concept on the field of intellectual disability. In M. L. Wehmeyer (Ed.). The oxford handbook of positive psychology and disability, (pp. 37-47), New York, NY: Oxford University Press.

Schalock, R. L., Borthwick-Duffy, S. A., Bradley, V. J., Buntinx, W. H. E., Coulter, D. L., Craig, E. M., et al. (2010). Intellectual disability: Definition, classification, and systems of supports. Washington, DC: American Association on Intellectual and Developmental Disabilities.

Schrank F. A., Mather N., McGrew K. S. (2014). Woodcock-Johnson IV Tests of Achievement. Rolling Meadows, IL: Riverside.

Scott, M., Foley, K.R., Bourke, J., Leonard, H., Girdler, S. (2014). "I have a good life”: The meaning of well-being from the perspective of young adults with Down 
syndrome. Disability and Rehabilitation, 36(15), 1290-1298.

Shogren, K. A., Palmer, S. B., Wehmeyer, M. L., Williams-Diehm, K., \& Little, T. D. (2012). Effect of intervention with the self-determined learning model of instruction on access and goal attainment. Remedial and Special Education, 33(5), 320-330.

Shogren, K. A., Wehmeyer, M. L., Forber-Pratt, A. J., \& Palmer, S. B. (2015). VIA Inventory of Strengths for Youth (VIA-Youth): Supplement for use when supporting youth with intellectual and developmental disabilities to complete the VIA-Youth. Lawrence, KS: Kansas University Center on Developmental Disabilities.

Siperstein, G. N., Glick, G. C., \& Parker, R. C. (2009). Social inclusion of children with intellectual disabilities in a recreational setting. Intellectual and Developmental Disabilities, 47(2), 97-107.

Skotko B. G., Levine, S. P., Goldstein R. (2011). Self-perceptions from people with Down syndrome, American Journal of Medical Genetics Part A, 155, 2360-2369.

Sparrow, S. S., Saulnier, C. A., \& Cicchetti, D. V., \& Doll, E. A. (2016). Vineland-3: Vineland adaptive behavior scales, manual. Minneapolis, MN: Pearson Assessments.

Spivey, C. E., \& Mechling, L. C. (2016). Video modeling to teach social safety skills to young adults with intellectual disability. Education and Training in Autism and Developmental Disabilities, 51(1), 79-92.

Stake, R. E. (1995). The art of case study research. Thousand Oaks, CA: Sage Publications. 
Stake, R. E. (2006). Multiple case study analysis. New York, NY: Guilford Press.

Talapatra, D., Roach, A. T., Varjas, K., Houchins, D. E., \& Crimmins, D. B. (2017).

Promoting school psychologist participation in transition services using the TPIE model. Contemporary School Psychology, doi:10.1007/s40688-017-0159-5.

Thompson, T., Coleman, C., \& Olmos, A. (Under review). The expressed emotion of parents of children with developmental disabilities: A meta-analysis.

Tice, C. J. \& Hall, D. M. H. (2008). Sexuality education and adolescents with developmental disabilities: Assessment, policy, and advocacy. Journal of Social Work in Disability \& Rehabilitation, 7(1), 47-62.

Tracy, S. J. (2010). Qualitative quality: Eight "big-tent" criteria for excellent qualitative research. Qualitative Inquiry, 16(10), 837-851.

Tsao, R., Kindelberger, C., Fréminville, B., Touraine, R., Bussy, G. (2015). Variability of the aging process in dementia-free adults with Down syndrome. American Journal on Intellectual and Developmental Disabilities, 120(1), 3-15.

Turner, S., Alborz, A., \& Gayle, V. (2008). Predictors of academic attainments of young people with Down's syndrome. Journal of Intellectual Disability Research, 52(5), 380-392.

Uditsky, B., \& Hughson, E. (2012). Inclusive postsecondary education: An evidencebased moral imperative. Journal of Policy and Practice in Intellectual Disabilities, 9(4), 298-302. doi:10.1111/jppi.12005

Van der Veek, S. M., Kraaij, V., \& Garnefski, N. (2009). Cognitive coping strategies and stress in parents of children with Down syndrome: A prospective study. Intellectual and Developmental Disabilities, 47(4), 295-306. 
Van Duijn, G., Dijkxhoorn, Y., Scholte, E. M., \& van Berckelaer-Onnes, I. A. (2010). The development of adaptive skills in young people with Down syndrome. Journal of Intellectual Disability Research, 54(11), 943-954.

Van Gameren-Oosterom, H. B., Fekkes, M., Reijneveld, S. A., Oudesluys-Murphy, A., Verkerk, P. H., Van Wouwe, J. P., \& Buitendijk, S. E. (2013). Practical and social skills of 16-19-year-olds with Down syndrome: Independence still far away. Research in Developmental Disabilities, 34(12), 4599-4607. doi:10.1016/j.ridd.2013.09.041

Walker, J. C., Dosen, A., Buitelaar, J. K.,\& Janzing, J. G. E. (2011). Depression in Down syndrome: A review of the literature. Research in Developmental Disabilities, 32(5), 1432-1440.

Wuang, Y., \& Su, C. (2012). Patterns of participation and enjoyment in adolescents with Down syndrome. Research In Developmental Disabilities, 33(3), 841-848.

Watt, K. J., Johnson, P., \& Virji-Babul, N. (2010). The perception of friendship in adults with Down syndrome. Journal of Intellectual Disability Research, 54(11), 10151023. doi:10.1111/j.1365-2788.2010.01330.x

Wehmeyer, M. L. (2013). The story of intellectual disability: An evolution of meaning, understanding, and public perception. Baltimore, MD: Brookes Publishing.

Weiss, J. \& Riosa, A. (2015). Thriving in youth with autism spectrum disorder and intellectual disability. Journal of Autism and Developmental Disorders, 45(8), 2474-2486.

Williams, K. T. (2007). Expressive Vocabulary Test, Second Edition. Minneapolis, MN: Pearson Publishing. 
Wishart, J. G. (2007). Socio-cognitive understanding: A strength or weakness in Down's syndrome? Journal of Intellectual Disability Research, 51(12), 996-1005. doi:10.1111/j.1365-2788.2007.01007.x

Wishart, J.G. (1996). Avoidant learning styles and cognitive development in young children. In B. Stratford \& P. Gunn, (Eds.), New Approaches to Down Syndrome, (pp.157-172), London: Cassell.

Wolcott, H. F. (1995). The art of fieldwork. Walnut Creek, CA: AltaMira Press.

Wolpert, G. (2001). What general educators have to say about successfully including students with Down syndrome in their classes. Journal of Research in Childhood Education, 16(1), 28-39.

Wyllie, R. (2012). Loving Andrew: A fifty-two-year story of Down syndrome. North Charleston, SC: CreateSpace Independent Publishing Platform.

Yin, R. K. (2014). Case study research: Design and methods. Los Angeles, CA: SAGE.

Yoder, P., Woynaroski, T., Fey, M., \& Warren, S. (2014). Effects of dose frequency of early communication intervention in young children with and without Down syndrome. American Journal on Intellectual and Developmental Disabilities, 119(1), 17-32. doi:10.1352/1944-7558-119.1.17 


\section{REFERENCES: CONCLUSION}

Dunn, D. S. \& Andrews, E. E. (2015). Person-first and identity-first language:

Developing psychologists' cultural competence using disability language. American Psychologist, 70(3). 255-264.

Dykens, E.M. (2006). Toward a positive psychology of mental retardation. American Journal of Orthopsychiatry, 76(2), 185-193.

Lipscomb, S., Haimson, J., Liu, A.Y., Burghardt, J., Johnson, D.R., \& Thurlow, M.L. (2017). Preparing for life after high school: The characteristics and experiences of youth in special education. Findings from the National Longitudinal Transition Study 2012. Volume 2: Comparisons across disability groups: Executive summary (NCEE 2017-4019). Washington, DC: U.S. Department of Education, Institute of Education Sciences, National Center for Education Evaluation and Regional Assistance.

Roach, A. T., Wixson, C. S., Talapatra, D., \& LaSalle, T. (2009) Missing voices in school psychology research: A review of the literature 2002-2007. The School Psychologist, 63, 6-10.

Roizen, N. (2013). Down syndrome (Trisomy 21). In M. Batshaw, N. Roizen, \& G. Lotrecchiano (Eds.), Children with disabilities, Seventh ed. (pp. 307-319), Baltimore, MD: Paul H. Brookes Publishing Co.

Skotko B. G., Levine, S. P., Goldstein R. (2011). Self-perceptions from people with Down syndrome, American Journal of Medical Genetics Part A, 155, 2360-2369.

Wehmeyer, M. L. (2013). The story of intellectual disability: An evolution of meaning, understanding, and public perception. Baltimore, MD: Brookes Publishing. 
APPENDICES

\section{APPENDIX A- PARENT CONSENT FORM

\author{
University of Denver \\ Consent Form for Participation in Research
}

Title of Research Study: Thriving with Down Syndrome: A Multiple Case Study

Researcher(s): Talia Thompson, EdS, Dr. Talapatra, University of Denver

Study Site: University of Denver

\section{Purpose}

You are being asked to participate in a research study. The purpose of this research is to understand what it means to thrive with Down syndrome, and the individual and environmental factors that facilitate thriving for people with Down syndrome. The end goal of this study is to inform service providers and families about the possibilities for living with Down syndrome, and inform the development of effective programming and policy.

\section{Procedures}

If you participate in this research study, you will be invited to:

- Provide educational and medical records for the researchers to review.

- Participate in 1-2 hours of interviewing about your child and your relationship. The interview will be audio recorded for transcription purposes.

Your child will be asked to:

- Take photos of things that "make his or her life good" and then share those photos in an interview with the researchers. The interview will be audio recorded for transcription purposes.

- The researchers will also observe your child for 6-12 hours during daily life activities in three different settings (home, school, work, community, church, etc.). You and your child will decide with the researcher where observations will take place.

- Finally, your child will also take part in approximately 4-6 hours of cognitive and educational testing, split up over 1-2 test sessions. Testing can take place in your home, a quiet setting of your child's choice, or the clinic at the University of Denver.

The researcher will also interview one other important adult (chosen by you and your child) about your child's life, and what facilitates his or her thriving. In all, your family will have contact with the researchers for a two-week period of time. You and your child may also be asked if you would like to review the findings from the study so you can give input about accuracy and any missing data.

\section{Voluntary Participation}

Participating in this research study is completely voluntary. Even if you decide to participate now, you may change your mind and stop at any time. You may choose not to answer interview questions, provide access to records, or allow observations for any reason without penalty or other benefits to which you are entitled.

\section{Risks or Discomforts}

Potential risks and/or discomforts of participation may include following: fatigue from participating in interviews or emotional discomfort when observed or confronted with questions that may probe personal information and breaches of confidentiality. 


\section{Benefits}

Possible benefits of participation include: improving our understanding of what it means to thrive with Down syndrome, what helps to facilitate thriving, and how we might support others with Down syndrome so they can also thrive.

\section{Incentives to participate}

Your child will receive a $\$ 25$ gift card to a store of choice for participating in this research project.

\section{Confidentiality}

The researcher will take measures to keep your and your child's information safe throughout this study. These measures will include password protection of electronic data and keeping hard copies of personal information in a locked file cabinet behind a locked door. All research records will be destroyed five years after the study has ended. Your individual identity will be kept private when information is presented or published about this study.

However, should any information contained in this study be the subject of a court order or lawful subpoena, the University of Denver might not be able to avoid compliance with the order or subpoena. The research information may be shared with federal agencies or local committees who are responsible for protecting research participants.

\section{Questions}

If you have any questions about this project or your participation, please feel free to ask questions now or contact Talia Thompson at 303-746-2226 or talia.thompson@du.edu at any time. You can also contact the faculty sponsor for this study, Dr. Devadrita Talapatra at (303) 871-3352 or devadrita.talapatra@du.edu.

If you have any questions or concerns about your research participation or rights as a participant, you may contact the DU Human Research Protections Program by emailing

IRBAdmin@du.edu or calling (303) 871-2121 to speak to someone other than the researchers.

Please take all the time you need to read through this document and decide whether you would like to participate in this research study.

If you agree to participate in this research study, please sign below. You will be given a copy of this form for your records. 
Please take all the time you need to read through this document and decide whether you would like your child to participate in this research study. Your child will also be asked to sign an assent form to participate in this study.

If you agree for your child to participate in this research study, please sign below. You will be given a copy of this form for your records.

Participant Signature

Date

Print Name 


\section{PARTICIPANT CONSENT/ASSENT FORM}

\section{University of Denver Consent/Assent Form for Participation in Research}

Title of Research Study: Thriving with Down Syndrome: A Case Study

Researcher(s): Talia Thompson, EdS, Advisor: Dr. Talapatra, PhD, University of Denver

\section{Study Site:}

\section{What is a research study?}

A research study is a way to find out new information about something. We would like to learn more about how some people with Down syndrome thrive, or live good lives, and what helps them to thrive and live a good life.

\section{Why are you being asked to be part of this research study?}

You are being asked to join the research study because you have Down syndrome and you have told us that you are living a good life; you are thriving.

\section{If you join the research study, what will you be asked to do?}

If you agree to join this study, you will be asked to take a variety of tests, be observed in your daily life, participate in an interview, and take photos of things that make your life good. Also, your parent and another important adult in your life will take part in interviews.

- Take pictures of things that make your life good.

- Show your pictures to the researchers and tell us why you took these pictures and what makes your life good. You can choose to have another adult with you for any, or all, of the interview.

- Be observed in your daily life for about 12 hours, over the course of 2 weeks as you go about your normal everyday life. This will be at work, school, home, or in the community. We will choose where the observations will take place together with you and your parent/s. You can choose if you do or do not us to observe in a setting.

- Your parents and one other important adult in your life will speak with us about you and your life in an interview.

- Finally, you will complete some psychological and educational tests as part of this study. We can complete the tests in your home, another quiet setting of your choice, or in a clinic room at the University of Denver. You 
can also choose to have another adult with you for any, or all, of the testing. The testing will take about four to six hours altogether. It can be broken up into two or more sessions if needed.

- You will be in the study for a total of two weeks.

- We will want to audio record you during the study as you answer questions in the interview.

\section{Do you have to be in the study?}

You do not have to be in this study. It is up to you. You can say okay now to be in the study and change your mind later. All you have to do is tell us when you want to stop. No one will be upset if you don't want to be in the study or if you change your mind later. You can take time to think about being in the study before you decide.

\section{Will any part of the study hurt or be uncomfortable?}

We do not think that you will be hurt or upset during the study.

We think that taking the tests will take up some of your time, and may be hard or make you tired.

\section{Will the study help you or others?}

We may learn something in this study that will help other people with Down syndrome some day. Maybe we will learn about what helps you to thrive, and how we can support others so they can thrive too.

\section{Do your parents or legal guardian know about the study?}

This study is also being explained to your parent or legal guardian. You can talk this over with your parent or legal guardian before deciding to participate if you want. You do not have to be in this study even if your parent or legal guardian thinks it is a good idea. It is up to you.

\section{Will anyone else know that you are in this study?}

We will not tell anyone else that you are in this study. You do not have to tell anyone about the study or your answers to the interview questions.

\section{Who will see the information collected about you?}

The information collected about you during this study will be kept safety locked up. Nobody will know it except the people doing the research. 
The study information about you will not be given to your parents/guardians, teachers, friends, doctors, or boss. The researchers will not tell your friends about the study or your answers to the questions.

Your individual identity will be kept private when we write our final report.

\section{What do you get for being in the study?}

You will receive a $\$ 25$ gift card to a store of your choice for participating in the research study.

\section{What if you have questions?}

You can ask any questions that you have about the study at any time. Just tell the researcher or your parent/guardian that you have a question. You or your parent/guardian can contact the researchers anytime during the study by calling,

Talia Thompson at 303-746-2226 or emailing talia.thompson@du.edu or by contacting her faculty advisor Dr. Tanya Talapatra at 303-871-3352 or devadrita.talapatra@du.edu.

Please take all the time you need to read through this document and decide whether you would like to participate in this research study.

If you agree to participate in this research study, please sign below. You will be given a copy of this form for your records.

Participant Signature

Date

Print Name

ㅁ Participant is a consenting adult

- Participant is unable to consent and provided assent

口 Participant did not consent/assent 
Please take all the time you need to read through this document and decide whether you would like your child to participate in this research study.

If you agree for your child to participate in this research study and you agree that your child willingly consented/ assented to participate in this study, please sign below. You will be given a copy of this form for your records.

Parent/Guardian Signature

Date

Print Name 


\title{
CONSENT FORM FOR ADULT IN SUPPORT SYSTEMS INTERVIEW
}

\author{
University of Denver \\ Consent Form for Participation in Research
}

Title of Research Study: Thriving with Down Syndrome: A Multiple Case Study

Researcher(s): Talia Thompson, EdS, Dr. Talapatra, University of Denver

Study Site:

\section{Purpose}

You are being asked to participate in a research study. The purpose of this research is to understand what it means to thrive with Down syndrome, and the individual and environmental factors that facilitate thriving for people with Down syndrome. The end goal of this study is to inform service providers and families about the possibilities for living with Down syndrome, and inform the development of effective programming and policy.

\section{Procedures}

If you participate in this research study, you will be invited to:

- Participate in 1 hour of interviewing about and what you see as the barriers and facilitators to his/her thriving. The interview will be audio recorded for transcription purposes.

\section{Voluntary Participation}

Participating in this research study is completely voluntary. Even if you decide to participate now, you may change your mind and stop at any time. You may choose not to answer any questions during the interview.

\section{Risks or Discomforts}

Potential risks and/or discomforts of participation may include following: fatigue from participating in interviews or emotional discomfort when confronted with questions that may probe personal information.

\section{Benefits}

Possible benefits of participation include improving our understanding of what it means to thrive with Down syndrome, what helps to facilitate thriving, what are the barriers to thriving, and how we might support others with Down syndrome so they can also thrive.

\section{Confidentiality}

The researcher will take measures to keep your information safe throughout this study. These measures will include password protection of electronic data and keeping hard copies of personal information in a locked file cabinet behind a locked door. All research records will be destroyed five years after the study has ended. Your individual identity will be kept private when information is presented or published about this study.

However, should any information contained in this study be the subject of a court order or lawful subpoena, the University of Denver might not be able to avoid compliance with the order or subpoena. The research information may be shared with federal agencies or local committees who are responsible for protecting research participants.

\section{Questions}

If you have any questions about this project or your participation, please feel free to ask questions now or contact Talia Thompson at 303-746-2226 or talia.thompson@du.edu at any time. You 
can also contact the faculty sponsor for this study, Dr. Devadrita Talapatra at (303) 871-3352 or devadrita.talapatra@du.edu.

If you have any questions or concerns about your research participation or rights as a participant, you may contact the DU Human Research Protections Program by emailing

IRBAdmin@du.edu or calling (303) 871-2121 to speak to someone other than the researchers.

Please take all the time you need to read through this document and decide whether you would like to participate in this research study.

If you agree to participate in this research study, please sign below. You will be given a copy of this form for your records.

Participant Signature

Date

Print Name 


\section{APPENDIX B}

\section{Capacity Assessment Checklist for Informed Consent with Subjects with Intellectual Disabilities}

Subject Name:

Subject \#:

Date of Consent /Assessment:

Time of Day:

ICF version: HIPAA date:

Protocol Staff Members Present:

1. 2.

Subject LAR or Family Present:

1. (relationship to subject:

2. (relationship to subject: Surrogate self-certification form completed? $\square$ Yes $\square$ No

Does subject have previously recorded IQ? $\square$ Yes $\square$ No If no, continue with capacity assessment.

If yes, what is IQ? Is subject non-verbal? $\square$ Yes* $\square$ No

*If IQ is below 70 or if subject is non-verbal, then subject is not cognitively capable to consent. Please skip to comment section.

\section{CAPACITY ASSESSMENT}

These questions should be considered within the context of consent or assent as applicable:

1-Did the subject understand the information provided?

$\square$ Yes $\square$ No

2-Did the subject have ample time in a pressure-free environment to make a decision?

$\square$ Yes $\square$ No

3-Did the subject understand there is a voluntary choice to participate in the research protocol?

$\square$ Yes $\square$ No

4-Did the subject make and communicate an informed choice about the research study?

$\square$ Yes $\square$ No

Please comment on capacity assessment: 
Was the response "no" for any of the above questions?

$\square$ Yes $\square \mathrm{No}^{*}$

*If any response was "no" for questions $1-4$, then the subject is not cognitively capable to consent or assent and the legally authorized representative or parent will be consented.

Completed by:

Signature: Date:

Investigator Review of Capacity to Consent:

Do you agree with the decision of capability to consent as determined above?

Yes $\square$ No $\square *$

*If no, please comment:

If you do not agree with the capacity assessment, please perform capacity assessment of the subject prior to continuing with study procedures.

Did the subject or subject's caregiver have any additional questions regarding the informed consent process?

Yes* $\square$ No $\square$

If yes, please comment:

Signature of Study Investigator

Date 


\section{APPENDIX C}

\section{SCREENING INTERVIEW QUESTIONS}

\section{Participant Questions:}

1. Can you tell me how often you feel satisfied or happy with your life?
a. All the time
b. Most of the time
c. Sometimes
d. Never

2. Some people generally feel happy most of the time. How true do you think that is for you lately?
a. Very true
b. Kind of true
c. Not true

3. Do you do things in your life that help you to learn new skills?

4. What are some of the new things you've learned to do recently?

\section{Family questions:}

1. Does skills?

participate in activities where $\mathrm{s} /$ he has the opportunity to learn new

2. What are some of the new skills that has learned in the past two years?

3. How have those skills helped him/her to build independence?

4. What is general mood on a daily basis?

5. Does_ ever express to you his/her feelings about how satisfied $\mathrm{s} / \mathrm{he}$ is with his/her life?

6. What records do you have available from

7. What is the feasibility of me observing 's education and medical history? in his/her daily life?

\begin{tabular}{|c|c|c|}
\hline Screening Question & Inclusion Criteria & Support from Literature \\
\hline $\begin{array}{l}\text { Participant questions } 1-2 \\
\text { Family member questions } 4 \text { - } \\
5\end{array}$ & High levels of SWB & $\begin{array}{l}\text { SWB is defined as self- } \\
\text { identified life satisfaction } \\
\text { coupled with positive } \\
\text { mood (Diener et al., 1985; } \\
\text { Diener et al., 2016) }\end{array}$ \\
\hline $\begin{array}{l}\text { Participant questions } 3-4 \\
\text { Family member questions } 1 \text { - } \\
3\end{array}$ & $\begin{array}{l}\text { Upward } \\
\text { developmental growth } \\
\text { trajectory }\end{array}$ & $\begin{array}{l}\text { Personal development is } \\
\text { measured by growth in } \\
\text { skills that are meaningful } \\
\text { to an individual with ID } \\
\text { (Gomez, Arias, Verdugo, } \\
\text { Tasse, \& Brown, 2015; } \\
\text { Schalock \& Alonso, } \\
\text { 2014) }\end{array}$ \\
\hline
\end{tabular}


APPENDIX D

DATA COLLECTION PROCESS

\begin{tabular}{|c|c|c|c|}
\hline Activity & Week 1 & Week 2 & Week 3 \\
\hline Consent & & & \\
\hline Document Review & & & \\
\hline Five Minute Speech Sample & & & \\
\hline Open-ended parent interview & & & \\
\hline Adult interview (Other) & & & \\
\hline Photo-elicitation interview & & & \\
\hline Participant observation & & & \\
\hline Standardized assessments & & & \\
\hline $\begin{array}{l}\text { Transcription, within-case unit } \\
\text { analysis }\end{array}$ & & & \\
\hline
\end{tabular}


APPENDIX E

DATA COLLECTION PROCESS AND RESEARCH QUESTION ALIGNMENT

\begin{tabular}{|c|c|c|c|c|}
\hline Research question & Interviews & Observation & $\begin{array}{c}\text { Document } \\
\text { Review }\end{array}$ & Assessi \\
\hline $\begin{array}{l}\text { 1. How do individuals } \\
\text { with DS and their } \\
\text { families define thriving } \\
\text { with DS? }\end{array}$ & $\mathrm{X}$ & & & \\
\hline $\begin{array}{l}\text { 2. What are the } \\
\text { individual } \\
\text { characteristics that } \\
\text { influence thriving for } \\
\text { individuals with DS? }\end{array}$ & & & & \\
\hline $\begin{array}{l}\text { a. What are the } \\
\text { individual } \\
\text { psychosocial profiles } \\
\text { of those who thrive } \\
\text { with DS? }\end{array}$ & $X$ & & $\mathrm{X}$ & $\mathrm{X}$ \\
\hline $\begin{array}{l}\text { b. How do individuals } \\
\text { with DS who thrive } \\
\text { experience SWB? }\end{array}$ & $X$ & $X$ & & $\mathrm{X}$ \\
\hline $\begin{array}{l}\text { c. In what ways do } \\
\text { thriving individuals } \\
\text { with DS demonstrate } \\
\text { developmental } \\
\text { growth? }\end{array}$ & $X$ & $\mathrm{X}$ & $X$ & $\mathrm{X}$ \\
\hline
\end{tabular}

3. What are the environmental factors that influence thriving for individuals with DS?

a. What are the major systems of support for individuals who thrive with DS and how do they $\mathrm{X} \quad \mathrm{X} \quad \mathrm{X}$ participate in these systems? 
b. What facilitates thriving for

X

X

X

individuals with DS?

c. What are some of the barriers to thriving

X

X

X

for individuals with

DS? 


\section{APPENDIX F}

\section{INTERVIEW PROTOCOL FOR PARENTS AND SUPPORTIVE ADULTS}

1. How would you describe $?^{*}$

2. What are some of his/her strengths?*

3. What is particularly challenging for him/her?*

4. Please tell me a little about your relationship with

5. Who are some other important people in his/her life?

6. How do you get along/partner/collaborate/work together with these people?

7. What are some important places or organizations for ?

8. How does interact with those settings? How do you interact with those settings?

9. How can you tell when is happy or satisfied with life?

10. What do you think contributes most to 's life satisfaction?*

11. When is most engaged in his or her life? Does he or she ever lose track of time or get lost in enjoyable tasks?

12. What is most meaningful for

13. In what ways does ?

14. What are some barriers to contribute to his/her community?

15. In what ways do you think 's happiness?*

16. What are some of 's best accomplishments/achievements?

17. What do you think facilitates his/her development and personal growth?*

18. What are some barriers to 's development and personal growth?*

19. Your family reports that_is currently thriving. Were there some times in his/her life when he/she was not thriving? What was different then?

20. Are there any large systems, political/social/cultural, that you think influence 's life for better or for worse?

21 . What does it mean for a person with DS to thrive?*

* Indicates questions that will be asked for interviews with the additional adults in the participants' systems of support. Parents will be asked all of the interview questions.

\begin{tabular}{llll}
\hline Interview Question & $\begin{array}{l}\text { Research } \\
\text { Question }\end{array}$ & Support from literature \\
\hline 1. How would you describe___? & 2 & $\begin{array}{l}\text { General open-ended } \\
\text { question in } \\
\text { conversational tone to } \\
\text { engage the interviewee } \\
\text { (Yin, 2014) }\end{array}$ \\
& & & $\begin{array}{l}\text { Consideration of } \\
\text { strengths as valuable } \\
\text { individual } \\
\text { characteristics (Peterson }\end{array}$ \\
& & What are some of his/strengths? & 2.a \\
& & \\
\hline
\end{tabular}


\& Seligman, 2004;

Wehmeyer et al., 2010)

3. What is particularly challenging 2 a for him/her?

Critical to consider the individual

characteristics that contribute to thriving

(Gilman et al., 2014)

and general human

functioning with disabilities (Wehmeyer

et al., 2010)

4. Please tell me a little about your 3.a relationship with

Influence of microsystem

(Bronfenbrenner, 1979;

Lerner et al., 2013;

Scott et al., 2014;

Seligman,

2011Wehmeyer et al., 2010).

5. Who are some other important 3.a people in his/her life?

a Influence of microsystem

(Bronfenbrenner, 1979;

Lerner et al., 2013;

Scott et al., 2014;

Seligman,

2011Wehmeyer et al., 2010).

6. How do you get

3.a Influence of along/partner/collaborate/work mesosystem together with these people?

(Bronfenbrenner, 1979)

7. What are some important places 3.a or organizations for ?

Influence of exosystems (Bronfenbrenner, 1979;

Lerner et al., 2013;

Wehmeyer et al., 2010)

8. How does ___ interact with 3.a Importance of those settings? How do you meaningful social interact with those settings? inclusion and 
supportive systems

(Bronfenbrenner, 1979;

Lerner et al., 2013;

Wehmeyer et al., 2010)

9. How can you tell when

$1 \& 2 . b \quad$ SWB is a critical is happy or satisfied with life?

component of thriving

(Prillleltensky, 2011;

Schalock \& Alonso, 2014; Seligman, 2011)

10. What do you think contributes

$2 . b \&$ most to 's life

3.b satisfaction?

SWB is influenced by multiple factors, including inherited temperament, but also life circumstances (Diener, 2016)

11. When is most engaged in 2.b his or her life? Does he or she ever lose track of time or get lost in enjoyable tasks?

Engagement and flow have been associated with SWB in the general population (Seligman, 2011)

12. What is most meaningful for

2.b

Contribution and meaningful social inclusion are associated with SWB/QOL (Hazel, 2016; Lerner et al., 2013 Schalock \&

Alonso, 2014;

Seligman, 2011)

13. In what ways does

2.b \& Contribution and contribute to his/her 3.b meaningful social community? inclusion are associated with SWB/QOL (Hazel, 2016; Lerner et al., 2013 Schalock \& Alonso, 2014; Seligman, 2011)

14. What are some barriers to $2 . b \& \quad$ Literature on facilitators 's happiness? $\quad 3 . c \quad$ and barriers to SWB for 
individuals with DS is

limited but may include

relationships,

independence, hopeful

disposition, and

inclusion (Scott et al.,

2014)

15. In what ways do you think

2.b is growing and

developing at this stage of life?

2.c

Personal growth is associated with QOL for those with ID (Schalock \& Alonso, 2014), learning and developmental progress are associated with thriving (Benson \& Scales, 2009; Lerner et al., 2013)

\section{What are some of
accomplishments/achievements?}

Personal growth is associated with QOL for those with ID (Schalock \& Alonso, 2014), learning and developmental progress are associated with thriving (Benson \& Scales, 2009; Lerner et al., 2013)

17. What do you think facilitates or 2.c \& has facilitated in the past his/her $3 . b$ development and personal growth?

Research indicates early intervention (Yoder et al., 2014), inclusive education (Turner et al., 2008), and supportive community settings (Wehmeyer et al., 2010) support the developmental growth of people with DS.

18. What are some barriers to 's development and

2.c \& 3.c Support systems inability to meet the unique personal needs personal growth? of an individual can 
impact development

and growth (Wehmeyer

et al., 2010)

19. Your family reports that is currently thriving. Were there some times in his/her life when he/she was not thriving? What was different then?

20. Are there any large systems, political/social/cultural, that you think influence 's life for better or for worse?
$1,3 . c$

Barriers to thriving with DS may include unique individual

characteristics or comorbid conditions as well as contextual factors (Weiss \& Riosa, 2015)

3.a Influence of macrosystems and social justice on thriving (Bronfenbrenner, 1979; Prilleltensky, 2012)

It is critical to document the lived experiences of those thriving with DS and their families in order to document the strengths of the DS community and broaden the phenotype of the disorder (Creswell, 2013; Dykens, 2006; Mertens, 2009) 
APPENDIX G

PARTICIPANT PHOTO ELICITATION INTERVIEW PROTOCOL

1. What is happening in this photograph?

2. What made you take this photograph?

3. How does [item in picture] help to make your life good? 
APPENDIX H

PHOTO ELICITATION INTERVIEW OPEN CODES LISTS

\begin{tabular}{|c|c|c|c|c|c|}
\hline Open Codes & $\begin{array}{l}\text { Case } \\
01\end{array}$ & $\begin{array}{l}\text { Case } \\
02\end{array}$ & $\begin{array}{l}\text { Case } \\
03\end{array}$ & $\begin{array}{l}\text { Case } \\
04\end{array}$ & $\begin{array}{l}\text { Total } \\
\text { quotes per } \\
\text { code }\end{array}$ \\
\hline Adaptive skills & 0 & 0 & 3 & 0 & 3 \\
\hline Adult or child? & 0 & 1 & 0 & 0 & 1 \\
\hline Appreciates Beauty & 4 & 0 & 0 & 1 & 5 \\
\hline Babies & 3 & 1 & 1 & 0 & 5 \\
\hline Barriers to thriving & 0 & 1 & 0 & 0 & 1 \\
\hline Boy Scouts & 0 & 1 & 0 & 0 & 1 \\
\hline Calendar & 0 & 3 & 0 & 0 & 3 \\
\hline Cheerleading & 0 & 0 & 0 & 2 & 2 \\
\hline Communication & 0 & 2 & 0 & 0 & 2 \\
\hline Contribution & 4 & 0 & 0 & 0 & 4 \\
\hline Cooking & 0 & 0 & 3 & 0 & 3 \\
\hline Dancing & 0 & 0 & 0 & 4 & 4 \\
\hline Dresses/Gowns & 0 & 0 & 0 & 1 & 1 \\
\hline Eating & 3 & 1 & 2 & 1 & 7 \\
\hline Education & 0 & 2 & 2 & 0 & 4 \\
\hline Elvis & 4 & 0 & 0 & 0 & 4 \\
\hline Emotional regulation & 1 & 0 & 0 & 0 & 1 \\
\hline $\begin{array}{l}\text { Entertainment- } \\
\text { Movies/TV/Theater }\end{array}$ & 3 & 3 & 0 & 0 & 6 \\
\hline Ex-Boyfriends & 1 & 0 & 0 & 1 & 2 \\
\hline Extended Family & 0 & 0 & 0 & 2 & 2 \\
\hline Father & 0 & 1 & 0 & 0 & 1 \\
\hline Friends & 3 & 0 & 3 & 1 & 7 \\
\hline Games/Play & 0 & 0 & 1 & 0 & 1 \\
\hline Grief & 0 & 0 & 4 & 0 & 4 \\
\hline Happiness & 4 & 1 & 4 & 2 & 11 \\
\hline Home/decor & 0 & 1 & 0 & 1 & 2 \\
\hline Humor & 7 & 0 & 0 & 0 & 7 \\
\hline Independence & 0 & 0 & 4 & 0 & 4 \\
\hline Living Options & 1 & 0 & 0 & 0 & 1 \\
\hline Love of learning & 1 & 0 & 0 & 0 & 1 \\
\hline Lying? & 1 & 0 & 0 & 0 & 1 \\
\hline Marriage & 0 & 1 & 1 & 0 & 2 \\
\hline Men's Group & 0 & 1 & 0 & 0 & 1 \\
\hline Microsystem & 3 & 2 & 2 & 1 & 8 \\
\hline
\end{tabular}




\begin{tabular}{|c|c|c|c|c|c|}
\hline Money & 0 & 0 & 1 & 0 & 1 \\
\hline Mother & 1 & 0 & 1 & 0 & 2 \\
\hline Music & 0 & 1 & 1 & 3 & 5 \\
\hline Participation & 3 & 1 & 0 & 0 & 4 \\
\hline Physical health & 1 & 0 & 0 & 4 & 5 \\
\hline Physical Therapist & 1 & 0 & 0 & 0 & 1 \\
\hline Respite Care & 0 & 2 & 0 & 0 & 2 \\
\hline Role Playing & 2 & 0 & 0 & 0 & 2 \\
\hline Romantic Partner & 4 & 0 & 2 & 0 & 6 \\
\hline Service dog & 0 & 1 & 0 & 0 & 1 \\
\hline Shared history & 5 & 0 & 0 & 0 & 5 \\
\hline Sibling & 2 & 1 & 1 & 2 & 6 \\
\hline Social & 1 & 0 & 0 & 0 & 1 \\
\hline Spanish & 0 & 0 & 0 & 1 & 1 \\
\hline \multicolumn{6}{|l|}{$\begin{array}{l}\text { Language/Hispanic } \\
\text { culture }\end{array}$} \\
\hline Spirituality/Christianity & 0 & 0 & 3 & 3 & 6 \\
\hline Sports & 0 & 3 & 0 & 1 & 4 \\
\hline Superhero & 0 & 0 & 1 & 0 & 1 \\
\hline Support & 2 & 1 & 2 & 2 & 7 \\
\hline Swimming & 0 & 0 & 0 & 1 & 1 \\
\hline Tae Kwan Do & 0 & 1 & 0 & 0 & 1 \\
\hline Technology & 0 & 0 & 0 & 2 & 2 \\
\hline Therapeutic Recreation & 0 & 0 & 0 & 3 & 3 \\
\hline Toast Masters & 0 & 1 & 0 & 0 & 1 \\
\hline Transportation & 0 & 2 & 1 & 2 & 5 \\
\hline Volunteering & 0 & 1 & 0 & 0 & 1 \\
\hline Weight Loss & 0 & 0 & 0 & 4 & 4 \\
\hline Work & 0 & 3 & 2 & 1 & 6 \\
\hline Zest & 0 & 1 & 0 & 0 & 1 \\
\hline
\end{tabular}




\section{APPENDIX I}

OBSERVATION PROTOCOL

\begin{tabular}{|c|c|c|}
\hline $\begin{array}{l}\text { Setting (choose } 3 \text { ) } \\
\text { and focus areas for } \\
\text { observation }\end{array}$ & $\begin{array}{l}\text { Research } \\
\text { Question }\end{array}$ & Support from literature \\
\hline $\begin{array}{l}\text { 口 Home } \\
\square \text { School } \\
\square \text { Work } \\
\square \text { Religious setting } \\
\square \text { Community } \\
\text { agency } \\
\square \text { Transitions } \\
\text { between settings } \\
\square \text { Other }\end{array}$ & 2.b\&c, 3.a-c & $\begin{array}{l}\text { Bioecological systems theory and } \\
\text { the social ecological model for } \\
\text { human functioning emphasizes the } \\
\text { key role of an individual's systems } \\
\text { of support (Bronfenbrenner, 1979; } \\
\text { Buntinx, 2014; Wehmeyer et al., } \\
2010 \text { ) }\end{array}$ \\
\hline $\begin{array}{l}\text { Social inclusion/ } \\
\text { participation }\end{array}$ & 3.a-c & $\begin{array}{l}\text { Meaningful social inclusion is a key } \\
\text { aspect of QOL concept (Schalock } \\
\& \text { Alonso, 2014) }\end{array}$ \\
\hline Access & 3.b\&c & $\begin{array}{l}\text { Issues of statutory rights and access } \\
\text { to supportive systems impacts } \\
\text { development and QOL } \\
\text { (Bronfenbrenner, 1979; Schalock \& } \\
\text { Alonso, 2014) }\end{array}$ \\
\hline Relationships & 2.b, 3.a & $\begin{array}{l}\text { Relationships have been determined } \\
\text { as key elements of SWB, QOL, and } \\
\text { thriving (Lerner et al., 2010; } \\
\text { Schalock \& Alonso, 2014; } \\
\text { Seligman, 2011) }\end{array}$ \\
\hline $\begin{array}{l}\text { Self-determination/ } \\
\text { Choice-making }\end{array}$ & 2.c, 3.b\&c & $\begin{array}{l}\text { Autonomy and choice-making are } \\
\text { key aspects of QOL concept } \\
\text { (Schalock \& Alonso, 2014) }\end{array}$ \\
\hline Emergent themes & $1-3$ & $\begin{array}{l}\text { Qualitative research is exploratory } \\
\text { and allows for themes to emerge } \\
\text { from the data to better understand a } \\
\text { phenomenon (Creswell, 2013; } \\
\text { Wolcott, 1995) }\end{array}$ \\
\hline
\end{tabular}


APPENDIX $\mathbf{J}$

OBSERVATION FIELD NOTE PROTOCOL

\begin{tabular}{|c|c|}
\hline \multicolumn{2}{|l|}{ Date } \\
\hline \multicolumn{2}{|l|}{ Time } \\
\hline \multicolumn{2}{|l|}{ Activity/setting } \\
\hline \multicolumn{2}{|l|}{ Participants } \\
\hline \multicolumn{2}{|l|}{ Research Question } \\
\hline Descriptive Notes & $\underline{\text { Reflective Notes }}$ \\
\hline Physical Layout (draw plan) & $\begin{array}{l}\text { Reflective comments: researcher questions to self, } \\
\text { observations of nonverbal behavior, } \\
\text { Interpretations, etc.] }\end{array}$ \\
\hline $\begin{array}{l}\text { Description of participants } \\
\text { Description of activities }\end{array}$ & $\begin{array}{l}\text { Reflective comments: questions to self, } \\
\text { observations of nonverbal behavior, my } \\
\text { interpretations] }\end{array}$ \\
\hline \multicolumn{2}{|c|}{ Description of individuals engaged in activity } \\
\hline \multicolumn{2}{|l|}{ Sequence of activity over time } \\
\hline \multicolumn{2}{|l|}{ Interactions } \\
\hline \multicolumn{2}{|l|}{ Unplanned events } \\
\hline \multicolumn{2}{|c|}{ Participants' comments (i.e., quotes) } \\
\hline $\begin{array}{l}\text { The researcher's observation } \\
\text { occurring] }\end{array}$ & \\
\hline
\end{tabular}




\section{APPENDIX K - RELEASE OF INFORMATION}

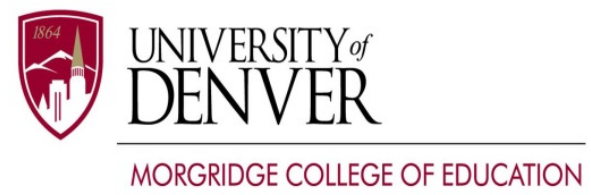

\section{Authorization to Release/Request Information}

$$
\text { University of Denver - Morgridge College of Education }
$$

I, hereby authorize the Educational Services Clinic of the University of Denver to:

[ ] Release the following information to: from:

[ ] Request the following information

Talia Thompson and Dr. Devadrita Talapatra

University of Denver

Person/Agency

Person/Agency

1999 E. Evans Ave.

Address

Address

Denver, CO 80208

City/State/Zip

City/State/Zip

(303) 871-2379

Phone

Phone

Information to be released: Educational history, records, assessment data (please circle) for:

\section{Participant's Name (please print)}

Date

Purpose of release/request: Research

I understand that I may revoke this authorization at any time by giving written notice to the University of Denver, Morgridge College of Education. Without such a revocation, this authorization shall expire on ___ _ _ _ _ If not date is specified, this authorization shall expire one year from the date of the signature.) I also herewith release the University of Denver, Morgridge College of Education from all liability for releasing such information.

Signature of participant or Legal Guardian

Date

Witness

NOTICE: The information disclosed by this authorization comes from records whose confidentiality is protected by federal law. Federal regulations prohibit you from making further disclosures of this information without the specific written consent of the person to whom it pertains. 


\section{APPENDIX L}

\section{SUBJECTIVE HAPPINESS SCALE (SHS; Lyubomirsky, \& Lepper,1999)}

For each of the following statements and/or questions, please circle the point on the scale that you feel is most appropriate in describing you.

1. In general, I consider myself:

$\begin{array}{ccccccc}1 & 2 & 3 & 4 & 5 & 6 & \begin{array}{c}7 \\ \text { not a very } \\ \text { happy } \\ \text { person }\end{array} \\ & & & & & & \\ \text { happy } \\ \text { person }\end{array}$

2. Compared with most of my peers, I consider myself:

$\begin{array}{cccccccc}\begin{array}{c}1 \\ \text { less } \\ \text { happy }\end{array} & 2 & 3 & 4 & 5 & 6 & \begin{array}{c}7 \\ \text { more } \\ \text { happy }\end{array}\end{array}$

3. Some people are generally very happy. They enjoy life regardless of what is going on, getting the most out of everything. To what extent does this characterization describe you?

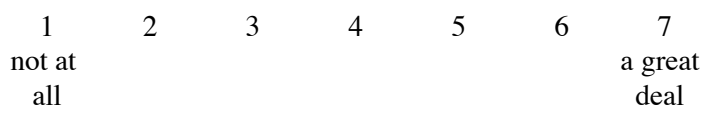

4. Some people are generally not very happy. Although they are not depressed, they never seem as happy as they might be. To what extent does this characterization describe you?

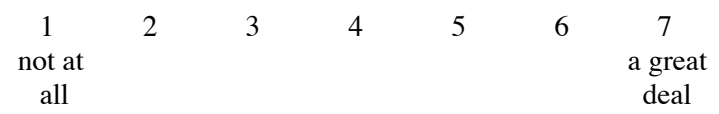




\section{APPENDIX M}

THE SATISFACTION WITH LIFE SCALE (Diener et al., 1985)

\section{The Satisfaction with Life Scale}

By Ed Diener, Ph.D.

DIRECTIONS: Below are five statements with which you may agree or disagree. Using the 1-7 scale below, indicate your agreement with each item by placing the appropriate number in the line preceding that item. Please be open and honest in your responding.

$1=$ Strongly Disagree

$2=$ Disagree

$3=$ Slightly Disagree

$4=$ Neither Agree or Disagree

$5=$ Slightly Agree

$6=$ Agree

$7=$ Strongly Agree

1. In most ways my life is close to my ideal.

2. The conditions of my life are excellent.

3. I am satisfied with life.

4. So far I have gotten the important things I want in life.

5. If I could live my life over, I would change almost nothing. 